\title{
SELEÇÃO DE PRÉ-CULTIVARES DE SOJA BASEADA EM ÍNDICES
}

\section{VANDERLEI DA SILVA SANTOS}

Tese apresentada à Escola Superior de Agricultura "Luiz de Queiroz", Universidade de São Paulo, para obtenção do título de Doutor em Agronomia, Área de Concentração: Genética e Melhoramento de Plantas.

$P \mid R A C I C A B A$

Estado de São Paulo - Brasil

Abril - 2005 


\section{SELEÇÃO DE PRÉ-CULTIVARES DE SOJA BASEADA EM ÍNDICES}

\section{VANDERLEI DA SILVA SANTOS}

Engenheiro Agrônomo

Orientador: Prof. Dr. ISAIAS OLÍVIO GERALDI

Tese apresentada à Escola Superior de Agricultura "Luiz de Queiroz", Universidade de São Paulo, para obtenção do título de Doutor em Agronomia, Área de Concentração: Genética e Melhoramento de Plantas.

PIR A C I C A B A

Estado de São Paulo - Brasil

Abril - 2005 
Dados Internacionais de Catalogação na Publicação (CIP) DIVISÃO DE BIBLIOTECA E DOCUMENTAÇÃO - ESALQ/USP

Santos, Vanderlei da Silva

Seleção de pré-cultivares de soja baseada em índices / Vanderlei da Silva Santos. - - Piracicaba, 2005

$104 \mathrm{p}$.

Tese (doutorado) - - Escola Superior de Agricultura Luiz de Queiroz, 2005. Bibliografia.

1. Linhagem vegetal 2. Melhoramento genético vegetal 3. Seleção genética 4. Soja I. Título

CDD 633.34

"Permitida a cópia total ou parcial deste documento, desde que citada a fonte - O autor" 
DEDICO

Aos meus pais, Celice da Silva Santos e Derival Ribeiro dos Santos, pelo sacrifício que fizeram para que eu pudesse estudar

A minha tia Luzivani e família, cujo auxílio foi fundamental para que eu pudesse chegar até aqui.

Ao povo brasileiro, que admiro e respeito, por custear os meus estudos desde o início. 


\section{AGRADECIMENTOS}

Ao professor Isaias Olívio Geraldi, pela orientação, e pela confiança e amizade demonstradas.

À Empresa Brasileira de Pesquisa Agropecuária (EMBRAPA), pela presteza em me liberar para continuar o Curso de Doutoramento, e pela compreensão e cooperação irrestritas, ao me deixar inteiramente dedicado ao trabalho de escrita da Tese.

Ao Departamento de Genética da ESALQ/USP, pela oportunidade que me concedeu de cursar o Doutoramento, e pela boa formação que me proporcionou.

Aos amigos Ademir Araújo e Francisco Cláudio, pelo convívio feliz, na república.

Aos colegas do laboratório, Fernandes Araújo, Gustavo Perina, Paulo Araújo, colega de Doutoramento, e aos trabalhadores do campo, pela amizade, e pelo valioso auxílio, na condução dos experimentos.

Ao casal Toshie e Toshiaki, e a todos os amigos da pensão, em especial, Cristiane Nardi e Rogério Freitas, pelo convívio agradável.

Aos colegas da pós-graduação, em especial, Adalgisa, Dyeme, Eulália, Fábia Giulianna, Fernando Cárdenas, Frederico Pina, José Ubirajara, Maria Clideana, Mateus Mondin e Rudimar Conte.

Ao professor Antonio Augusto Franco Garcia, pela ajuda que me prestou em várias ocasiões, e pela amizade.

Aos casais Alderi e Márcia, Clóvis e Walnice, Farias e Agacy, Marcelo e Lia, Marcelino e Cláudia, Paulo e Natália, Oriel e Rose, Raimundo e Cristina e às amigas Ana, Fátima e Salete, cujo convívio me ajudou a enfrentar as dificuldades. 


\section{SUMÁRIO}

Página

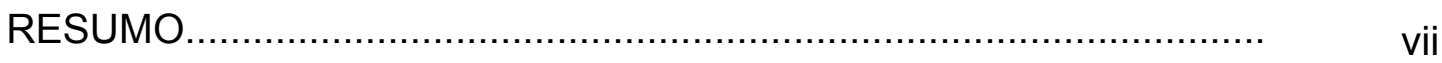

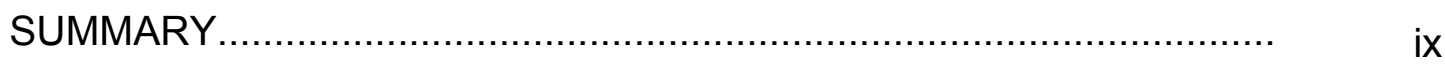

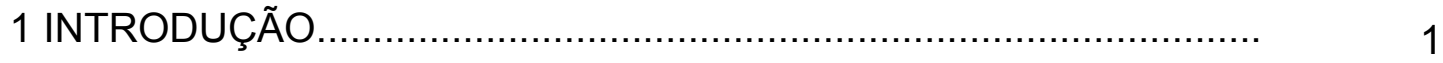

2 REVISÃO DE LITERATURA .........................................................

2.1 Índices de seleção lineares........................................................

2.2 Índices de seleção não lineares....................................................

2.2.1 Índice multiplicativo..............................................................

2.2.2 Índice baseado em medidas de distâncias.................................. 13

2.2.2.1 Distância Euclidiana................................................................

2.2.2.2 Distância Generalizada de Mahalanobis.................................. 17

2.2.3 Índice de soma de postos...................................................... 23

2.2.4 Índice para a seleção de cultivares (Garcia, 1998)....................... 24

2.3 Aplicação de índices de seleção no melhoramento vegetal............. 28

3 MATERIAL E MÉTODOS .......................................................... 37

3.1 Delineamento experimental..................................................... 37

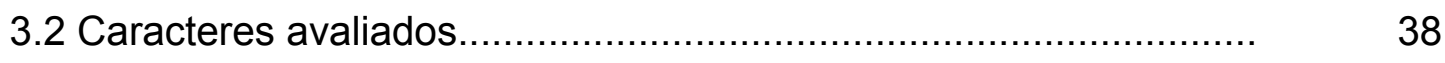

3.3 Análises estatísticas............................................................... 39

3.4 Etapas do desenvolvimento do índice de seleção............................ 41 
3.4.1 Etapas preliminares....................................................... 41

3.4.2 Distância Euclidiana.......................................................... 45

3.4.3 Distância Generalizada de Mahalanobis................................... 49

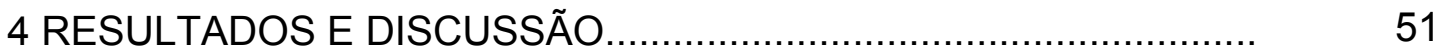

4.1 Análise geral dos dados e estimação dos parâmetros................... 51

4.2 Avaliação dos índices de seleção..................................................

4.3 Comparações entre os índices.................................................. 83

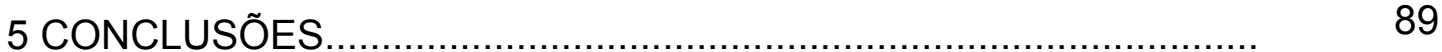

REFERÊNCIAS BIBLIOGRÁFICAS............................................. 90

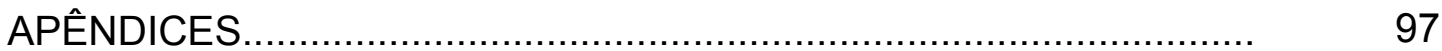




\title{
SELEÇÃO DE PRÉ-CULTIVARES DE SOJA BASEADA EM ÍNDICES
}

\author{
Autor: VANDERLEI DA SILVA SANTOS \\ Orientador: Prof. Dr. ISAIAS OLÍVIO GERALDI
}

\section{RESUMO}

Os índices de seleção foram inicialmente propostos para a seleção simultânea de diversos caracteres e, por requerem a obtenção de estimativas de variâncias e covariâncias, são mais apropriados para programas de seleção recorrente. Posteriormente, desenvolveram-se outros índices, que por não requererem o conhecimento de tais estimativas, podem ser aplicados tanto em programas de seleção recorrente, como para a seleção de genótipos já fixados, como clones, linhagens e híbridos. Recentemente, Garcia (1998) desenvolveu um índice específico para a seleção de genótipos fixados, que se baseia no cálculo da distância de cada genótipo a um ideótipo. As principais vantagens são que este índice permite a aplicação de testes de comparações de médias, bem como a identificação de genótipos com performances aquém daquela exigida para os cultivares comerciais para um dado caráter. O objetivo deste trabalho foi avaliar a eficiência do índice de Garcia (1998) para a seleção de linhagens de soja na fase de pré-cultivares. O material experimental consistiu de 88 linhagens (Geração $F_{7}$ ), derivadas pelo método S.S.D. e oriundas do cruzamento entre os genitores BR-80-14853 x PI-123439, e três testemunhas comerciais: IAC-12, IAC-Foscarin-31 e IAS-5. Os experimentos foram conduzidos no delineamento em blocos casualizados em seis anos agrícolas, com diferentes números de 
repetições por ano: 3 (1995/6), 4 (1996/7), 6 (1998/9), 6 (1999/0), 10 (2000/1) e 10 (2001/2). Os caracteres avaliados foram: produção de grãos (PG: g/parcela) altura das plantas na maturação (AM: cm/planta), e acamamento (AC: notas de 1 a 5). No cálculo das distâncias utilizaram-se a Distância Euclidiana e a Distância de Mahalanobis. Os resultados obtidos mostraram que os índices baseados tanto na Distância Euclidiana quanto na de Mahalanobis foram eficientes para a discriminação dos genótipos, embora os melhores resultados tenham sido obtidos com a Distância de Mahalanobis. Devido a isso, sugere-se o uso da Distância de Mahalanobis para identificar e selecionar pré-cultivares de soja e também, como proposto por Garcia (1998), que esta seleção seja acompanhada da avaliação de caracteres individuais, para evitar que genótipos promissores sejam descartados por apresentarem pequenos defeitos em caracteres de importância secundária. 


\title{
SELECTION OF SOYBEAN PRE-CULTIVARS BASED ON INDICES
}

\author{
Author: VANDERLEI DA SILVA SANTOS
}

Adviser: Prof. Dr. ISAIAS OLÍVIO GERALDI

\section{SUMMARY}

Selection indices were first proposed for the selection of several traits at the same time, and because of the requirement of variances and covariances estimates, they are useful for recurrent selection programs. Later on, other indices were proposed, which do not require the knowledge of these estimates, and thus are useful for both recurrent selection programs and for the selection of fixed genotypes, such as clones, inbred lines and hybrids. Recently, Garcia (1998) proposed a new index for the selection of fixed genotypes which is based on the distance of each genotype to and ideotype. The main advantages of this index is that multiple comparison tests can be done and also the identification of genotypes that perform below than those required by commercial cultivars for a given trait. The objective of this work was to evaluate the efficiency of Garcia (1998)'s index for the selection of pre-cultivars in soybeans. Experimental material comprised 88 lines $\left(F_{7}\right.$ generation) derived by the S.S.D. method from the cross between the BR-80-14853 and PI-123439 parents, and three cultivars as checks: IAC-12, IAC-Foscarin-31 and IAS-5. The evaluation trials were carried out in randomized block designs across six growing seasons, with different number of replications each: 3 (1995/6), 4 (1996/7), 6 (1998/9), 6 
(1999/0), 10 (2000/1) and 10 (2001/2). The following traits were evaluated: grain yield (PG: g/plot), plant height at maturity (AM: $\mathrm{cm} /$ plant) and lodging (AC: scale: 1 to 5). For the calculation of the distance of each genotype to the ideotype, the Euclidean and Mahalanobis methods were used. General results have shown that the index based on both Euclidean and Mahalanobis distances were efficient to discriminate the genotypes, but the best results were reached by using Mahalanobis distance. Consequently, in order to identify and select fixed genotypes of soybeans we suggest the use of Mahalanobis distance, and as proposed by Garcia (1998), that the selection be based on the index and also on the evaluation of each trait, in order to avoid the discard of superior genotypes showing small problems in traits of minor importance. 


\section{INTRODUÇÃO}

Os índices de seleção foram inicialmente propostos visando à seleção simultânea de vários caracteres e, por exigirem o conhecimento de estimativas de variâncias e covariâncias, são apropriados para programas de seleção recorrente. Posteriormente, foram propostos outros índices, que por não requererem o conhecimento destas estimativas, podem ser utilizados tanto em programas de seleção recorrente quanto para a seleção de genótipos fixados. Apesar da eficiência teoricamente comprovada dos índices de seleção, estes têm sido pouco utilizados no melhoramento genético de plantas, sendo mais comumente utilizados no melhoramento genético animal.

Entretanto, nas fases finais dos programas de melhoramento têm-se cultivares ou pré-cultivares que precisam ser comparados e, portanto, as diferenças entre os genótipos precisam ser testadas com rigor estatístico. Uma vez que não serão mais recombinados, estes genótipos devem apresentar um desempenho no mínimo igual ao dos cultivares existentes no mercado, para todos os caracteres de importância, para que possam ser aceitos pelos produtores. Estes requerimentos não eram atendidos pelos índices existentes até então.

Visando atender à situação específica de genótipos fixados, tais como clones, linhagens, e híbridos, Garcia (1998) propôs um novo índice, denominado "Índice para a seleção de cultivares" que preconiza tanto o estabelecimento de desempenhos mínimos para os caracteres individualmente, quanto a adoção de testes de médias, de modo a possibilitar que a seleção de 
genótipos seja feita com rigor estatístico. Também, define-se um valor ideal para cada caráter, e esse conjunto de valores ideais constitui um genótipo ideal, ou ideótipo. O índice de cada genótipo corresponde a uma medida da distância deste ao ideótipo, sendo o genótipo tanto melhor quanto menor o valor do índice.

Pelas razões já mencionadas anteriormente, a literatura é escassa quanto a trabalhos de índices de seleção aplicados a genótipos fixados. Devido a isso, os objetivos deste trabalho compreendem:

a) avaliar a viabilidade do uso do índice proposto por Garcia (1998) para selecionar linhagens de soja na fase de pré-cultivares;

b) comparar duas medidas de distâncias na construção do referido índice. 


\section{REVISÃO DE LITERATURA}

\section{1 Índices de seleção lineares}

O índice otimizado, o primeiro relatado na literatura, foi desenvolvido por Smith (1936), e tem como objetivo maximizar a correlação entre o índice e o valor genotípico dos indivíduos. Posteriormente, Hazel (1943) o adaptou para ser aplicado no melhoramento animal, e por isso, alguns autores o denominam índice de Smith-Hazel. Segundo Garcia (1998), o termo otimizado "foi empregado a partir de sugestão posterior de Williams (1962), para permitir sua diferenciação de modificações mais recentes aplicadas à idéia original".

Assim, sendo $G_{j}$ o valor genotípico do caráter $j$, o valor genotípico total do genótipo i, levando em conta os $n$ caracteres de importância, é o seguinte:

$$
G_{i}=a_{1} G_{1}+a_{2} G_{2}+\ldots+a_{n} G_{n}=\sum_{j=1}^{n} a_{j} G_{j}
$$

em que:

$$
\begin{aligned}
& \mathrm{G}_{\mathrm{i}} \text { : valor genotípico do genótipo i; } \\
& \mathrm{a}_{\mathrm{j}} \text { : peso econômico relativo, atribuído pelo melhorista, ao caráter } \mathrm{j} \text {; } \\
& \mathrm{G}_{\mathrm{j}} \text { : valor genotípico do caráter } \mathrm{j} \text {. }
\end{aligned}
$$


Estes valores de $G_{j}$ não são observáveis, uma vez que o que se pode observar são os fenótipos, e estes são compostos por uma parte genética e outra ambiental, que não é herdável, e portanto, faz com que o fenótipo não reflita fielmente o genótipo correspondente (Smith, 1936). Entretanto, pode-se definir um índice fenotípico:

$$
\mathrm{I}_{\mathrm{i}}=\mathrm{b}_{1} \overline{\mathrm{F}}_{1}+\mathrm{b}_{2} \overline{\mathrm{F}}_{2}+\ldots+\mathrm{b}_{\mathrm{n}} \overline{\mathrm{F}}_{\mathrm{n}}=\sum_{\mathrm{j}=1}^{\mathrm{n}} \mathrm{b}_{\mathrm{j}} \overline{\mathrm{F}}_{\mathrm{j}}
$$

em que:

$\mathrm{l}_{\mathrm{i}}$ : índice (valor fenotípico) do genótipo i;

$\overline{\mathrm{F}}_{\mathrm{j}}$ : valor fenotípico do caráter $\mathrm{j}$;

$b_{j}$ : peso do caráter $j$, a ser estimado.

Desse modo, embora o valor genotípico $G$ não possa ser diretamente mensurado, ele pode ser inferido, por meio do índice $I$, uma função linear de valores fenotípicos observáveis. Assim, de acordo com Smith (1936), a questão é obter valores de $b$ tais que a função $/$ possa discriminar os genótipos que possuem o maior valor de $G$.

Assim, tendo como objetivo a maximização da correlação entre os valores fenotípicos e genotípicos $\left(r_{\mid G}\right)$, obtém-se a seguinte expressão (Wricke \& Weber, 1986; Garcia, 1998):

$$
\mathrm{Fb}=\mathrm{Ga},
$$

em que: 
F: matriz de variâncias e covariâncias fenotípicas;

$b$ : vetor dos coeficientes dos valores fenotípicos $\left(b_{j}\right)$, a serem estimados;

G: matriz de variâncias e covariâncias genéticas;

a: vetor dos pesos econômicos relativos atribuídos aos caracteres;

Assim, o vetor b é estimado da seguinte maneira:

$\mathrm{b}=\mathrm{F}^{-1} \mathrm{Ga}$

sendo $\mathrm{F}^{-1}$ a inversa da matriz $\mathrm{F}$.

Como as variâncias e covariâncias fenotípicas (matriz F) e genéticas (matriz G) são obtidas a partir de amostras, o que se obtém na realidade são estimativas dos parâmetros populacionais, de modo que o sistema é melhor representado por meio da seguinte notação:

$$
\hat{b}=\hat{F}^{-1} \hat{G} a .
$$

Vê-se, por essa expressão, que para aplicar-se um índice otimizado, é preciso que se conheçam as matrizes $F$ e $G$, além de se terem definidos os pesos relativos dos caracteres. Pode-se dizer, então, que a eficiência de um índice desse tipo depende da precisão com que os dados experimentais são obtidos, e da experiência do melhorista, ao atribuir os pesos aos caracteres que serão levados em consideração. Segundo Hazel \& Lush (1942), a principal dificuldade do uso deste método é definir que importância deve ser dada a cada caráter, ou seja, a definição de qual peso econômico será atribuído a cada um dos caracteres que comporão o índice. Entretanto, atualmente, devido à disponibilidade de computadores, a aplicação de índices tornou-se bem mais fácil, pois o pesquisador pode definir várias combinações de pesos econômicos $\left(a_{j, s}\right)$, obter os índices, em seguida calcular as respostas esperadas à seleção, 
e adotar a combinação que resulte na melhor resposta. Uma discussão acerca da atribuição de pesos econômicos a caracteres pode ser vista em Baker (1986).

As estimativas das variâncias e covariâncias fenotípicas são obtidas diretamente a partir das observações fenotípicas; entretanto, para estimar variâncias e covariâncias genéticas, é necessária a adoção de delineamentos específicos, como pode ser visto no trabalho de Wricke \& Weber (1986).

Este índice otimizado foi concebido de modo a maximizar a correlação entre os valores genotípicos $\left(G_{i, s}\right)$ e os valores do índice, ou valores fenotípicos $\left(\mathrm{I}_{\mathrm{i}, \mathrm{S}}\right)$, sendo por isso apropriado para o uso em programas de seleção recorrente, nos quais, a cada ciclo, as progênies selecionadas são recombinadas, com o objetivo de obter-se uma nova população, que possua uma concentração de alelos favoráveis superior à do ciclo anterior, isto é, uma população com um valor genotípico maior. Caso algum dos genótipos selecionados tenha um desempenho aquém do requerido pelos produtores, em um ou mais caracteres, isso poderá ser corrigido nas recombinações posteriores.

Nas etapas finais dos programas de melhoramento, a situação é diferente. Os genótipos pré-comerciais podem não ser aleatórios, e assim, não faz sentido estimar variâncias e covariâncias genéticas. Outra peculiaridade desta fase é que, como não serão mais recombinados, as pré-cultivares necessitam ter um desempenho no mínimo igual ao das cultivares em uso pelos agricultores, em cada um dos caracteres de interesse, para que possam vir a ser liberadas como cultivares (Garcia, 1998). Além disso, nessa fase, é necessário que os genótipos selecionados tenham sua superioridade estatisticamente comprovada, isto é, com base em um teste de médias. Por estas razões, o índice otimizado não é adequado para ser empregado na seleção de cultivares. 
Posteriormente, foram desenvolvidos outros índices lineares, aplicáveis a situações específicas (uma revisão destes índices pode ser vista nos trabalhos de Lin (1978), e Garcia (1998)); entretanto, nenhum deles atende plenamente às especificidades da seleção de cultivares.

\section{2 Índices de seleção não lineares}

Um segundo grupo é o dos índices não lineares, que pelo menos teoricamente, podem ser aplicados tanto na seleção recorrente quanto para selecionar cultivares. O primeiro foi o índice multiplicativo, proposto por Elston (1963). Em seguida, surgiu o índice que baseia-se em medidas de distâncias dos genótipos a um ideótipo (genótipo existente ou não na população, e que possui o melhor desempenho em todos os caracteres visados na seleção), desenvolvido por Schwarzbach $(1972)^{1}$, citado por Wricke \& Weber (1986), e finalmente, tem-se o índice de soma de postos, proposto por Mulamba \& Mock (1978). Estes índices não lineares serão revisados a seguir.

\subsection{1 Índice multiplicativo}

Este índice, proposto por Elston (1963), pode ser aplicado tanto em programas de seleção recorrente, quanto nas etapas finais dos programas de melhoramento, por permitir a fixação de valores críticos, abaixo dos quais os genótipos são descartados. Tem a vantagem de prescindir da atribuição de

\footnotetext{
${ }^{\top}:$ SCHWARZBACH, E. Einige Anwendungsmöglichkeiten elektronischer Datenverarbeitung (EDV) für die Beurteilung von Zuchtmaterial. Arb. Tag. Oesterr. Pflanzenz. Gumpenstein: 277-87, 1972.
} 
pesos aos caracteres e de estimativas de variâncias e covariâncias, o que torna a sua aplicação mais fácil, em relação aos índices lineares.

O autor ilustrou o índice proposto com um exemplo de seleção de aves, utilizando os caracteres número de ovos/ano $\left(X_{1}\right)$ e o peso da ave com dez semanas de idade $\left(X_{2}\right)$, e supondo que o melhorista deseja selecionar uma fração $\lambda$ das aves, de modo a maximizar $X_{1}$ e $X_{2}$, dando o mesmo peso aos dois caracteres. Assim, se for usado um índice linear do tipo $X_{1}+X_{2}$, a influência de $X_{2}$ na formação do mesmo e, conseqüentemente, na classificação das aves, será menor, uma vez que este é um caráter menos variável. Sendo assim, supondo $X_{1}$ "a" vezes mais variável que $X_{2}, X_{1}+a X_{2}$ seria o índice que atribuiria o mesmo peso a ambos os caracteres. Entretanto, este valor "a" nem sempre é conhecido. Então, Elston (1963) propôs tomar $X_{1} \geq 0$, sendo $X_{1}=0$, se a ave não põe nenhum ovo; nesse caso, ela deve ser descartada, por melhor que seja o seu desempenho com relação ao peso com dez semanas de idade $\left(X_{2}\right)$. Da mesma forma, $X_{2} \geq K$, sendo $K$ um valor mínimo fixado para $X_{2}$, e se $\mathrm{X}_{2}<\mathrm{K}$, deve-se descartar a ave, não importando o seu valor de $\mathrm{X}_{1}$. Para atender a esta exigência, o índice deve satisfazer às três condições seguintes:

i) assumir como menor valor $X_{1}=0$, qualquer que seja o valor de $X_{2}$;

ii) assumir como menor valor $X_{2}=K$, qualquer que seja o valor de $X_{1}$, e;

iii) assumir seu valor máximo quando $X_{1}$ e $X_{2}$ forem maiores.

A função matemática mais simples que atende a estas três exigências é $\mathrm{X}_{1}\left(\mathrm{X}_{2}-\mathrm{K}\right)$, que pode ser escrita de um modo mais geral como $\left(\mathrm{X}_{1}-\mathrm{K}_{1}\right)\left(\mathrm{X}_{2}-\mathrm{K}_{2}\right)$, sendo $\mathrm{K}_{1}$ e $\mathrm{K}_{2}$ o menor valor selecionável dos caracteres $\mathrm{X}_{1}$ e $\mathrm{X}_{2}$, respectivamente. Considerando-se $n$ caracteres, o índice torna-se 


$$
\prod_{j=1}^{n}\left(X_{j}-K_{j}\right)
$$

Pode-se perceber que um indivíduo que possua $X_{j}=K_{j}$, ou seja, $\mathrm{X}_{\mathrm{j}}-\mathrm{K}_{\mathrm{j}}=0$ para pelo menos um caráter terá um índice zero. A Figura 1 ilustra a maximização da função $\prod_{j=1}^{2}\left(X_{j}-K_{j}\right)=\left(X_{1}-K_{1}\right)\left(X_{2}-K_{2}\right)$, ou seja, considerando dois caracteres. Nesta Figura, a elipse representa a população total e a área escura, a porção selecionada $\lambda$.

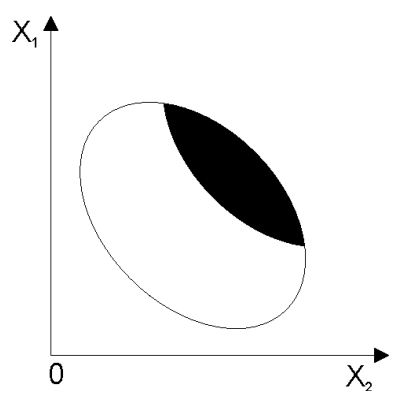

Figura 1 - Seleção com base em um índice não linear. Fonte: Elston (1963)

A atribuição de diferentes valores a $\mathrm{K}_{1}$ e $\mathrm{K}_{2}$ gera um conjunto de curvas, como mostrado na Figura 2. Estas curvas descrevem a função $A=\left(X_{1}-K_{1}\right)\left(X_{2}-K_{2}\right), A>0$.

As três curvas da Figura 2 representam três valores diferentes de $\lambda$. Observa-se que à medida que diminui-se o valor de $\lambda$, isto é, que aumenta-se a pressão de seleção, por meio do aumento dos valores de $\mathrm{K}_{1}$ e $\mathrm{K}_{2}$, ou seja, à medida que diminui-se a porção selecionada, o índice multiplicativo passa a selecionar aproximadamente a mesma fração da população que o índice linear, ilustrado na Figura 3. 
Assim, o índice multiplicativo possibilita que, sem necessidade de estimativas de parâmetros genéticos e fenotípicos, sejam selecionados aproximadamente os mesmos genótipos que seriam pelo emprego do índice linear, tendo ainda a vantagem de permitir o descarte dos genótipos com caracteres em níveis inferiores, pelo simples uso da função multiplicativa (Garcia, 1998).

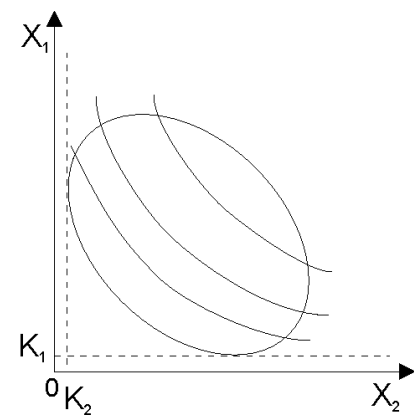

Figura 2 - Séries de curvas obtidas por meio da maximização da função $A=\left(X_{1}-K_{1}\right)\left(X_{2}-K_{2}\right)$. Cada curva representa uma combinação de valores de $\mathrm{K}_{1}$ e $\mathrm{K}_{2}$. Fonte: Elston (1963)

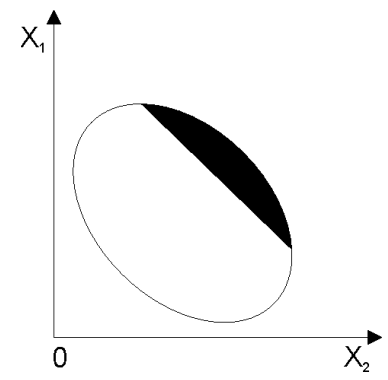

Figura 3 - Seleção com base em um índice linear. Fonte: Elston (1963) 
Usando-se a propriedade do logaritmo, que permite transformar produtos em somas, isto é, $\log (a X)=\log a+\log X$, e fazendo-se $X_{j}^{\prime}=\log \left(X_{j}-K_{j}\right)$, temse que

$$
\sum_{j=1}^{n} \log \left(X_{j}-K_{j}\right)=\sum_{j=1}^{n} X_{j}^{\prime}=\log \prod_{j=1}^{n}\left(X_{j}-K_{j}\right)
$$

Este índice não sofre a influência de pesos. Isto pode ser provado da seguinte maneira: supondo-se que o melhorista desejasse aplicar um índice linear e atribuísse pesos $a_{\mathrm{j}, \mathrm{s}}$ quaisquer aos caracteres, ter-se-ia o índice $a_{1} X_{1}+a_{2} X_{2}+\ldots+a_{n} X_{n}=\sum_{j=1}^{n} a_{j} X_{j}$. A aplicação da transformação logarítmica a este índice resultaria em $\sum_{j=1}^{n} \log a_{j} X_{j}=\sum_{j=1}^{n} \log X_{j}+\sum_{j=1}^{n} \log a_{j}$. Como pode ser visto, os pesos afetam somente o segundo termo. Assim, mesmo que se atribuam pesos aos caracteres, a aplicação do logaritmo faz com que a ponderação de cada caráter pelo peso atribuído a ele deixe de existir, pois, como o segundo termo $\left(\sum_{\mathrm{j}=1}^{\mathrm{n}} \log \mathrm{a}_{\mathrm{j}}\right)$ é uma constante aplicada a todos os genótipos, não interfere na ordem de classificação destes.

Como foi visto, os índices lineares não são adequados quando se trata de caracteres com distribuições de freqüência distintas, a menos que sejam feitas ponderações. O problema é que nem sempre se conhecem os coeficientes de ponderação. Elston (1963) demonstrou que numa situação como esta, o índice multiplicativo é mais apropriado. Isto pode ser ilustrado por meio do seguinte exemplo numérico: supondo-se $X_{1}=1000$ e $X_{2}=100$, temse que os dois caracteres diferem por um fator de escala $a=10$, ou seja, $\mathrm{X}_{1}=10 \mathrm{X}_{2}$. Denominando-se 100 de $100 \times 1$ e 1000 de $100 \times 10$, e aplicando- 
se 0 logaritmo, tem-se: $\log (100 \times 1)=\log 100+\log 1 \quad$ e $\log (100 \times 10)=\log 100+\log 10$. Como $\log 1=0, \log 10=1$ e $\log 100=2$, então, $\log 100=2+0$ e $\log 1000=2+1$, ou seja, enquanto os valores 100 e 1000 diferem por um fator de escala $a=10$, seus logaritmos diferem por um parâmetro de localização $\log a=1$. Este exemplo mostra a utilidade da aplicação da transformação logarítmica em tornar mais semelhantes as distribuições dos caracteres, evitando assim, a predominância de algum deles no valor do índice e, conseqüentemente, na classificação dos genótipos.

O autor salienta que, além da uniformização das variâncias, feita por meio da transformação logarítmica, é necessário que as distribuições dos caracteres sejam adequadamente centradas; desse modo, se a distribuição de $\mathrm{X}_{1}$ é igual à distribuição de $a \mathrm{X}_{2}$ (isto é, se $\mathrm{X}_{1}$ é "a" vezes mais variável que $\mathrm{X}_{2}$ ), deve-se ter $\mathrm{K}_{1}=\mathrm{aK}_{2}$. Caso uma transformação logarítmica não seja suficiente para eliminar as diferenças de escalas entre os caracteres, pode-se teoricamente aplicá-la quantas vezes forem necessárias.

Uma característica do índice multiplicativo é que ele pressupõe que as observações fenotípicas são boas aproximações dos valores genotípicos, de onde deduz-se a necessidade de se obterem dados experimentais precisos, para que o índice possa realmente possibilitar a seleção dos melhores genótipos. Outra característica é que, como não requer a obtenção de estimativas de parâmetros, ele pode ser empregado tanto na seleção dos genótipos a serem recombinados, em programas de seleção recorrente, quanto na seleção de genótipos pré-comerciais, nas etapas finais do processo seletivo.

O fato de não requerer a obtenção de estimativas de parâmetros, o que economiza trabalho, e a possibilidade da fixação de valores de descarte $\left(\mathrm{k}_{\mathrm{j}, \mathrm{s}}\right)$ são duas vantagens deste índice em relação aos índices lineares, quando se pensa em seleção de cultivares. Entretanto, a impossibilidade de se atribuírem pesos aos caracteres, decorrente da transformação logarítmica, é uma 
desvantagem, pois às vezes na obtenção do índice, o pesquisador tem interesse em atribuir um peso maior a um ou mais caracteres, como por exemplo, a produção (Garcia, 1998).

\subsection{2 Índice baseado em medidas de distâncias}

O índice construído a partir de medidas de distâncias foi proposto por Schwarzbach $(1972)^{1}$, citado por Wricke \& Weber (1986), e baseia-se na estimação de distâncias de cada genótipo a um ideótipo, isto é, a um genótipo definido pelo melhorista, que é possuidor do desempenho ideal em todos os caracteres de interesse. Vale ressaltar que esse genótipo pode nem existir na população sob seleção, podendo ser definido arbitrariamente, pelo melhorista. Assim como no índice multiplicativo, neste pressupõe-se que os valores fenotípicos são boas aproximações dos valores genotípicos, o que requer a obtenção de dados experimentais com boa precisão. Definidos os valores do ideótipo, pode-se aplicar qualquer medida de distância, para a estimação do índice. A seguir, serão descritas a Distância Euclidiana e a Distância Generalizada de Mahalanobis, que, de acordo com Cruz \& Regazzi (2001), são as duas mais empregadas no melhoramento de plantas.

\footnotetext{
${ }^{1}:$ SCHWARZBACH, E. Einige Anwendungsmöglichkeiten elektronischer Datenverarbeitung (EDV) für die Beurteilung von Zuchtmaterial. Arb. Tag. Oesterr. Pflanzenz. Gumpenstein: 27787, 1972.
} 


\subsubsection{Distância Euclidiana}

A estimação desta distância será exemplificada com base na Figura 4. Nessa figura, $X_{11}$ e $X_{21}$ são as médias do caráter 1, observadas nos genótipos $1\left(G_{1}\right)$ e $2\left(G_{2}\right)$, respectivamente, e $X_{12}$ e $X_{22}$ são as médias do caráter 2 , observadas nos genótipos 1 e 2, respectivamente. Pode-se ver por essa figura, que a distância entre os genótipos $G_{1}$ e $G_{2}$ corresponde à hipotenusa do triângulo $A B C$. Sendo os caracteres $X_{1}$ e $X_{2}$ independentes, isto é, não correlacionados, o ângulo formado pelos eixos que os representam é de $90^{\circ}$; então, aplicando-se o teorema de Pitágoras, a distância entre $G_{1}$ e $G_{2}$ é

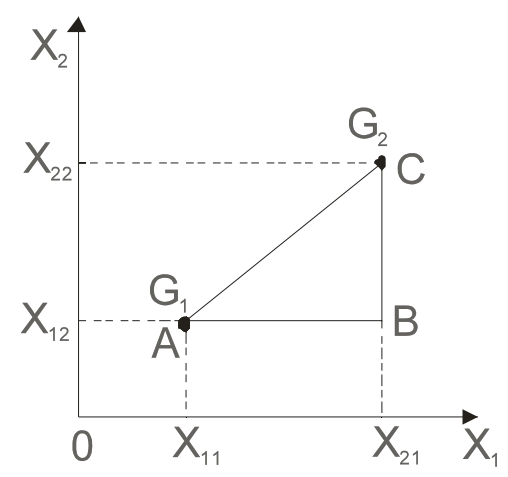

Figura 4 - Distância euclidiana entre os genótipos $G_{1}$ e $G_{2}$, com base em dois caracteres, $\mathrm{X}_{1}$ e $\mathrm{X}_{2}$. Adaptado de Cruz \& Regazzi (2001)

$$
(A C)^{2}=(A B)^{2}+(B C)^{2}, \quad \text { ou: } \quad(A C)=\sqrt{(A B)^{2}+(B C)^{2}}
$$

ou, exprimindo isso em termos das coordenadas dos caracteres $\mathrm{X}_{1}$ e $\mathrm{X}_{2}$,

$$
A C=d_{G_{1} G_{2}}=\sqrt{\left(X_{21}-X_{11}\right)^{2}+\left(X_{22}-X_{12}\right)^{2}}
$$


Generalizando para $n$ caracteres, essa expressão pode ser escrita da seguinte forma:

$$
\mathrm{d}_{\mathrm{G}_{1} \mathrm{G}_{2}}=\sqrt{\sum_{\mathrm{j}=1}^{\mathrm{n}}\left(\mathrm{X}_{1 \mathrm{j}}-\mathrm{X}_{2 \mathrm{j}}\right)^{2}}
$$

Esta expressão aplica-se à estimação da Distância Euclidiana entre dois genótipos quaisquer, podendo ser empregada, por exemplo, em estudos de divergência genética, seja para escolher genitores a serem cruzados em programas de melhoramento, seja para auxiliar na organização e eliminação de acessos duplicados, em bancos de germoplasma. Outra aplicação desta é a estimação da distância de cada genótipo a um genótipo padrão, que pode ser idealizado pelo melhorista (ideótipo). Neste caso, a expressão da Distância Euclidiana é a seguinte:

$$
d_{G_{i} l}=\sqrt{\sum_{j=1}^{n}\left(X_{i j}-X_{l j}\right)^{2}} .
$$

Nesta expressão:

$d_{G_{i}}$ : Distância Euclidiana entre o genótipo $G_{i}$ e o ideótipo I;

$\mathrm{X}_{\mathrm{ij}}$ e $\mathrm{X}_{\mathrm{lj}}$ : valores do caráter $\mathrm{j}$, observado no genótipo $\mathrm{i}$ e atribuído ao ideótipo I, respectivamente.

É importante ressaltar que quando se emprega o índice com base em distâncias, é possível a atribuição de pesos aos caracteres (Wricke \& Weber, 1986). 
De acordo com Cruz \& Regazzi (2001), a Distância Euclidiana possui os inconvenientes de ser alterada com a mudança de escala de medição dos caracteres, com o número de caracteres, e de não levar em conta a existência de correlações entre os mesmos. A seguir, serão mostradas maneiras de sanar essas deficiências.

O problema da escala é contornado por meio da padronização dos dados, ou seja, da divisão de cada observação pelo desvio-padrão correspondente:

$$
Z_{i j}=\frac{X_{i j}}{\sigma_{j}} \text {, em que: }
$$

$Z_{\mathrm{ij}}$ : observação fenotípica estandardizada do caráter j, medido no genótipo i;

$$
\sigma_{\mathrm{j}}: \text { desvio-padrão do caráter } \mathrm{j} \text {. }
$$

Esta estandardização evita que caracteres medidos numa escala maior tenham maior peso no valor de distância e também permite que se incluam num mesmo valor de distância caracteres medidos em escalas não comparáveis, como centímetros e quilogramas, por exemplo (Bussab et al., 1990).

O problema do número de caracteres ocorre quando, por algum motivo, um ou mais caracteres não são medidos num dado genótipo, o que é resolvido dividindo-se a distância euclidiana pelo número de caracteres, e desse modo, a Distância Euclidiana Média estandardizada entre o genótipo i e o ideótipo é definida pela seguinte expressão:

$$
\mathrm{dm}_{\mathrm{G}_{\mathrm{i}}}=\sqrt{\frac{1}{\mathrm{n}} \sum_{\mathrm{j}=1}^{\mathrm{n}}\left(\mathrm{z}_{\mathrm{ij}}-\mathrm{z}_{\mathrm{lj}}\right)^{2}} .
$$


Esta distância difere da distância euclidiana apenas por ser dividida pelo número de caracteres $(n)$, o que permite a comparação de valores de distâncias obtidos a partir de números diferentes de observações.

Segundo Cruz \& Regazzi (2001), a Distância Euclidiana pode ser estimada a partir de dados individuais dos genótipos, não sendo necessária a condução de experimentos com delineamento experimental, para a sua obtenção. Assim, mesmo que se disponha de dados coletados em experimentos com repetições, o delineamento experimental é ignorado, quando se emprega esta medida de distância, embora as médias obtidas de repetições possam ser mais precisas, possibilitando a obtenção de estimativas mais confiáveis de distâncias.

Finalmente, a principal limitação da Distância Euclidiana, que só pode ser superada por meio do uso de outra medida de distância, é o fato de ela pressupor que os caracteres são independentes entre si, isto é, não correlacionados, o que nem sempre é verdadeiro, principalmente quando se trabalha com vários caracteres, como é o caso dos índices de seleção.

Desse modo, quando se dispõe de dados de vários caracteres, obtidos a partir de repetições, a aplicação da Distância Generalizada de Mahalanobis é mais apropriada, por essa levar em conta a existência de correlações entre eles. Entretanto, deve-se ressaltar que o emprego da Distância Generalizada de Mahalanobis exige que os dados tenham distribuição normal (Arunachalam, 1981).

\subsubsection{Distância Generalizada de Mahalanobis}

Quando dois caracteres são independentes um do outro, isto é, quando não são correlacionados, os eixos correspondentes a eles são perpendiculares 
entre si, como mostrado na Figura 4, e, sob essa condição, a Distância Euclidiana estimada com base neles é uma medida válida da distância entre dois genótipos, por exemplo. Porém, quando muitos caracteres estão envolvidos, dificilmente todas as correlações serão nulas. Sendo dois caracteres correlacionados, seja em virtude da pleiotropia, ou da ligação entre os genes, a relação entre eles é a mostrada na Figura 5. Nessa Figura, $X_{11} e$ $\mathrm{X}_{21}$ são as médias do caráter 1 , observadas, respectivamente, nos genótipos 1 $\left(G_{1}\right)$ e $2\left(G_{2}\right), X_{12}$ e $X_{22}$ representam as médias do caráter 2, observadas nos genótipos 1 e 2, respectivamente, e as coordenadas $Y_{11}, Y_{21}, Y_{12}$ e $Y_{22}$ correspondem, nessa ordem, a $X_{11}, X_{21}, X_{12}$ e $X_{22}$, levando em conta a existência de correlação entre os caracteres $X_{1}$ e $X_{2}$.

Pela Figura 5 observa-se que em virtude da correlação existente entre eles, o ângulo formado pelas observações dos caracteres $X_{1}$ e $X_{2}$ é $\theta<90^{\circ}$.

Segundo Chatfield \& Collins (1986), o cosseno de $\theta$ é a correlação entre $\mathrm{X}_{1}$ e $\mathrm{X}_{2}$ e, assim, a aplicação do teorema de Pitágoras à estimação da distância entre dois genótipos com base em observações destes dois caracteres não é válida. Pode-se, entretanto, a partir de $\mathrm{X}_{1}$ e $\mathrm{X}_{2}$, criar dois outros "caracteres", $\mathrm{Y}_{1}$ e $Y_{2}$, independentes entre si.

Da Figura 5, tem-se que $Y_{11}=X_{11}+\left(Y_{11}-X_{11}\right)$. Também, no triângulo formado pelos vértices $X_{11}, Y_{11}$ e $A$, o segmento $\left(Y_{11}-X_{11}\right)$ corresponde ao cateto adjacente ao ângulo $\theta$. Assim, pela função cosseno, deduz-se que $\left(\mathrm{Y}_{11}-\mathrm{X}_{11}\right)=\mathrm{X}_{12} \cos \theta$, e portanto,

$$
\mathrm{Y}_{11}=\mathrm{X}_{11}+\mathrm{X}_{12} \cos \theta
$$

$\mathrm{O}$ segmento que vai de $\mathrm{Y}_{11}$ até $\mathrm{A}$ (que tem o mesmo comprimento do segmento $Y_{12}-0$, da mesma forma que $X_{12}-0$ é igual ao segmento que vai de 
$\mathrm{X}_{11}$ até $\mathrm{A}$ ), corresponde ao cateto oposto ao ângulo $\theta$, então, pela função seno,

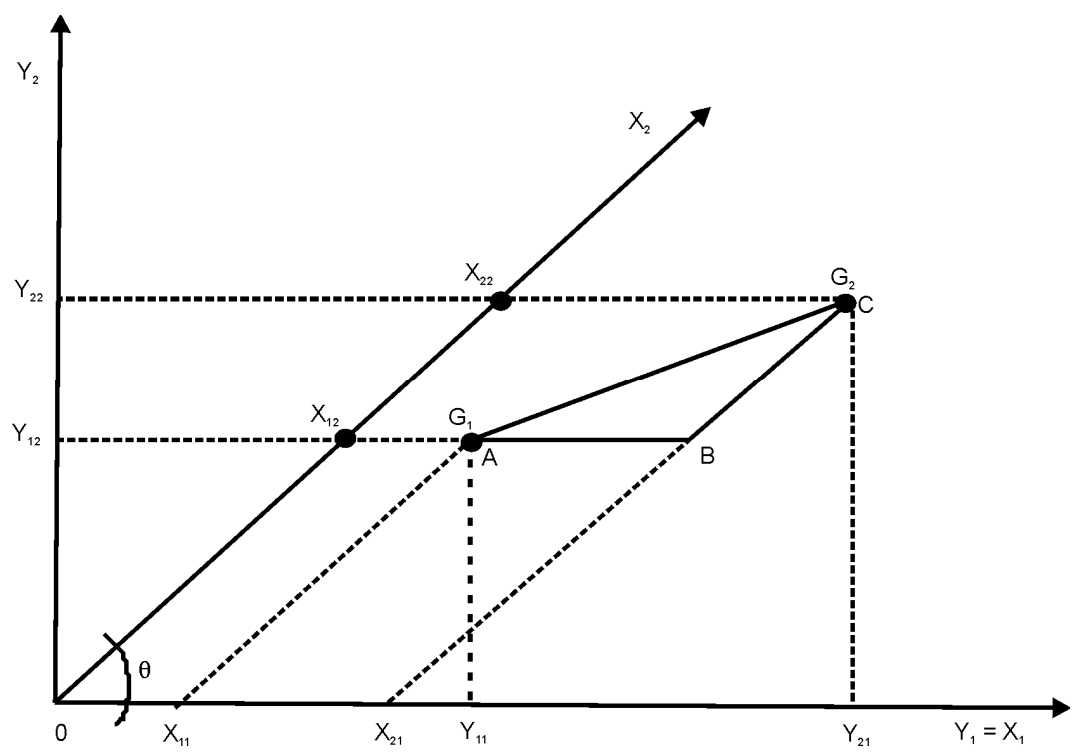

Figura 5 - Distância entre os genótipos $\mathrm{G}_{1}$ e $\mathrm{G}_{2}$, com base em dois caracteres correlacionados, $\mathrm{X}_{1}$ e $\mathrm{X}_{2}$. Adaptado de Cruz \& Regazzi (2001)

$$
Y_{12}=X_{12} \operatorname{sen} \theta
$$

Seguindo-se o mesmo raciocínio na dedução dos Y's relativos ao genótipo $G_{2}$, com base no triângulo de vértices $X_{21}, Y_{21}$ e $C$, obtêm-se os seguintes resultados:

$$
\begin{aligned}
& Y_{21}=X_{21}+X_{22} \cos \theta, e \\
& Y_{22}=X_{22} \operatorname{sen} \theta .
\end{aligned}
$$

Desse modo, os genótipos $G_{1}$ e $G_{2}$ passam a ser representados pelas seguintes coordenadas: 


$$
\begin{aligned}
& G_{1}:\left(Y_{11}, Y_{12}\right):\left(X_{11}+X_{12} \cos \theta, X_{12} \operatorname{sen} \theta\right) \\
& G_{2}:\left(Y_{21}, Y_{22}\right):\left(X_{21}+X_{22} \cos \theta, X_{22} \operatorname{sen} \theta\right) .
\end{aligned}
$$

Aplicando-se o teorema de Pitágoras a estes "caracteres" não correlacionados $Y_{1}$ e $Y_{2}$, obtém-se a distância generalizada de Mahalanobis (Mahalanobis, 1936) entre os genótipos $G_{1}$ e $G_{2}$, com base nos caracteres $X_{1} e$ $\mathrm{X}_{2}$ :

$$
\begin{aligned}
& D_{G_{1} G_{2}}^{2}=\left(Y_{21}-Y_{11}\right)^{2}+\left(Y_{22}-Y_{12}\right)^{2} \\
& =\left[\left(X_{21}+X_{22} \cos \theta\right)-\left(X_{11}+X_{12} \cos \theta\right)\right]^{2}+\left[X_{22} \operatorname{sen} \theta-X_{12} \operatorname{sen} \theta\right]^{2} \\
& =\left(X_{21}-X_{11}\right)^{2}+\left(X_{22}-X_{12}\right)^{2}+2\left(X_{21}-X_{11}\right)\left(X_{22}-X_{12}\right) \cos \theta .
\end{aligned}
$$

Na literatura, como uma forma de simplificar a apresentação, considerase $\left(X_{21}-X_{11}\right)=d_{1}$ e $\left(X_{22}-X_{12}\right)=d_{2}$, e assim:

$$
\mathrm{D}_{\mathrm{G}_{1} \mathrm{G}_{2}}^{2}=\mathrm{d}_{1}^{2}+\mathrm{d}_{2}^{2}+2 \mathrm{~d}_{1} \mathrm{~d}_{2} \cos \theta
$$

Pela expressão anterior verifica-se que, em relação à Distância Euclidiana, a Distância Generalizada de Mahalanobis é acrescida de um termo que inclui o $\cos \theta$, que é a correlação entre $X_{1}$ e $X_{2}$. Caso estes caracteres sejam completamente independentes entre si, $\theta=90^{\circ}$, e $\operatorname{como} \cos 90^{\circ}=0$, a distância de Mahalanobis iguala-se à distância euclidiana (expressão no item 2.2.2.1.).

A expressão apresentada anteriormente, segundo Jacquard (1974), e Arunachalam (1981), pode ser escrita matricialmente, da seguinte maneira: 


$$
\begin{aligned}
D_{G_{1} G_{2}}^{2} & =\left[\left(Y_{21}-Y_{11}\right)\left(Y_{22}-Y_{12}\right)\right]\left[\left(Y_{21}-Y_{11}\right)\left(Y_{22}-Y_{12}\right)\right]^{\prime} \\
& =\left[\left(X_{21}-X_{11}\right)\left(X_{22}-X_{12}\right)\right] S^{-1}\left[\left(X_{21}-X_{11}\right)\left(X_{22}-X_{12}\right)\right]^{\prime},
\end{aligned}
$$

em que $S^{-1}$ é a inversa da matriz de variâncias e covariâncias do resíduo, ou, conforme a convenção feita anteriormente,

$$
D_{G_{1} G_{2}}^{2}=\left[d_{1} d_{2}\right] S^{-1}\left[d_{1} d_{2}\right]^{\prime}=\left[d_{1} d_{2}\right]\left[\begin{array}{cc}
\sigma_{1}^{2} & \sigma_{12} \\
\sigma_{12} & \sigma_{2}^{2}
\end{array}\right]^{-1}\left[d_{1} d_{2}\right]^{\prime} .
$$

A resolução deste sistema matricial resulta em:

$$
D_{G_{1} G_{2}}^{2}=\frac{d_{1}^{2} \sigma_{2}^{2}+d_{2}^{2} \sigma_{1}^{2}-2 d_{1} d_{2} \sigma_{12}}{\sigma_{1}^{2} \sigma_{2}^{2}-\sigma_{12}^{2}}
$$

que após algumas simplificações, torna-se:

$$
D_{\mathrm{G}_{1} \mathrm{G}_{2}}^{2}=\frac{1}{\operatorname{sen}^{2} \theta}\left(\frac{\mathrm{d}_{1}^{2}}{\sigma_{1}^{2}}+\frac{\mathrm{d}_{2}^{2}}{\sigma_{2}^{2}}-\frac{2 \mathrm{~d}_{1} \mathrm{~d}_{2} \cos \theta}{\sigma_{1} \sigma_{2}}\right)
$$

conforme pode ser visto em Arunachalam (1981).

Como já foi visto, $\mathrm{d}_{1}=\left(\mathrm{X}_{21}-\mathrm{X}_{11}\right)$ e $\mathrm{d}_{2}=\left(\mathrm{X}_{22}-\mathrm{X}_{12}\right)$, de modo que a expressão anterior pode ser escrita assim:

$$
D_{G_{1} G_{2}}^{2}=\frac{1}{\operatorname{sen}^{2} \theta}\left(\frac{X_{21}-X_{11}}{\sigma_{1}}+\frac{X_{22}-X_{12}}{\sigma_{2}}-\frac{2\left(X_{21}-X_{11}\right)\left(X_{22}-X_{12}\right) \cos \theta}{\sigma_{1} \sigma_{2}}\right) .
$$

Por essa expressão, observa-se que se dois caracteres possuírem escalas semelhantes, e supondo-se que tenham sido mensurados com igual 
precisão, exercerá maior peso sobre o valor da distância aquele cuja variância do resíduo for menor, isto é, aquele de maior herdabilidade. Pode-se deduzir também, que, como o termo que contém o $\cos \theta$ é subtraído do restante da expressão, dois caracteres afetados da mesma maneira pelo ambiente, isto é, que tenham entre si uma correlação ambiental alta, terão um valor de distância menor do que teriam dois caracteres independentes entre si (Johnson \& Wichern, 1998).

Generalizando para um número qualquer de caracteres, a representação matricial da Distância Generalizada de Mahalanobis é a seguinte (Cruz \& Regazzi, 2001):

$$
\mathrm{D}^{2}=\delta^{\prime} \psi^{-1} \delta
$$

em que:

$\delta$ : vetor-coluna, composto pelos desvios (vetor $\mathrm{d}$, na notação desse trabalho), de dimensões $1 \mathrm{xn}$, sendo $\mathrm{n}$ o número de caracteres;

$\psi$ : matriz de variâncias e covariâncias dos resíduos, de dimensões $\mathrm{n} \times \mathrm{n}$ (matriz S, na notação adotada nesse trabalho).

Os autores anteriormente citados apresentam ainda um segundo método para se estimar a Distância Generalizada de Mahalanobis, por meio do qual evita-se a inversão da matriz de variâncias e covariâncias dos resíduos. Este método torna os cálculos mais simples e evita os grandes erros que resultam da inversão da referida matriz, quando ela é de grandes dimensões, isto é, quando muitos caracteres estão sendo incluídos na estimação da distância. 


\subsection{3 Índice de soma de postos}

Este índice, que também pode ser empregado nas duas situações já comentadas, foi proposto por Mulamba \& Mock (1978) e baseia-se no seguinte princípio: classificam-se os genótipos, em relação a cada um dos caracteres a serem incluídos no índice. Em seguida, obtém-se, para cada genótipo, o seguinte índice, a partir do seu número de ordem com relação a cada um dos $n$ caracteres:

$$
\mathrm{l}_{\mathrm{i}}=\sum \mathrm{n}_{\mathrm{ij}}
$$

sendo:

$\mathrm{I}_{\mathrm{i}}$ : índice do genótipo i;

$\mathrm{n}_{\mathrm{ij}}$ : número de classificação do genótipo i , com relação ao caráter j .

Por este índice, os menores valores de $\mathrm{I}_{\mathrm{i}}$ correspondem aos melhores genótipos, que assim são facilmente classificados, sem a necessidade de obtenção de estimativas de parâmetros genéticos e fenotípicos. Embora teoricamente possa ser aplicado à seleção de genótipos pré-comerciais, este índice não permite o descarte de genótipos que possuam um ou mais caracteres cujo desempenho esteja aquém do requerido pelo mercado. Outra desvantagem, comum a este e ao índice multiplicativo, é não prever o emprego de testes estatísticos por meio dos quais se possa verificar a significância das diferenças observadas entre os genótipos.

A aplicação destes índices é mais fácil, em comparação com os lineares, uma vez que não requerem estimação de parâmetros, nem a atribuição de 
pesos econômicos aos caracteres. Entretanto, nenhum deles preconiza a aplicação de um teste de médias que permita ao pesquisador saber se as diferenças entre as médias são estatisticamente significativas ou não, e somente o índice multiplicativo permite o estabelecimento de valores de descarte.

Assim, visando a atender às exigências da seleção de cultivares, Garcia (1998) desenvolveu um índice com esta finalidade, e cujas etapas serão descritas a seguir.

\subsection{4 Índice para a seleção de cultivares (Garcia, 1998)}

Como foi visto, o índice de Smith (1936), pela própria maneira como foi concebido, não é apropriado para a seleção de cultivares, o mesmo podendo-se dizer dos demais índices lineares. Os não lineares, pelo fato de não exigirem a estimação de parâmetros, podem ser aplicados para essa finalidade, sendo que o índice multiplicativo (Elston, 1963) permite o estabelecimento de valores de descarte, uma das exigências que um índice deve atender para poder selecionar cultivares. Entretanto, nenhum deles, lineares e não lineares, preconiza a aplicação de um teste de médias, que permita ao pesquisador avaliar as diferenças entre os genótipos em bases estatísticas.

O índice para a seleção de cultivares (Garcia, 1998), que também prescinde da estimação de parâmetros, além de preconizar a fixação de valores de descarte e o emprego de um teste de médias, atende as exigências da seleção de cultivares, sendo também de fácil aplicação. As etapas da obtenção desse índice são as seguintes: 
a) agrupamento das médias e obtenção dos recíprocos

O agrupamento das médias é feito por meio do teste de Scott-Knott (Scott \& Knott, 1974). Este teste é empregado por não formar classes sobrepostas, ao contrário dos demais testes de médias.

Depois do agrupamento, transformam-se, por meio da obtenção dos recíprocos $\left(1 / \mathrm{P}_{\mathrm{i}}\right)$, os valores originais dos caracteres sobre os quais a seleção tem como objetivo a diminuição da média (seleção dos menores valores). Esta transformação faz com que os valores de interesse, de todos os caracteres, passem a ser os maiores, uma vez que o valor recíproco é tanto maior quanto menor for o valor original.

Obtidos os recíprocos dos caracteres em que isso é necessário, calculam-se o desvio-padrão, a média de cada uma das classes (formadas pelo teste de Scott-Knott), e a média geral, de cada caráter. Em seguida, o valor de cada tratamento é substituído pela média da classe a que ele pertence, uma vez que dentro de uma mesma classe, as diferenças entre as médias não são estatisticamente significativas.

b) definição do valor mínimo aceitável de cada caráter $\left(\mathrm{N}_{\mathrm{i}}\right)$

Na seleção de pré-cultivares, o estabelecimento de valores de descarte $\left(\mathrm{N}_{\mathrm{i}}{ }^{\prime} \mathrm{s}\right)$ é fundamental porque, para ser aceito pelos agricultores, um genótipo precisa ter um desempenho no mínimo igual ao das cultivares em uso, em todos os caracteres de importância agronômica e econômica. Assim, uma alternativa de valor de descarte poderia ser a média destas cultivares, o que requer que o pesquisador possua conhecimento dos requerimentos dos produtores, em relação à cultura em questão.

Outra alternativa é incluir testemunhas comerciais nos experimentos, e tomar a sua média como sendo $\mathrm{N}_{\mathrm{i}}$ de cada caráter. No trabalho em questão, 
como não havia testemunhas, definiu-se como $N_{i}$ a média geral do experimento. $\mathrm{Na}$ verdade, após calculada a média geral de cada caráter, verificou-se em que classe ela se enquadrava, fixando-se então como $N_{i}$ daquele caráter a média daquela classe.

c) estandardização dos dados

Esta estandardização tem o objetivo de permitir que os caracteres exerçam todos a mesma influência sobre a classificação final dos genótipos. Como os valores individuais são substituídos pela média da classe correspondente, na verdade, a estandardização a ser aplicada sobre as médias de classes, considera a seguinte expressão:

$$
P_{i}^{\prime}=\frac{\left(P_{i}-N_{i}\right)}{s_{i}}, \text { em que: }
$$

$\mathrm{P}_{\mathrm{i}}^{\prime}$ : média estandardizada do caráter $\mathrm{i}$;

$P_{\mathrm{i}}$ : média do caráter i (média da classe em que o genótipo foi classificado pelo teste de Scott-Knott);

$\mathrm{N}_{\mathrm{i}}$ : menor valor selecionável (valor de descarte), estabelecido para o caráter i;

$\mathrm{s}_{\mathrm{i}}$ : desvio-padrão fenotípico entre as médias de quadrados mínimos do caráter i.

Todos os genótipos agrupados numa mesma classe, pelo teste de ScottKnott, têm os seus valores substituídos pela média da sua classe, ou seja, passam a ter o mesmo valor de $P_{i} e$, conseqüentemente, depois da estandardização, todos eles passam a ser representados por um único valor de 
$P_{i}^{\prime}$. Esta estandardização faz com que as observações fenotípicas passem a ser expressas em unidades de desvio-padrão, não sendo, entretanto, centradas na média, mas nos valores de descarte fixados $\left(\mathrm{N}_{\mathrm{i}}{ }^{\prime} \mathrm{s}\right)$.

Assim, são descartados os genótipos que tenham $P_{i}^{\prime}$ negativo $\left(P_{i}<N_{i}\right)$ para pelo menos um caráter, por não atingirem o desempenho mínimo estabelecido pelo melhorista.

d) definição do ideótipo

O ideótipo é um genótipo, existente ou não entre os que estão sendo testados, que possui o melhor valor para todos os caracteres considerados na formação do índice. No trabalho em questão, o autor considerou como ideótipo um genótipo com valor igual à média da classe superior, para todos os caracteres. As exceções foram os parâmetros de adaptabilidade (b) e estabilidade $\left(R^{2}\right)$, calculados somente para a produção de grãos, pelo método de Eberhart \& Russell (1966), e incluídos no índice, como dois caracteres adicionais: no caso do $b$, o valor tomado como $N_{i}$ foi 1,0 e quanto ao $R^{2}$, o autor adotou como ideótipo, o maior valor observado deste parâmetro, entre os genótipos avaliados, isto é, 97,39\%.

e) cálculo das distâncias ao ideótipo

Como no índice em questão o interesse é selecionar os genótipos mais próximos do ideótipo fixado pelo melhorista, a aplicação de uma medida de distância genética se justifica, por permitir que genótipos que têm valores semelhantes para o conjunto de caracteres sejam classificados próximos uns dos outros. Assim, quanto menor o valor da distância ao ideótipo, melhor é o genótipo. 
No índice em questão, Garcia (1998) empregou a Distância Euclidiana Média estandardizada, calculada por meio da expressão já explicada anteriormente (item 2.2.2.1.). Segundo o autor, esta medida de distância foi adotada por ser de fácil interpretação e perfeitamente adequada ao objetivo do trabalho.

Sendo esta medida uma soma de desvios ao quadrado, a unidade em que os caracteres são medidos exerce influência sobre as distâncias, de modo que os caracteres cujas unidades são de maior magnitude têm maior peso nas estimativas das distâncias ao ideótipo. No índice em questão, este problema é resolvido por meio da estandardização dos dados (item c), que garante que todos os caracteres exerçam a mesma influência sobre o valor da distância (Garcia, 1998). Este autor salienta que, embora a distância euclidiana média seja apenas um reescalonamento da distância euclidiana, possuindo as mesmas propriedades que ela, tem a vantagem de poder ser empregada na falta de dados de um ou mais caracteres, uma vez que a distância de cada genótipo ao ideótipo é dividida pelo número de caracteres.

f) classificação e posterior seleção dos indivíduos superiores

Aplicados todos os passos descritos, classificam-se os genótipos, com base nos seus valores de distâncias ao ideótipo. A classificação deve ser feita em ordem crescente, uma vez que devem ser selecionados os genótipos que possuam os menores valores de distâncias (melhor classificação).

\subsection{Aplicação de índices de seleção no melhoramento vegetal}

Desde que foi desenvolvido o primeiro índice, em 1936, muitos outros foram propostos para atender a objetivos mais específicos, e desde então, têm 
sido aplicados, tanto no melhoramento de plantas quanto no de animais. A seguir, será feita uma apreciação da aplicação de alguns destes índices no melhoramento vegetal.

Eagles \& Frey (1974), estudando a produção de grãos e de palha na cultura da aveia, compararam os seguintes métodos seletivos: seleção truncada para a produção de grãos, seleção truncada para a produção de palha, seleção por meio do método dos níveis independentes de descarte, do índice base (Williams, 1962), e do índice otimizado (Smith, 1936). As linhagens foram avaliadas em três locais, por dois anos, e desse modo, pôde-se calcular as respostas esperadas e observadas, sob duas intensidades de seleção, 10\% e $25 \%$.

A seleção truncada para a produção de grãos proporcionou a maior resposta observada deste caráter, mas em contrapartida, resultou no menor ganho na produção de palha, enquanto a seleção truncada para a produção de palha possibilitou a maior resposta deste caráter em dois dos três locais na intensidade de $25 \%$, e nos três locais, na de $10 \%$. Entre métodos que visam a melhorar simultaneamente os dois caracteres, e considerando a média geral (dos ambientes e intensidades de seleção), o índice otimizado, o índice base e a seleção com níveis independentes de descarte possibilitaram a obtenção de ganhos aproximadamente iguais.

Nestas mesmas linhagens de aveia citadas anteriormente, Rosielle \& Frey (1975) aplicaram o índice restrito (Kempthorne \& Nordskog, 1959), visando aumentar a produção, sem alterar a altura da planta e o ciclo, por serem estes dois últimos caracteres positivamente correlacionados à produção. O ganho esperado na produção, com a aplicação do índice restrito incluindo os três caracteres, foi $57 \%$ do que seria obtido por meio da seleção direta sobre a produção; quando o índice de colheita foi incluído no índice como um caráter secundário, o ganho passou a ser de $70 \%$. Em ambos os casos, as médias do ciclo e da altura de plantas permaneceram inalteradas, conforme se desejava. 
Smith et al. (1981) aplicaram o índice otimizado (Smith, 1936), uma modificação deste, que consistiu em empregar as herdabilidades como pesos, e o índice base (Williams, 1962). O objetivo do trabalho foi comparar a eficiência dos outros dois índices, em relação ao otimizado; assim, estimou-se a resposta de cada caráter à seleção efetuada por meio do índice correspondente, sendo a eficiência medida por meio da comparação entre a resposta do caráter à seleção com base no índice base e no índice otimizado modificado, em relação à resposta do mesmo caráter à seleção feita sobre os valores do índice otimizado. Os autores constataram eficiências que variaram de 94,2\% a 99,8\%, o que indica a possibilidade de aplicar estes índices alternativos ao otimizado, com pequena perda de eficiência, especialmente o que utiliza as herdabilidades como pesos, pela facilidade com que estas são obtidas.

Compton \& Lonnquist (1982), aplicaram o índice desenvolvido por Subandi et al. (1973), composto pela produção, acamamento e quebramento de espigas, na cultura do milho. O índice possibilitou um ganho de 4,7\% por ciclo, na produção, enquanto os outros caracteres não tiveram alterações significativas, apesar destes serem na direção desejada.

Coterill (1985) comparou os índice base (Williams, 1962), otimizado (Smith, 1936) e multiplicativo (Elston, 1963) em Pinus radiata e P. Caribaea, sendo cada índice formado pela altura de plantas, diâmetro do tronco, retidão do tronco e diâmetro dos ramos. De um modo geral, o índice otimizado proporcionou respostas melhores, especialmente na espécie $P$. caribaea, em que ocorre uma forte correlação negativa entre os caracteres de crescimento (altura da planta e diâmetro do tronco) e os relacionados à forma da planta (retidão do tronco e diâmetro dos ramos). Entretanto em $P$. radiata, como estas correlações negativas não ocorrem, os índices base e multiplicativo apresentaram resultados razoáveis, de modo que o autor pondera que eles poderiam ser empregados quando não se dispõe de estimativas precisas de 
variâncias e covariâncias genéticas e fenotípicas, necessárias à implementação do índice otimizado.

Trabalhando com Panicum virgatum L., Godshalk et al. (1988), avaliaram os ganhos realizados à seleção efetuada com base no índice de Smith (1936), envolvendo os caracteres produção de forragem, desaparecimento de matéria seca in vitro (IVDMD), fibra em detergente ácido (ADF), e fibra em detergente neutro (NDF). Depois de dois ciclos de seleção, feita com base nos valores do índice, os autores avaliaram a eficiência do mesmo, em comparação com a população original, em duas épocas de corte, verificando que as respostas variaram de um caráter para outro, e em um mesmo caráter, variaram de um corte para outro.

Holbrook et al. (1989), empregaram o índice restrito (Kempthorne \& Nordskog, 1959) na cultura da soja, com o objetivo de aumentar a produção, sem alterar o teor de proteína, que é um caráter negativamente correlacionado à produção. Após dois ciclos de seleção recorrente, os autores estudaram a eficiência do índice em aumentar a produção mantendo inalterado o teor de proteína, e compararam a resposta destes caracteres à seleção feita com base no índice (resposta correlacionada) à resposta obtida com a seleção direta. $\mathrm{O}$ índice proporcionou um progresso de 3,8\% na produção, sem alterar o teor de proteína. Entretanto, a comparação das respostas ao índice com as respostas à seleção direta não permitiram obter respostas conclusivas.

$\mathrm{Na}$ cultura do tabaco, Matzinger et al. (1989) aplicaram o índice restrito (Kempthorne \& Nordskog, 1959), objetivando aumentar o teor de alcalóides totais e manter inalterada a produção, caracteres que são negativamente correlacionados. Para isso, eles partiram da geração $F_{2}$ (população original) de um cruzamento biparental e cruzaram ao acaso 240 plantas $F_{2}$, obtendo 120 famílias de irmãos germanos, que foram avaliadas, sendo as 20 melhores selecionadas e intercruzadas, por meio das sementes remanescentes, obtendose novamente 120 famílias de irmãos germanos. Esse procedimento foi 
repetido durante três ciclos seletivos, após os quais verificou-se que a seleção com base no índice resultou em aumento estatisticamente significativo de 2,5\% por ciclo no teor de alcalóides totais, e numa redução, não significativa, de $0,5 \%$ por ciclo, na produção.

Whiteman et al. (1992), estudaram o efeito de sete índices, na seleção de 32 famílias de meios-irmãos de Eucalyptus nitens, aos nove anos de idade, levando em conta o diâmetro e a retidão do tronco e a retenção de ramos. A altura da planta não foi incluída no índice, por ser altamente correlacionada ao diâmetro do tronco (os autores observaram uma correlação genética aditiva de 0,92 e fenotípica de 0,83). Os índices caracterizaram-se por incluir valores de plantas individuais, médias de famílias, ou de ambas; pela ênfase dada aos caracteres (seleção para aumentar o diâmetro e a retidão do tronco, ou para diminuir a retenção de ramos), e por prever o aumento do diâmetro e da retidão do tronco mantendo inalterada a retenção de ramos, e vice-versa. Os ganhos variaram de $-3 \%$ a $20 \%$ no diâmetro do tronco, de $-6 \%$ a $12 \%$ na retidão do mesmo, e de $-28 \%$ a $18 \%$ na retenção de ramos. Quando a seleção foi realizada com o objetivo de aumentar o diâmetro e retidão do tronco, sem alterar a retenção de ramos, os ganhos foram de $10 \%$ e 1\%, respectivamente; quando buscou-se diminuir a retenção de ramos sem alterar a média dos outros dois caracteres, o ganho foi de $9 \%$. Entretanto, em razão das correlações genéticas desfavoráveis entre a retidão do tronco e a retenção de ramos $\left(r_{A}=0,73\right)$ e entre este caráter e o diâmetro do tronco $\left(r_{A}=0,53\right)$, nenhum dos índices possibilitou a obtenção de ganhos nos três caracteres, simultaneamente.

Humphreys (1994), empregou o índice otimizado (Smith, 1936) na seleção de famílias de meios-irmãos de azevém (Lolium perenne L.), observando uma boa concordância entre a resposta predita à seleção com base no índice, e a resposta observada à seleção feita sem a aplicação de um índice formal. 
$\mathrm{Na}$ cultura do feijoeiro comum (Phaseolus vulgaris L.), Ferreira et al. (1995) testaram três combinações do índice otimizado (Smith, 1936) e um quarto índice, formado a partir dos escores de variáveis canônicas, e compararam, em cada caráter, o ganho esperado à seleção sobre a produção de grãos com os que seriam obtidos se a seleção fosse feita com bases nos índices, que foram compostos por 10 caracteres. A seleção direta para a produção de grãos resultou em alterações na direção desejada, na maioria dos caracteres. Entre os índices, o da variável canônica mostrou-se superior, proporcionando em relação à seleção truncada para a produção de grãos, ganhos maiores na reação à antracnose e à mancha angular, e ganhos semelhantes, na produção de grãos. Além disso, esse método prescinde da atribuição de pesos aos caracteres, uma das dificuldades à aplicação do índice otimizado.

Barbosa \& Pinto (1998), compararam a seleção feita por meio do método dos níveis independentes de descarte com os seguintes índices: otimizado (Smith, 1936), dos ganhos desejados (Pesek \& Baker, 1969), índice base (Williams, 1962), índice proposto por Subandi et al. (1973), de soma de postos (Mulamba \& Mock, 1978) e multiplicativo (Elston, 1963). Os caracteres estudados foram a aparência e densidade de tubérculos, a produção de tubérculos por planta, e a porcentagem de tubérculos graúdos. Os autores concluíram que os índices otimizado, base, dos ganhos desejados, e o de soma de postos, são indicados no melhoramento da batata.

Bueno Filho \& Vencovsky (2000) avaliaram o diâmetro à altura do peito, a altura da planta e o volume de madeira, em 97 famílias de meios-irmãos de Eucaliptus grandis, aos sete anos de idade, e por meio destes três caracteres, compararam a eficiência de um índice na seleção de árvores individuais, composto por informações das árvores per se, e de seus descendentes (método que denominaram seleção combinada), com a seleção seqüencial, que consistiu na seleção entre e dentro de famílias. A comparação entre os dois 
métodos seletivos foi feita por meio das suas respostas (observadas) à seleção. Os autores concluíram que a seleção combinada foi superior à seleção seqüencial, sendo esta superioridade maior nos caracteres de herdabilidade baixa, ou quando as parcelas eram pequenas, e menor quando o tamanho da população era o mesmo, em ambos os métodos. Dessa forma, recomendaram a seleção combinada, especialmente quando o tamanho efetivo não for importante.

Silva et al. (2003), propuseram uma modificação no índice de Mulamba \& Mock (1978), e aplicaram-na à seleção de 40 genótipos de batata. A modificação consistiu em associar o referido teste de médias ao índice, o que foi feito de duas maneiras. No primeiro índice, o teste foi aplicado às médias gerais dos genótipos, e com base no agrupamento feito pelo teste, implementou-se o índice, atribuindo-se o mesmo posto aos genótipos pertencentes a cada grupo. Como nos três caracteres em questão (produção de tubérculos por planta, porcentagem de tubérculos graúdos e peso específico de tubérculos), o interesse é pelos maiores valores, a atribuição de postos foi feita de modo que quanto menor o posto, maior a média, e como o índice é o resultado da soma dos postos de cada caráter, quanto menor o valor do índice, melhor o genótipo. No segundo índice, as médias de cada caráter foram classificadas, por meio do índice (obtenção dos postos), em cada uma das três repetições do experimento, obtendo-se, para cada genótipo, um posto final, que foi o resultado da soma dos postos dos três caracteres. Esse procedimento permitiu aos autores considerar o índice como um quarto caráter, sobre o qual aplicou-se uma análise de variância, a partir da qual obtiveram-se as médias de postos, sobre as quais aplicou-se o teste de médias.

Constatou-se que ambos os procedimentos permitiram selecionar genótipos com médias elevadas dos três caracteres; entretanto, as correlações entre o segundo procedimento e os caracteres foram maiores, o que levou os autores a considerá-lo mais eficiente. 
Como pode-se concluir da revisão desses trabalhos, os resultados da aplicação dos índices de seleção no melhoramento vegetal são muito inconsistentes, não permitindo que se tenha certeza da sua eficiência prática, apesar de os resultados teóricos terem apontado esse método como sendo superior à seleção em tandem e à seleção com adoção de níveis independentes de descarte. Baker (1986) fez uma revisão a esse respeito, e apontou alguns problemas, discutidos a seguir, e que talvez sejam a razão para a incerteza dos resultados obtidos até então.

$\mathrm{Na}$ maioria das vezes, os índices são aplicados com o objetivo de aumentar a produção, e para isso, empregam-se caracteres que a compõem, além da própria produção. O problema é que não se sabe com clareza, o que esperar quando um caráter e seus componentes são incluídos em um índice, com o objetivo de melhorá-lo.

Outro problema é a obtenção de respostas desfavoráveis, resultantes da atribuição arbitrária de pesos econômicos aos caracteres.

Com relação às estimativas de variâncias e covariâncias fenotípicas e genotípicas, necessárias à implementação do índice otimizado, embora já existam metodologias amplamente consolidadas para a sua obtenção, persiste a dúvida a respeito do tamanho ideal da amostra, que permita a obtenção de estimativas confiáveis, sendo muito variável o número de repetições de um experimento para outro.

Finalmente, segundo Baker (1986), ainda não se pode afirmar que índices de seleção são extensivamente empregados no melhoramento de plantas, apesar de a literatura tender a demonstrar que a adoção de um método objetivo de atribuição de pesos a caracteres poderia possibilitar avanços maiores na seleção simultânea.

Desse modo, percebe-se que, apesar de ser uma técnica promissora que, pelo menos teoricamente, permite melhorar mais de uma caráter por vez, existem várias questões que necessitam ser elucidadas, para que os índices de 
seleção passem a ser amplamente adotados pelos melhoristas de plantas. Uma vez resolvidos esses problemas, é provável que, conforme previsto pela teoria, essa técnica permita a obtenção de resultados satisfatórios na seleção simultânea de caracteres, resultando assim, em diminuição do tempo necessário para a obtenção de uma cultivar.

O índice para a seleção de cultivares (Garcia, 1998) representa um avanço, uma vez que atende aos requisitos fundamentais da seleção de précultivares: a adoção de um teste estatístico para comparação das médias, e o estabelecimento de valores críticos, ou de descarte. Ainda não se têm, entretanto, resultados práticos do emprego desse índice, em virtude de ele ter sido desenvolvido há pouco tempo. 


\section{MATERIAL E MÉTODOS}

\subsection{Delineamento experimental}

O material básico deste trabalho compreende linhagens de uma população de soja, resultante do cruzamento entre as linhagens BR-80-14853 e $\mathrm{PI}-123439$.

A partir da geração $F_{3}$ do cruzamento entre esses genitores, a população foi conduzida, sem seleção artificial, por meio do método SSD (Single Seed Descent, ou descendente de uma única semente), até a geração $F_{7}$, quando, aleatoriamente, derivaram-se 88 linhagens, as quais constituíram o material avaliado neste trabalho.

Os experimentos foram conduzidos nos anos agrícolas de 1995/96, 1996/97, 1998/99, 1999/00, 2000/01 e 2001/02, na área experimental do Departamento de Genética da Escola Superior de Agricultura "Luiz de Queiroz", da Universidade de São Paulo, localizada em Piracicaba-SP, a $22^{\circ} 42^{\prime} 30^{\prime \prime}$ de latitude sul e $47^{\circ} 38^{\prime} 00^{\prime \prime}$ de longitude oeste, e a $537 \mathrm{~m}$ de altitude.

As parcelas foram constituídas de uma linha de 2,0 $\mathrm{m}$ de comprimento com espaçamento de 0,5 m entre linhas. Na semeadura, adotou-se uma densidade de 30 sementes por metro linear; após a germinação fez-se o desbaste, mantendo-se aproximadamente 17 plantas por metro linear. 
Em todos os experimentos, além das 88 linhagens, foram incluídas as cultivares testemunhas IAC-12, IAC-Foscarin-31 e IAS-5. O delineamento adotado foi o de blocos casualizados. Nos quatro primeiros anos agrícolas (1995/96, 1996/97, 1998/99 e 1999/00), os experimentos foram instalados com os seguintes números de repetições: 3, 4, 6 e 6, respectivamente. Nos anos agrícolas de 2000/01 e 2001/02, os experimentos foram instalados com 10 repetições.

\subsection{Caracteres avaliados}

Os caracteres avaliados foram os seguintes:

Acamamento $(A C)$ : caráter avaliado visualmente na maturação, por meio de uma escala de notas, que variou de 1 a 5 , na qual a nota 1 corresponde a uma parcela com todas as plantas eretas, e a nota 5, a uma parcela com todas as plantas acamadas. Esse caráter foi avaliado nos quatro primeiros anos agrícolas;

Altura de plantas na maturação (AM): distância $(e m \mathrm{~cm})$ do nível do solo ao ápice da haste principal, na época da maturação (época em que cerca de 95\% das vagens já haviam atingido a maturidade), avaliada em cinco plantas por parcela. Esse caráter foi avaliado em todos os anos agrícolas. Em 2000/01 e 2001/02, foi avaliado somente em cinco repetições;

Produção de grãos (PG): avaliada por meio da pesagem dos grãos da parcela, utilizando-se balança de precisão, em laboratório. Esse caráter foi avaliado em todos os anos agrícolas, e em todas as repetições. 


\subsection{Análises estatísticas}

Inicialmente, foram feitas as análises de variância individuais (por ano) e as análises conjuntas, para os três caracteres, utilizando-se o programa SAS (Statistical Analysis System, SAS, 1992).

As análises estatísticas foram efetuadas com base nos seguintes modelos matemáticos:

-Análises de variância individuais:

$Y_{i j}=\mu+t_{i}+r_{j}+e_{i j}$, em que:

$\mathrm{Y}_{\mathrm{ij}}$ : valor observado do i-ésimo tratamento, na j-ésima repetição;

$\mu$ : média geral;

$t_{\mathrm{i}}$ : efeito aleatório do tratamento (linhagem) $\mathrm{i} ; \quad \mathrm{i}=1,2, \ldots, \mathrm{T}$;

$r_{j}$ : efeito aleatório da repetição j; $j=1,2, \ldots, R$;

$\mathrm{e}_{\mathrm{ij}}$ : erro experimental, associado à parcela ij.

Com base nesse modelo, o esquema da análise de variância é o seguinte:

\begin{tabular}{lccc}
\hline Fonte de Variação & G. L. & Q.M. & $F$ \\
\hline Repetições & $\mathrm{R}-1$ & $\mathrm{Q}_{3}$ & \\
Tratamentos & $\mathrm{T}-1$ & $\mathrm{Q}_{2}$ & $\mathrm{Q}_{2} / \mathrm{Q}_{1}$ \\
Erro & $(\mathrm{R}-1)(\mathrm{T}-1)$ & $\mathrm{Q}_{1}$ & \\
\hline Total & $\mathrm{RT}-1$ & &
\end{tabular}


-Análises de variância conjuntas:

$Y_{i j k}=\mu+t_{i}+a_{k}+t a_{i k}+r_{j(k)}+\bar{e}_{i j(k)}$

$\mathrm{Y}_{\mathrm{ijk}}$ : observação referente ao tratamento i, na repetição j, do ano k;

$\mu$ : média geral;

$\mathrm{t}_{\mathrm{i}}$ : efeito aleatório do tratamento $\mathrm{i} ; \mathrm{i}=1,2, \ldots, \mathrm{T}$;

$a_{k}$ : efeito aleatório do ano $k ; \quad k=1,2, \ldots, A$;

ta $a_{\mathrm{ik}}$ : efeito aleatório da interação entre o tratamento i e o ano k;

$r_{j(k)}$ : efeito aleatório da repetição j dentro do ano $k ; j=1,2, \ldots, R$;

$\overline{\mathrm{e}}_{\mathrm{ij}(\mathrm{k})}$ : erro experimental médio, associado à parcela ijk.

Com base nesse modelo, o quadro de análise de variância conjunta é o seguinte:

\begin{tabular}{lccc}
\hline Fonte de variação & G.L. & Q.M. & $F$ \\
\hline Repetições/Anos & $\mathrm{A}(\mathrm{R}-1)$ & $\mathrm{Q}_{5}$ & \\
Anos & $\mathrm{A}-1$ & $\mathrm{Q}_{4}$ & $\left(\mathrm{Q}_{1}+\mathrm{Q}_{4}\right) /\left(\mathrm{Q}_{2}+\mathrm{Q}_{5}\right)$ \\
Tratamentos & $\mathrm{T}-1$ & $\mathrm{Q}_{3}$ & $\mathrm{Q}_{3} / \mathrm{Q}_{2}$ \\
Tratamentos x Anos & $(\mathrm{T}-1)(\mathrm{A}-1)$ & $\mathrm{Q}_{2}$ & $\mathrm{Q}_{2} / \mathrm{Q}_{1}$ \\
Erro Médio/Anos & $\mathrm{A}(\mathrm{R}-1)(\mathrm{T}-1)$ & $\mathrm{Q}_{1}$ & \\
\hline Total & $\mathrm{ART}-1$ & &
\end{tabular}

As análises dos caracteres AM e PG foram feitas com as unidades originais, enquanto AC, por ter sido avaliado por meio de uma escala de notas, foi transformado para $\sqrt{x+0,5}$. 
Utilizando os mesmos procedimentos das análises de variância, foram realizadas as análises de covariâncias entre os caracteres dois a dois, de onde foi possível estimar as covariâncias do resíduo.

\subsection{Etapas do desenvolvimento do índice de seleção}

\subsubsection{Etapas preliminares}

Obtidas as médias de quadrados mínimos das análises de variância conjuntas, submeteu-se 0 arquivo com as médias das 88 linhagens ao programa SISVAR (Ferreira, 2000), para aplicação do teste de Scott-Knott (Scott \& Knott, 1974). Para isso, o referido programa requer as seguintes informações: número de tratamentos, número de graus de liberdade e valor do quadrado médio do resíduo, provenientes das análises de variância conjuntas, e o nível de significância desejado. Nesse trabalho, adotaram-se os seguintes níveis de significância: 0,01; 0,01; e 0,05; para os caracteres AC, AM e PG, respectivamente. O nível de significância definido para $P G$ foi maior que os de AC e AM, para possibilitar a formação de um número maior de grupos, ou seja, para atribuir um peso maior a esse caráter, por ser ele o mais importante dos três. Escolheu-se o teste de Scott-Knott, porque esse é um teste que não forma grupos sobrepostos, ou seja, por ele, um tratamento nunca é classificado em mais de um grupo.

Depois do agrupamento, o passo seguinte foi o cálculo da média de cada grupo, e posteriormente, a substituição das médias dos tratamentos pela média do grupo correspondente, uma vez que as diferenças existentes entre essas 
médias não são estatisticamente significativas, dentro da margem de erro escolhida.

Este procedimento também aplicou-se ao valor de descarte $\left(\mathrm{N}_{\mathrm{j}}\right)$, ou seja, uma vez definido este valor, observou-se em qual dos grupos ele se enquadrava, adotando-se a média deste grupo como $\mathrm{N}_{\mathrm{j}}$. Entretanto, em $\mathrm{AM}$ e PG, ocorreu de esse valor situar-se exatamente entre dois grupos, gerando uma dúvida: em qual dos grupos incluí-lo? Para se contornar este problema, o valor adotado como $\mathrm{N}_{\mathrm{j}}$ foi submetido ao teste de Scott-Knott, juntamente com as médias das 88 linhagens, de modo que o valor de descarte de AM, que situou-se entre os grupos 4 e 5, foi alocado no grupo 5, e o de PG, situado entre os grupos 3 e 4 foi alocado no grupo 4 .

Como em AC e em AM, o interesse é pelas menores médias, antes de calcular as médias de grupos, obteve-se o recíproco $\left(1 / \mathrm{X}_{\mathrm{ij}}\right)$ de cada valor individual, de modo que as médias de grupos transformadas ( $Z_{\mathrm{i}, \mathrm{s}}$ e $Y_{\mathrm{ij}, \mathrm{s}}$ ) negativas correspondessem aos genótipos não selecionáveis, isto é, àqueles cujas médias originais estão acima do valor de descarte. Entretanto, os recíprocos dos valores individuais (médias das linhagens) não são apresentados, uma vez que foram substituídos pelas médias de grupos, as quais foram efetivamente empregadas nas etapas posteriores da obtenção dos índices. Como em PG, a seleção tem como objetivo aumentar a média, não houve necessidade de obtenção dos recíprocos das médias desse caráter.

O teste de Scott-Knott agrupa as médias em ordem crescente, de modo que o grupo de menor média é o de número 1. Em AC e em AM, o interesse é pelas menores médias, que em virtude da obtenção dos recíprocos (item 2.2.4.), correspondem a $Z_{\mathrm{ij}, \mathrm{s}}$ e $\mathrm{Y}_{\mathrm{i}, \mathrm{s}}$ positivos. Assim, nestes dois caracteres, as médias selecionáveis, isto é, as menores, pertencem aos grupos de menores números. 
Em PG, a seleção busca as maiores médias, de modo que a obtenção dos recíprocos não foi necessária, uma vez que ao subtrair-se o valor de descarte das médias de grupos, os $Z_{\mathrm{ij}, \mathrm{s}}$ e $\mathrm{Y}_{\mathrm{ij}, \mathrm{s}}$ positivos eram os das linhagens selecionáveis, da mesma forma que para os outros dois caracteres. Havia, entretanto, o problema de que essas médias selecionáveis de PG pertenciam aos grupos de números maiores, situação inversa à de $A C$ e $A M$. Assim, para fazer com que as médias selecionáveis $\left(X_{i j}>N_{j}\right)$ de $P G$ passassem a pertencer aos grupos de menores números, inverteu-se a numeração dos grupos nos quais o teste de Scott-Knott classificou as médias desse caráter. Como foram formados oito grupos, na inversão, o grupo 1 passou a ser 8 , o 2 passou a ser 7, e assim por diante. Desse modo, o grupo 4, no qual o referido teste classificou o valor estabelecido como $N_{j}$ de PG (sendo selecionáveis as linhagens pertencentes aos grupos 4, 5, 6, 7 e 8), passou a ser grupo 5, depois da inversão, e assim, as linhagens selecionáveis passaram a pertencer aos grupos 1, 2, 3, 4 e 5 .

O parâmetro b e o coeficiente de determinação $\left(R^{2} \%\right)$, do método de análise de estabilidade e adaptabilidade desenvolvido por Eberhart \& Russell (1966), foram estimados para o caráter PG, e incluídos no cálculo da Distância Euclidiana Média, como dois "caracteres" adicionais, para possibilitar a identificação de linhagens que, além de possuírem desempenho satisfatório em $A C, A M$ e $P G$, fossem também responsivas à melhoria do ambiente, isto é tivessem estabilidade ampla (b próximo de 1,0), e comportamento previsível de um ambiente para outro $\left(\mathrm{R}^{2}\right.$ próximo de $\left.100 \%\right)$.

Para estimá-los, obtiveram-se, no programa SAS (Statistical Analysis System, SAS, 1992), as médias de quadrados mínimos da PG, em cada um dos seis anos. Em seguida, essas médias foram submetidas ao programa GENES (Cruz, 2001), que estimou o b e o $R^{2}$.

O coeficiente de regressão linear (b), que mede a adaptabilidade, é dado pela seguinte expressão: 
$b_{i}=\frac{\operatorname{COV}_{X Y}}{\sigma_{X}^{2}}$, em que:

b : coeficiente de regressão linear da variável dependente $Y(P G$, nesse caso), observada no genótipo $\mathrm{i}$, sobre $\mathrm{o}$ índice ambiental $\mathrm{l}_{\mathrm{j}}$ (variável independente $\mathrm{X}$ ), obtido como o desvio da média de cada ambiente em relação à média geral;

$\mathrm{COV}_{\mathrm{XY}}$ : covariância entre as médias de $\mathrm{PG}$ de cada linhagem e os índices ambientais;

$\sigma_{X}^{2}$ : variância dos índices ambientais.

No contexto do método de Eberhart \& Russell (1966), o coeficiente de regressão b mede o quanto a média da variável dependente se altera (aumenta ou diminui, conforme o b seja positivo ou negativo), quando a variável independente é aumentada em uma unidade. Desse modo, os valores de b podem ser classificados em (Cruz \& Regazzi, 2001):

$\mathrm{b}<1$ : indica genótipos com adaptabilidade específica a ambientes desfavoráveis;

$\mathrm{b}=1$ : indica genótipos com adaptabilidade geral ou ampla;

b $>1$ : indica genótipos com adaptabilidade específica a ambientes favoráveis.

O parâmetro que define a estabilidade ou previsibilidade de comportamento da média de um dado genótipo de um ambiente para outro é a variância dos desvios da regressão $\left(\sigma_{\mathrm{di}}^{2}\right)$, sendo considerado como estável o genótipo cuja $\sigma_{\mathrm{di}}^{2}$ é igual ou próxima de zero (Cruz \& Regazzi, 2001). Estes autores observam, entretanto, que algumas vezes, genótipos de média altamente satisfatória têm $\sigma_{\mathrm{di}}^{2}$ estatisticamente diferente de zero. Para contornar 
esse problema, prosseguem os autores, adota-se como medida de estabilidade, o coeficiente de determinação $\left(R^{2}\right)$, dado pela seguinte expressão:

$$
R_{i}^{2}=\frac{S Q(\text { regressão linear })_{i}}{S Q\left(A / G_{i}\right)} \times 100 .
$$

Nessa expressão,

$\mathrm{R}_{\mathrm{i}}^{2}$ : coeficiente de determinação do genótipo i;

$S Q(\text { regressão linear) })_{i}$ : soma de quadrados da regressão linear relativa ao genótipo i;

$S Q\left(A / G_{i}\right)$ : soma de quadrados de ambientes dentro do genótipo i.

O coeficiente de determinação expressa o quanto da soma de quadrados de ambientes dentro do genótipo i é explicado pela soma de quadrados da regressão linear, ou ainda, quão próximos são os valores observados e os estimados por meio da regressão linear. Desse modo, quanto mais próximo de $100 \%$ for o valor de $\mathrm{R}^{2}$ de um dado genótipo, maior a previsibilidade do seu comportamento, ou a sua estabilidade.

\subsubsection{Distância Euclidiana}

Para estimar a distância euclidiana, as médias de grupos foram transformadas, por meio da seguinte expressão: 


$$
Z_{i j}=\frac{X_{i j}-N_{j}}{\sigma_{j}} .
$$

Nesta equação,

$Z_{\mathrm{ij}}$ : média estandardizada do caráter $\mathrm{j}$, medido nos genótipos pertencentes a um mesmo grupo, formado pelo teste de Scott-Knott;

$\mathrm{X}_{\mathrm{ij}}$ : média original do caráter $\mathrm{j}$, medido nos genótipos pertencentes a um mesmo grupo, formado pelo teste de Scott-Knott;

$\mathrm{N}_{\mathrm{j}}$ : média da classe à qual verificou-se pertencer o valor de descarte estabelecido para o caráter j;

$\sigma_{\mathrm{j}}$ : desvio-padrão fenotípico entre as médias de quadrados mínimos do caráter j, obtidas da análise de variância conjunta. Os valores dos desviospadrão dos caracteres $A C$, AM e $P G$, do parâmetro b e do coeficiente de determinação $R^{2}$ são apresentados no Apêndice 1 , no qual são exemplificadas em detalhes as etapas da obtenção das Distâncias Euclidiana e de Mahalanobis.

A subtração $X_{i j}-N_{j}$ serve para indicar quais genótipos devem ser descartados, ou seja, os genótipos cujos $Z_{\mathrm{ij}, \mathrm{s}}$ são negativos $\left(X_{\mathrm{ij}}<\mathrm{N}_{\mathrm{j}}\right)$, enquanto a divisão pelo desvio-padrão (estandardização) evita que algum caráter exerça um peso maior que os demais no valor da distância.

Os valores de descarte $\left(\mathrm{N}_{\mathrm{j}}\right)$ e os atribuídos ao ideótipo, nos três caracteres, no parâmetro b e no $\mathrm{R}^{2}$, são mostrados na Tabela 1.

Vale salientar que os valores efetivamente empregados como $\mathrm{N}_{\mathrm{j}, \mathrm{s}}$ foram as médias das classes às quais pertencem os valores apresentados na Tabela 1: 0,714221 , que é o recíproco da média do grupo 2, para AC; 0,012021, que é 
o recíproco da média do grupo 5 para AM; e 245,1858, que é a média do grupo 5 , para PG. Como as estimativas de b e de $R^{2}$ não foram agrupadas, os valores empregados como $\mathrm{N}_{\mathrm{j}, \mathrm{s}}$ desses dois parâmetros foram os apresentados na Tabela 1, isto é, 0,70 e $48,9 \%$, respectivamente.

Tabela 1. Valores de descarte $\left(\mathrm{N}_{\mathrm{j}, \mathrm{s}}\right)$ e atribuídos ao ideótipo, para os caracteres AC, AM e PG, o parâmetro de adaptabilidade (b), e o coeficiente de determinação ( $R^{2}$; estabilidade)

\begin{tabular}{ccc}
\hline Caráter & Valor de descarte $\left(\mathrm{N}_{\mathrm{j}}\right)$ & Valor atribuído ao ideótipo \\
\hline $\mathrm{AC}$ & Abaixo de 1,42 (média geral) & 1,0 (ideal) \\
$\mathrm{AM}$ & Abaixo de $80,1 \mathrm{~cm}$ (média geral) & $71,4 \mathrm{~cm}^{*}$ \\
$\mathrm{PG}$ & Acima de $236,1 \mathrm{~g} /$ parcela (média geral) & $373,9 \mathrm{~g} /$ parcela** \\
$\mathrm{B}$ & Acima de 0,70 (valor arbitrário) & 1,0 (ideal) \\
$\mathrm{R}^{2}$ & Acima de $48,9 \%{ }^{* * *}$ & $100 \%$ (ideal) \\
\hline
\end{tabular}

*: média das testemunhas IAC-12 e IAS-5 (de menor porte);

**: média da testemunha IAC Foscarin 31 (mais produtiva) + 5\%;

***: média da testemunha IAC Foscarin $31\left(\mathrm{R}^{2}\right.$ mais baixo entre as testemunhas)

Definido o valor de descarte de cada caráter, o passo seguinte foi calcular o desvio-padrão $\left(\sigma_{\mathrm{j}}\right)$, para em seguida, fazer a estandardização das médias de grupos.

Os valores atribuídos ao ideótipo (Tabela 1) também foram estandardizados, de modo a colocá-los na mesma escala das médias de grupos $\left(Z_{\mathrm{i}, \mathrm{s}}\right)$. O valor atribuído ao ideótipo para AC foi a nota 1,0 , a menor da escala adotada, correspondente a 0\% de acamamento. Em AM, escolheu-se a média entre as testemunhas IAC-12 e IAS-5, as duas de menor porte $(71,4 \mathrm{~cm})$, e em PG, a média da testemunha mais produtiva, a IAC Foscarin 31 (356,1 $\mathrm{g} /$ parcela), mais $5 \%$, o que resultou em um valor de $373,9 \mathrm{~g} /$ parcela. 
Para o parâmetro de adaptabilidade (b), definiu-se como ideal o valor 1,0, que corresponde a estabilidade ampla, e para o $\mathrm{R}^{2}$, fixou-se o valor de $100 \%$, o maior valor possível (Tabela 1).

A estandardização dos valores atribuídos ao ideótipo foi feita do seguinte modo:

$Z_{\mathrm{lj}}=\frac{\mathrm{X}_{\mathrm{lj}}-\mathrm{N}_{\mathrm{j}}}{\sigma_{\mathrm{j}}}$, na qual:

$\mathrm{Z}_{\mathrm{lj}}$ : valor estandardizado do caráter j, atribuído ao ideótipo I;

$\mathrm{X}_{\mathrm{lj}}$ : valor definido como o ideal a ser buscado, ou o valor atribuído ao caráter $\mathrm{j}$, no ideótipo I. Os demais termos já foram definidos.

Estandardizadas as médias de classes $\left(X_{i, s}\right)$ e os valores atribuídos ao ideótipo, obtiveram-se os desvios $\left(d=Z_{i j}-Z_{i j}\right)$. Desse modo, a Distância Euclidiana, com base em desvios de AC, AM, PG, b e $\mathrm{R}^{2}$ foi estimada por meio da seguinte expressão:

$$
\mathrm{dm}_{\mathrm{G}_{\mathrm{i}}}=\sqrt{\frac{1}{5} \sum_{\mathrm{j}=1}^{5} \mathrm{~d}^{2}}=\sqrt{\frac{1}{5}\left[\left(Z_{\mathrm{i} 1}-Z_{11}\right)^{2}+\left(Z_{\mathrm{i} 2}-Z_{\mathrm{I} 2}\right)^{2}+\left(Z_{\mathrm{i} 3}-Z_{13}\right)^{2}+\left(Z_{\mathrm{i} 4}-Z_{14}\right)^{2}+\left(Z_{i 5}-Z_{15}\right)^{2}\right]},
$$

em que:

$\mathrm{dm}_{\mathrm{G}_{\mathrm{i}}}$ : Distância Euclidiana Média do genótipo (linhagem) i ao ideótipo I;

$Z_{\mathrm{i} 1}, Z_{\mathrm{i} 2}, Z_{\mathrm{i} 3}, Z_{\mathrm{i} 4}$ e $Z_{\mathrm{i} 5}$ : médias de grupos estandardizadas, de AC, AM, PG, b e $R^{2}$, respectivamente; 
$Z_{11}, Z_{12}, Z_{13}, Z_{14}$ e $Z_{15}$ : valor (estandardizado) atribuído ao ideótipo, em AC, $A M, P G, b$ e $R^{2}$, respectivamente.

Estimou-se também a distância euclidiana sem incluir o b e o $\mathrm{R}^{2}$, para verificar se a inclusão desses parâmetros resultaria em alterações na classificação das linhagens.

\subsubsection{Distância Generalizada de Mahalanobis}

Para a estimação da Distância Generalizada de Mahalanobis, aplicou-se a seguinte transformação às médias de grupos $\left(X_{i j, s}\right)$ :

$$
Y_{i j}=X_{i j}-N_{j}
$$

ou seja, $\mathrm{Y}_{\mathrm{ij}}-\mathrm{N}_{\mathrm{j}}$ não foi estandardizado, pois, como foi visto no item 2.2.2.2., ao aplicar-se a Distância Generalizada de Mahalanobis, as médias (neste caso, os desvios de cada genótipo ao ideótipo), já são divididas pelo desvio-padrão do resíduo correspondente.

Da mesma forma que as médias de grupos, o valor atribuído ao ideótipo foi transformado, da seguinte forma:

$$
Y_{\mathrm{lj}}=X_{\mathrm{lj}}-\mathrm{N}_{\mathrm{j}} \text {, em que: }
$$

$\mathrm{Y}_{\mathrm{lj}}$ : valor transformado do caráter $\mathrm{j}$, atribuído ao ideótipo. Os termos $\mathrm{X}_{\mathrm{lj}} \mathrm{e}$ $\mathrm{N}_{\mathrm{j}}$ já foram definidos. 
Desse modo, obtiveram-se os desvios de $A C, A M$ e $P G$, com base nos quais estimou-se a Distância Generalizada de Mahalanobis entre cada linhagem e o ideótipo, por meio da seguinte expressão:

$$
\begin{gathered}
D_{G_{i} 1}^{2}=d^{\prime} S^{-1} d=\left[\begin{array}{lll}
d_{1} & d_{2} & d_{3}
\end{array}\right]\left[\begin{array}{ccc}
V_{1} & \operatorname{COV}_{12} & \operatorname{COV}_{13} \\
\operatorname{COV}_{12} & V_{2} & \operatorname{COV}_{23} \\
\operatorname{COV}_{13} & \operatorname{COV}_{23} & V_{3}
\end{array}\right]^{-1}\left[\begin{array}{l}
d_{1} \\
d_{2} \\
d_{3}
\end{array}\right] \\
=\left[\left(Y_{i 1}-Y_{11}\right)\left(Y_{i 2}-Y_{12}\right)\left(Y_{i 3}-Y_{13}\right)\right]\left[\begin{array}{ccc}
V_{1} & \operatorname{COV}_{12} & \operatorname{COV}_{13} \\
\operatorname{COV}_{12} & V_{2} & \operatorname{COV}_{23} \\
\operatorname{COV}_{13} & \operatorname{COV}_{23} & V_{3}
\end{array}\right]^{-1}\left[\begin{array}{c}
Y_{i 1}-Y_{11} \\
Y_{i 2}-Y_{12} \\
Y_{i 3}-Y_{13}
\end{array}\right],
\end{gathered}
$$

Nessas expressões:

$\mathrm{Y}_{\mathrm{i} 1}, \mathrm{Y}_{\mathrm{i} 2}$ e $\mathrm{Y}_{\mathrm{i} 3}$ : médias de grupos transformadas, dos caracteres AC, AM e $P G$, respectivamente;

$\mathrm{Y}_{11}, \mathrm{Y}_{12}$ e $\mathrm{Y}_{13}$ : valores (transformados) atribuídos ao ideótipo, nos caracteres AC, AM e PG, respectivamente;

$\mathrm{S}^{-1}$ : inversa da matriz de variâncias e covariâncias do erro ou resíduo. Nesta matriz, $V_{1}, V_{2}$ e $V_{3}$ são, respectivamente, as variâncias dos resíduos (QMerro da análise de variância conjunta) de $A C, A M$ e $P G$, e $\mathrm{COV}_{12}, \mathrm{COV}_{13}$ e COV 23 são as covariâncias entre os resíduos desses caracteres. A matriz de variâncias e covariâncias dos resíduos empregada nesse trabalho é apresentada no Apêndice 2.

Dessa maneira, para cada genótipo estimou-se um valor de distância ao ideótipo. Este valor de distância é o próprio índice, por meio do qual os genótipos foram classificados. Como trata-se de distância a um ideótipo, o genótipo é tanto melhor quanto menor for o seu valor de distância. 


\section{RESULTADOS E DISCUSSÃO}

\subsection{Análise geral dos dados e estimação dos parâmetros}

Os resultados das análises de variância conjuntas dos caracteres acamamento $(A C)$, altura da planta na maturação (AM) e produção de grãos (PG) encontram-se na Tabela 2. Todas as fontes de variação foram altamente significativas $(P<0,01)$, nos três caracteres. A significância da fonte de variação Tratamentos indica a existência de variabilidade entre as linhagens, essencial para que se possa efetuar a seleção, enquanto a significância da interação Anos x Tratamentos indica que o comportamento relativo das linhagens não foi consistente entre os diferentes anos.

Os coeficientes de variação (CV,s) foram os seguintes: AC $(14,33 \%)$, AM $(9,75 \%)$ e PG $(27,4 \%)$. Observa-se que o CV da PG é elevado; entretanto, esse valor situa-se na faixa observada em experimentos nos quais se adotaram parcelas do tamanho das que foram empregadas nesse trabalho (Rossmann, 2001).

Nas Tabelas 3, 4 e 5, são apresentadas as médias dos caracteres AC, AM e PG, respectivamente, avaliados nas 88 linhagens e nas três testemunhas: IAC-12, IAC Foscarin 31 e IAS-5. As médias de AC apresentadas na Tabela 3 estão em sua unidade original. Observam-se nessa Tabela, algumas notas menores que 1,0. Isso ocorreu porque nas safras 1995/96 e 1996/97, adotou- 
Tabela 2. Análises de variância conjuntas dos caracteres Acamamento (AC, notas de 1 a 5), Altura da Planta na Maturação ( $A M$, em cm) e Produção de Grãos (PG, em g/parcela), avaliados em 88 linhagens de soja, e mais três cultivares testemunhas (IAC-12, IAC Foscarin 31 e IAS-5), durante seis anos agrícolas*, no delineamento de blocos casualizados

\begin{tabular}{lrrrrrr}
\hline Fontes de Variação & \multicolumn{2}{c}{ AC (notas de 1 a 5) $)^{\text {al }}$} & \multicolumn{2}{c}{ AM (cm) } & \multicolumn{2}{c}{ PG (g/parcela) } \\
& G.L. & Q.M. & G.L. & Q.M. & G.L. & Q.M. \\
\hline Anos & 3 & $6,7599^{* *}$ & 5 & $57.689,0^{* *}$ & 5 & $1.924 .658,2^{* *}$ \\
Repetições/Anos & 15 & $0,2971^{* *}$ & 23 & $310,1^{* *}$ & 33 & $18.411,1^{* *}$ \\
Tratamentos & 90 & $1,0057^{* *}$ & 90 & $7.675,5^{* *}$ & 90 & $127.418,0^{* *}$ \\
Anos x Tratamentos & 270 & $0,1309 * *$ & 450 & $265,6^{* *}$ & 450 & $18.647,8^{* *}$ \\
Erro & 1.564 & 0,0403 & 2.360 & 62,0 & 3.038 & $4.208,7$ \\
Média geral & \multicolumn{2}{c}{1,40} & & 80,8 & & 237,2 \\
CV (\%) & \multicolumn{2}{c}{14,33} & & 9,75 & 27,4
\end{tabular}

al: transformado por meio da função $\sqrt{\mathrm{x}+0,5}$;

*: Exceto AC, avaliado em quatro anos. 
Tabela 3. Médias do caráter acamamento ( $A C$, notas de 1 a 5 ), para as 88 linhagens de soja e testemunhas

\begin{tabular}{|c|c|c|c|}
\hline Linhagens & Médias & Linhagens & Médias \\
\hline 1 & 1,792 & 45 & 1,313 \\
\hline 2 & 3,421 & 46 & 2,042 \\
\hline 3 & 0,875 & 47 & 1,438 \\
\hline 4 & 1,125 & 48 & 3,542 \\
\hline 5 & 1,125 & 49 & 1,458 \\
\hline 6 & 1,458 & 50 & 1,083 \\
\hline 7 & 1,083 & 51 & 1,604 \\
\hline 8 & 3,417 & 52 & 1,229 \\
\hline 9 & 1,229 & 53 & 0,979 \\
\hline 10 & 1,729 & 54 & 2,271 \\
\hline 11 & 1,333 & 55 & 1,521 \\
\hline 12 & 1,229 & 56 & 2,854 \\
\hline 13 & 3,813 & 57 & 1,208 \\
\hline 14 & 4,292 & 58 & 3,792 \\
\hline 15 & 0,979 & 59 & 1,375 \\
\hline 16 & 1,750 & 60 & 0,875 \\
\hline 17 & 1,333 & 61 & 1,021 \\
\hline 18 & 1,146 & 62 & 1,083 \\
\hline 19 & 1,333 & 63 & 1,188 \\
\hline 20 & 1,092 & 64 & 1,729 \\
\hline 21 & 1,530 & 65 & 0,875 \\
\hline 22 & 1,113 & 66 & 3,729 \\
\hline 23 & 1,667 & 67 & 1,458 \\
\hline 24 & 1,208 & 68 & 1,854 \\
\hline 25 & 1,125 & 69 & 1,958 \\
\hline 26 & 1,208 & 70 & 1,042 \\
\hline 27 & 1,188 & 71 & 1,188 \\
\hline 28 & 1,045 & 72 & 2,104 \\
\hline 29 & 1,467 & 73 & 1,292 \\
\hline 30 & 1,521 & 74 & 1,750 \\
\hline 31 & 1,271 & 75 & 1,146 \\
\hline 32 & 3,988 & 76 & 1,208 \\
\hline 33 & 1,458 & 77 & 1,125 \\
\hline 34 & 1,167 & 78 & 1,792 \\
\hline 35 & 1,729 & 79 & 1,646 \\
\hline 36 & 3,958 & 80 & 1,375 \\
\hline 37 & 2,250 & 81 & 1,880 \\
\hline 38 & 1,813 & 82 & 1,854 \\
\hline 39 & 1,875 & 83 & 1,396 \\
\hline 40 & 1,155 & 84 & 1,521 \\
\hline 41 & 0,979 & 85 & 1,938 \\
\hline 42 & 1,271 & 86 & 1,104 \\
\hline 43 & 1,146 & 87 & 1,271 \\
\hline 44 & 1,646 & 88 & 1,021 \\
\hline
\end{tabular}

Testemunhas: IAC-12:1,379; IAC-Foscarin-31:1,922; IAS-5:1,099 
Tabela 4. Médias do caráter Altura da Planta na Maturação ( $A M$, em cm/pl.), para as 88 linhagens de soja e testemunhas

\begin{tabular}{|c|c|c|c|}
\hline Linhagens & Médias & Linhagens & Médias \\
\hline 1 & 84,2 & 45 & 60,3 \\
\hline 2 & 105,9 & 46 & 87,1 \\
\hline 3 & 72,1 & 47 & 69,5 \\
\hline 4 & 79,3 & 48 & 93,3 \\
\hline 5 & 74,2 & 49 & 84,3 \\
\hline 6 & 72,2 & 50 & 66,3 \\
\hline 7 & 67,1 & 51 & 68,5 \\
\hline 8 & 97,6 & 52 & 77,6 \\
\hline 9 & 71,6 & 53 & 74,5 \\
\hline 10 & 69,4 & 54 & 95,9 \\
\hline 11 & 70,7 & 55 & 82,6 \\
\hline 12 & 72,4 & 56 & 94,7 \\
\hline 13 & 84,0 & 57 & 70,3 \\
\hline 14 & 103,5 & 58 & 94,2 \\
\hline 15 & 77,3 & 59 & 83,3 \\
\hline 16 & 79,4 & 60 & 63,2 \\
\hline 17 & 70,9 & 61 & 60,1 \\
\hline 18 & 69,9 & 62 & 65,2 \\
\hline 19 & 70,0 & 63 & 70,0 \\
\hline 20 & 89,9 & 64 & 120,0 \\
\hline 21 & 94,1 & 65 & 63,8 \\
\hline 22 & 79,7 & 66 & 112,4 \\
\hline 23 & 70,7 & 67 & 108,8 \\
\hline 24 & 81,2 & 68 & 75,0 \\
\hline 25 & 63,0 & 69 & 77,9 \\
\hline 26 & 80,4 & 70 & 65,5 \\
\hline 27 & 68,2 & 71 & 70,0 \\
\hline 28 & 72,8 & 72 & 84,3 \\
\hline 29 & 68,8 & 73 & 72,4 \\
\hline 30 & 111,2 & 74 & 112,0 \\
\hline 31 & 117,7 & 75 & 68,9 \\
\hline 32 & 89,2 & 76 & 65,7 \\
\hline 33 & 72,3 & 77 & 75,9 \\
\hline 34 & 78,5 & 78 & 70,5 \\
\hline 35 & 71,4 & 79 & 69,7 \\
\hline 36 & 94,2 & 80 & 78,6 \\
\hline 37 & 120,0 & 81 & 71,0 \\
\hline 38 & 72,3 & 82 & 116,4 \\
\hline 39 & 80,9 & 83 & 74,8 \\
\hline 40 & 68,3 & 84 & 75,0 \\
\hline 41 & 66,7 & 85 & 76,8 \\
\hline 42 & 78,9 & 86 & 71,8 \\
\hline 43 & 76,0 & 87 & 70,4 \\
\hline 44 & 120,1 & 88 & 64,1 \\
\hline
\end{tabular}

Testemunhas: $\quad$ IAC-12: 77,7; IAC-Foscarin-31: 112,3; IAS-5: 65,1 
Tabela 5. Médias do caráter Produção de Grãos (PG, em g/parcela), das 88 linhagens de soja e testemunhas

\begin{tabular}{|c|c|c|c|}
\hline Linhagens & Médias & Linhagens & Médias \\
\hline 1 & 236,6 & 45 & 220,0 \\
\hline 2 & 226,9 & 46 & 283,9 \\
\hline 3 & 244,1 & 47 & 275,6 \\
\hline 4 & 287,9 & 48 & 161,3 \\
\hline 5 & 291,4 & 49 & 186,6 \\
\hline 6 & 253,0 & 50 & 240,7 \\
\hline 7 & 246,6 & 51 & 244,8 \\
\hline 8 & 194,7 & 52 & 275,4 \\
\hline 9 & 292,7 & 53 & 297,1 \\
\hline 10 & 246,9 & 54 & 272,4 \\
\hline 11 & 230,0 & 55 & 320,3 \\
\hline 12 & 313,4 & 56 & 333,4 \\
\hline 13 & 139,7 & 57 & 186,0 \\
\hline 14 & 189,9 & 58 & 126,3 \\
\hline 15 & 277,6 & 59 & 310,1 \\
\hline 16 & 182,8 & 60 & 185,8 \\
\hline 17 & 197,7 & 61 & 223,9 \\
\hline 18 & 298,3 & 62 & 153,1 \\
\hline 19 & 204,9 & 63 & 149,7 \\
\hline 20 & 380,1 & 64 & 336,0 \\
\hline 21 & 328,6 & 65 & 154,5 \\
\hline 22 & 281,5 & 66 & 246,5 \\
\hline 23 & 243,8 & 67 & 316,9 \\
\hline 24 & 272,4 & 68 & 231,7 \\
\hline 25 & 208,9 & 69 & 222,8 \\
\hline 26 & 294,3 & 70 & 148,1 \\
\hline 27 & 222,3 & 71 & 202,5 \\
\hline 28 & 208,3 & 72 & 221,0 \\
\hline 29 & 226,3 & 73 & 159,3 \\
\hline 30 & 318,4 & 74 & 335,4 \\
\hline 31 & 314,9 & 75 & 173,4 \\
\hline 32 & 155,2 & 76 & 250,8 \\
\hline 33 & 266,5 & 77 & 206,2 \\
\hline 34 & 276,4 & 78 & 205,5 \\
\hline 35 & 176,4 & 79 & 156,2 \\
\hline 36 & 126,0 & 80 & 229,0 \\
\hline 37 & 334,6 & 81 & 198,4 \\
\hline 38 & 236,4 & 82 & 319,9 \\
\hline 39 & 175,1 & 83 & 257,5 \\
\hline 40 & 250,3 & 84 & 156,3 \\
\hline 41 & 154,9 & 85 & 200,6 \\
\hline 42 & 292,8 & 86 & 239,1 \\
\hline 43 & 170,5 & 87 & 240,7 \\
\hline 44 & 308,3 & 88 & 144,7 \\
\hline
\end{tabular}

Testemunhas: $\quad$ IAC-12: 307,8; IAC-Foscarin-31: 356,1; IAS-5: 260,3 
se, devido a um engano, uma escala de notas de 0 a 5 , e não de 1 a 5 , conforme adotou-se nos demais anos agrícolas.

As médias de AC variaram de 0,87 a 4,29 (Tabela 3), o que evidencia que há na população, desde linhagens que quase não acamam, até as altamente susceptíveis ao acamamento. As médias das testemunhas foram as seguintes: IAC-12: 1,38, IAC Foscarin 31: 1,92, e IAS-5: 1,10. Observa-se que as médias das três testemunhas são baixas, sendo as médias das testemunhas IAC-12 e IAS-5 menores que a média do experimento, que foi de 1,42.

Na Tabela 4 observa-se que as médias de AM variaram de 60,1 a 120,1 $\mathrm{cm}$, situando-se, portanto, no intervalo comum às cultivares brasileiras de soja, isto é, entre 60 e $120 \mathrm{~cm}$ (Borém et al., 1999). Constata-se um número maior de linhagens cujas médias são mais próximas do menor valor, o que é um fato positivo, uma vez que há uma tendência de plantas mais altas acamarem mais. As médias das testemunhas IAC-12, IAC Foscarin 31 e IAS-5 foram de 77,7 cm, $112,3 \mathrm{~cm}$, e $65,1 \mathrm{~cm}$, respectivamente.

A variação das médias de PG (Tabela 5) foi de 126,0 a 380,1 g/parcela, enquanto as médias das testemunhas foram as seguintes: IAC-12: (307,8 g/parcela), IAC Foscarin 31: (356,1 g/parcela), e IAS-5: (260,3 g/parcela). Um pouco mais da metade das linhagens (45) têm médias de PG superiores à média geral $(236,1 \mathrm{~g} /$ parcela $)$.

$\mathrm{Na}$ Tabela 6, são apresentadas as médias do caráter número de dias para a maturação (DM), que refere-se ao número de dias transcorridos da semeadura à maturação de aproximadamente $95 \%$ das vagens, e ao lado das médias de DM, as médias correspondentes de PG. Observa-se que as médias de DM variaram de 123 dias (linhagem 47) a 143 dias (linhagem 56).

A classificação das linhagens quanto ao ciclo, adotada nesse trabalho é a apresentada pela Embrapa (2002), segundo a qual, na região Sudeste, as cultivares de soja são classificadas da seguinte maneira, quanto a esse caráter: precoces (ciclo de até 120 dias), semi-precoces (121 a 130 dias), de ciclo médio 
Tabela 6. Médias do caráter dias para a maturação (DM), em ordem crescente, e acompanhadas das médias da produção de grãos (PG)

\begin{tabular}{|c|c|c|c|c|c|}
\hline Linhagens & $\mathrm{DM}^{*}$ & $P G$ & Linhagens & DM & $P G$ \\
\hline 47 & $123^{\mathrm{SP}}$ & 275,55 & 64 & $137^{\mathrm{CM}}$ & 336,02 \\
\hline 85 & $125^{\mathrm{SP}}$ & 200,62 & 10 & $137^{\mathrm{CM}}$ & 246,86 \\
\hline 45 & $125^{\mathrm{SP}}$ & 219,98 & 22 & $137^{\mathrm{CM}}$ & 281,51 \\
\hline 84 & $126^{S P}$ & 156,26 & 28 & $138^{\mathrm{CM}}$ & 208,25 \\
\hline 88 & $126^{\mathrm{SP}}$ & 144,72 & 48 & $138^{\mathrm{CM}}$ & 161,34 \\
\hline 17 & $127^{\mathrm{SP}}$ & 197,74 & 6 & $138^{\mathrm{CM}}$ & 252,99 \\
\hline 79 & $127^{\mathrm{SP}}$ & 156,22 & 53 & $138^{\mathrm{CM}}$ & 297,15 \\
\hline 65 & $128^{S P}$ & 154,52 & 74 & $138^{\mathrm{CM}}$ & 335,36 \\
\hline 41 & $128^{S P}$ & 154,86 & 58 & $139^{\mathrm{CM}}$ & 126,31 \\
\hline 81 & $128^{S P}$ & 198,44 & 83 & $139^{\mathrm{CM}}$ & 257,53 \\
\hline 62 & $128^{S P}$ & 153,06 & 30 & $139^{\mathrm{CM}}$ & 318,36 \\
\hline 73 & $129^{S P}$ & 159,30 & 14 & $139^{\mathrm{CM}}$ & 189,86 \\
\hline 60 & $129^{\mathrm{SP}}$ & 185,77 & 86 & $139^{\mathrm{CM}}$ & 239,09 \\
\hline 11 & $129^{S P}$ & 229,98 & 13 & $139^{\mathrm{CM}}$ & 243,76 \\
\hline 70 & $129^{S P}$ & 148,13 & 23 & $139^{\mathrm{CM}}$ & 139,72 \\
\hline 29 & $130^{S P}$ & 226,30 & 32 & $139^{\mathrm{CM}}$ & 155,16 \\
\hline 39 & $130^{\mathrm{SP}}$ & 175,09 & 44 & $139^{\mathrm{CM}}$ & 308,25 \\
\hline 19 & $131^{\mathrm{CM}}$ & 204,91 & 12 & $139^{\mathrm{CM}}$ & 313,44 \\
\hline 78 & $131^{\mathrm{CM}}$ & 205,50 & 36 & $139^{\mathrm{CM}}$ & 126,00 \\
\hline 61 & $132^{\mathrm{CM}}$ & 223,86 & 18 & $139^{\mathrm{CM}}$ & 298,27 \\
\hline 35 & $133^{\mathrm{CM}}$ & 176,39 & 59 & $139^{\mathrm{CM}}$ & 310,11 \\
\hline 50 & $133^{\mathrm{CM}}$ & 240,70 & 37 & $139^{\mathrm{CM}}$ & 334,58 \\
\hline 63 & $134^{\mathrm{CM}}$ & 149,66 & 38 & $139^{\mathrm{CM}}$ & 236,38 \\
\hline 76 & $134^{\mathrm{CM}}$ & 250,85 & 5 & $139^{\mathrm{CM}}$ & 291,45 \\
\hline 77 & $134^{\mathrm{CM}}$ & 206,17 & 8 & $139^{\mathrm{CM}}$ & 292,76 \\
\hline 25 & $134^{\mathrm{CM}}$ & 208,94 & 42 & $139^{\mathrm{CM}}$ & 275,44 \\
\hline 71 & $134^{\mathrm{CM}}$ & 202,46 & 52 & $139^{\mathrm{CM}}$ & 194,65 \\
\hline 16 & $135^{\mathrm{CM}}$ & 182,81 & 87 & $139^{\mathrm{CM}}$ & 240,71 \\
\hline 68 & $135^{\mathrm{CM}}$ & 231,67 & 21 & $140^{\mathrm{CM}}$ & 328,57 \\
\hline 57 & $135^{\mathrm{CM}}$ & 185,97 & 55 & $140^{\mathrm{CM}}$ & 320,29 \\
\hline 43 & $135^{\mathrm{CM}}$ & 170,47 & 34 & $140^{\mathrm{CM}}$ & 276,44 \\
\hline 72 & $135^{\mathrm{CM}}$ & 220,95 & 9 & $140^{\mathrm{CM}}$ & 292,72 \\
\hline 54 & $136^{\mathrm{CM}}$ & 272,41 & 46 & $140^{\mathrm{CM}}$ & 283,90 \\
\hline 75 & $136^{\mathrm{CM}}$ & 173,40 & 4 & $140^{\mathrm{CM}}$ & 287,87 \\
\hline 1 & $136^{\mathrm{CM}}$ & 236,64 & 33 & $140^{\mathrm{CM}}$ & 266,49 \\
\hline 40 & $136^{\mathrm{CM}}$ & 250,33 & 2 & $140^{\mathrm{CM}}$ & 226,94 \\
\hline 80 & $136^{\mathrm{CM}}$ & 228,95 & 82 & $140^{\mathrm{CM}}$ & 319,92 \\
\hline 51 & $137^{\mathrm{CM}}$ & 244,81 & 31 & $140^{\mathrm{CM}}$ & 314,91 \\
\hline 49 & $137^{\mathrm{CM}}$ & 186,60 & 66 & $140^{\mathrm{CM}}$ & 246,47 \\
\hline 69 & $137^{\mathrm{CM}}$ & 222,76 & 24 & $140^{\mathrm{CM}}$ & 272,39 \\
\hline 7 & $137^{\mathrm{CM}}$ & 246,58 & 26 & $141^{\mathrm{ST}}$ & 294,28 \\
\hline 67 & $137^{\mathrm{CM}}$ & 316,89 & 15 & $141^{\mathrm{ST}}$ & 277,57 \\
\hline 3 & $137^{\mathrm{CM}}$ & 244,09 & 20 & $141^{\mathrm{ST}}$ & 380,14 \\
\hline 27 & $137^{\mathrm{CM}}$ & 222,34 & 56 & $143^{\mathrm{ST}}$ & 333,35 \\
\hline
\end{tabular}

Testemunhas: IAC 12: 131,61, IAC Foscarin 31: 127,43, IAS 5: 122,27

*: SP: semi-precoce, CM: ciclo médio, ST: semi-tardia 
(131 a 140 dias), semi-tardias (141 a 150 dias) e tardias (ciclo acima de 150 dias). Observa-se que das 88 linhagens, 17 são semi-precoces (SP), 57 são de ciclo médio (CM), e quatro são semi-tardias (ST). A linhagem 20, a mais produtiva, é semi-tardia (141 dias), e, de um modo geral, observa-se que há uma tendência de as linhagens mais produtivas terem ciclo maior, isto é, maior valor de DM. Em razão dessa correlação genética positiva e indesejável, uma vez que normalmente, o interesse é por cultivares precoces, o caráter DM não foi empregado no cálculo dos índices.

Nas Tabelas 7 e 8, têm-se, respectivamente, as estimativas do parâmetro de adaptabilidade (b) e do coeficiente de determinação $\left(R^{2}\right)$, do método de Eberhart \& Russell (1966). As estimativas de b (Tabela 7) variaram de -0,21 (linhagem 36) a 2,02 (linhagem 74), mostrando a existência de linhagens adaptadas aos ambientes mais favoráveis $(b>1)$, aos ambientes mais desfavoráveis (b próximo de zero), e de adaptação ampla (b próximo de 1), conforme o conceito de adaptabilidade de Eberhart \& Russell (1966). As testemunhas IAC-12, IAC Foscarin 31 e IAS-5 apresentaram estimativas de 1,10, 0,90 e 1,32, respectivamente, para esse parâmetro, isto é, próximos a 1,0.

$\mathrm{Na}$ Tabela 8 observa-se que a menor estimativa de $R^{2}$ foi $0,10 \%$ (linhagem 58, de baixíssima estabilidade), e a maior, 97,27\% (linhagem 80, altamente estável, ou previsível), enquanto as testemunhas apresentaram as estimativas de 84,40 \% (IAC-12), 48,99\% (IAC Foscarin 31), e 80,03\% (IAS-5).

$\mathrm{Na}$ Tabela 9 estão as médias do caráter $\mathrm{AC}$, transformadas para $\sqrt{x+0,5}$, em ordem crescente, e acompanhadas dos números de grupos correspondentes. Os números de grupos, em sobrescrito ao lado das médias, são provenientes do teste de Scott-Knott. Observa-se que o referido teste classificou as médias desse caráter em seis grupos.

Os $Z_{\mathrm{ij}, \mathrm{s}}$ e $\mathrm{Y}_{\mathrm{i}, \mathrm{s}}$ das linhagens dos grupos 3 a 6 , mostrados, respectivamente, na quarta e sexta colunas da Tabela 9, são negativos, indicando que pelo critério adotado, essas linhagens não são selecionáveis, 
Tabela 7. Estimativas dos parâmetros de adaptabilidade (b) de Eberhart \& Russell (1966), para as 88 linhagens de soja e testemunhas, da produção de grãos (PG)

\begin{tabular}{|c|c|c|c|}
\hline Linhagens & Médias & Linhagens & Médias \\
\hline 1 & 0,697 & 45 & 1,120 \\
\hline 2 & 0,375 & 46 & 0,600 \\
\hline 3 & 1,569 & 47 & 0,463 \\
\hline 4 & 1,561 & 48 & 1,106 \\
\hline 5 & 1,396 & 49 & 1,229 \\
\hline 6 & $-0,109$ & 50 & 1,889 \\
\hline 7 & 1,383 & 51 & 1,704 \\
\hline 8 & $-0,179$ & 52 & 0,696 \\
\hline 9 & 1,912 & 53 & 1,046 \\
\hline 10 & 1,144 & 54 & 0,405 \\
\hline 11 & 1,753 & 55 & 0,869 \\
\hline 12 & 0,732 & 56 & $-0,047$ \\
\hline 13 & 0,547 & 57 & 0,913 \\
\hline 14 & $-0,044$ & 58 & 0,020 \\
\hline 15 & 1,176 & 59 & 1,154 \\
\hline 16 & 0,854 & 60 & 1,405 \\
\hline 17 & 1,059 & 61 & 1,378 \\
\hline 18 & 0,690 & 62 & 0,893 \\
\hline 19 & 0,653 & 63 & 1,177 \\
\hline 20 & 0,654 & 64 & 1,485 \\
\hline 21 & 1,180 & 65 & 1,272 \\
\hline 22 & 1,709 & 66 & 0,343 \\
\hline 23 & 0,652 & 67 & 1,749 \\
\hline 24 & 0,631 & 68 & 0,492 \\
\hline 25 & 0,838 & 69 & 1,466 \\
\hline 26 & 0,790 & 70 & 0,997 \\
\hline 27 & 1,443 & 71 & 1,002 \\
\hline 28 & 1,347 & 72 & 1,102 \\
\hline 29 & 1,116 & 73 & 1,615 \\
\hline 30 & 1,540 & 74 & 2,020 \\
\hline 31 & 0,396 & 75 & 1,622 \\
\hline 32 & 0,085 & 76 & 1,650 \\
\hline 33 & 0,355 & 77 & 0,923 \\
\hline 34 & 1,081 & 78 & 1,310 \\
\hline 35 & 0,869 & 79 & 1,166 \\
\hline 36 & $-0,215$ & 80 & 1,424 \\
\hline 37 & 1,772 & 81 & 0,785 \\
\hline 38 & 0,679 & 82 & 1,320 \\
\hline 39 & 0,610 & 83 & 0,539 \\
\hline 40 & 1,620 & 84 & 0,364 \\
\hline 41 & 1,046 & 85 & 1,163 \\
\hline 42 & 0,806 & 86 & 1,070 \\
\hline 43 & 0,699 & 87 & 1,549 \\
\hline 44 & 1,160 & 88 & 1,201 \\
\hline
\end{tabular}

Testemunhas:

IAC-12: 1,102; IAC Foscarin 31: 0,905; $\quad$ IAS-5: 1,315 
Tabela 8. Estimativas do coeficiente de determinação $\left(R^{2} \%\right)$ de Eberhart \& Russell (1966), para as 88 linhagens de soja e testemunhas, da produção de grãos (PG)

\begin{tabular}{|c|c|c|c|}
\hline Linhagens & Médias & Linhagens & Médias \\
\hline 1 & 80,093 & 45 & 68,572 \\
\hline 2 & 17,112 & 46 & 28,384 \\
\hline 3 & 75,607 & 47 & 20,801 \\
\hline 4 & 85,029 & 48 & 76,884 \\
\hline 5 & 63,935 & 49 & 92,705 \\
\hline 6 & 0,935 & 50 & 90,505 \\
\hline 7 & 87,451 & 51 & 86,545 \\
\hline 8 & 4,699 & 52 & 70,041 \\
\hline 9 & 91,569 & 53 & 76,039 \\
\hline 10 & 73,215 & 54 & 26,909 \\
\hline 11 & 82,470 & 55 & 37,861 \\
\hline 12 & 47,834 & 56 & 0,118 \\
\hline 13 & 32,922 & 57 & 38,148 \\
\hline 14 & 0,206 & 58 & 0,104 \\
\hline 15 & 80,911 & 59 & 63,586 \\
\hline 16 & 56,261 & 60 & 80,077 \\
\hline 17 & 56,938 & 61 & 52,812 \\
\hline 18 & 42,031 & 62 & 53,790 \\
\hline 19 & 38,471 & 63 & 90,777 \\
\hline 20 & 18,410 & 64 & 42,636 \\
\hline 21 & 44,172 & 65 & 66,255 \\
\hline 22 & 68,955 & 66 & 10,008 \\
\hline 23 & 44,645 & 67 & 68,684 \\
\hline 24 & 81,675 & 68 & 26,140 \\
\hline 25 & 50,544 & 69 & 82,604 \\
\hline 26 & 64,783 & 70 & 64,505 \\
\hline 27 & 93,195 & 71 & 55,448 \\
\hline 28 & 85,610 & 72 & 87,226 \\
\hline 29 & 70,869 & 73 & 93,118 \\
\hline 30 & 57,337 & 74 & 66,904 \\
\hline 31 & 36,917 & 75 & 74,108 \\
\hline 32 & 0,887 & 76 & 89,549 \\
\hline 33 & 9,579 & 77 & 59,145 \\
\hline 34 & 48,212 & 78 & 51,061 \\
\hline 35 & 65,985 & 79 & 84,471 \\
\hline 36 & 6,102 & 80 & 97,275 \\
\hline 37 & 71,523 & 81 & 45,024 \\
\hline 38 & 55,821 & 82 & 63,378 \\
\hline 39 & 53,297 & 83 & 42,556 \\
\hline 40 & 86,747 & 84 & 31,494 \\
\hline 41 & 57,619 & 85 & 72,748 \\
\hline 42 & 88,031 & 86 & 61,039 \\
\hline 43 & 66,799 & 87 & 94,745 \\
\hline 44 & 37,780 & 88 & 71,448 \\
\hline
\end{tabular}

Testemunhas:

IAC-12: 84,399; IAC-Foscarin-31: 48,999; IAS-5: 80,033 
Tabela 9. Médias individuais, de grupos, médias transformadas $\left(Z_{i, s}\right.$ e $\left.Y_{i j, s}\right)$ e respectivos desvios, do acamamento (AC), para a estimação das Distâncias Euclidiana e de Mahalanobis

\begin{tabular}{|c|c|c|c|c|c|c|}
\hline \multirow[b]{2}{*}{ Linhagens } & \multicolumn{2}{|c|}{ Médias } & \multicolumn{2}{|c|}{ Dist. Eucliana } & \multicolumn{2}{|c|}{ Dist. Mahalanobis } \\
\hline & Individuais & Grupos $^{(1)}$ & $Z_{i j}$ & Desvios & $Y_{i j}$ & Desvios \\
\hline 65 & $1,16^{1}$ & 0,793 & 0,794 & $-2,083$ & 0,0788 & $-0,2069$ \\
\hline 60 & $1,16^{1}$ & 0,793 & 0,794 & $-2,083$ & 0,0788 & $-0,2069$ \\
\hline 3 & $1,16^{1}$ & 0,793 & 0,794 & $-2,083$ & 0,0788 & $-0,2069$ \\
\hline 41 & $1,18^{1}$ & 0,793 & 0,794 & $-2,083$ & 0,0788 & $-0,2069$ \\
\hline 53 & $1,21^{1}$ & 0,793 & 0,794 & $-2,083$ & 0,0788 & $-0,2069$ \\
\hline 15 & $1,21^{1}$ & 0,793 & 0,794 & $-2,083$ & 0,0788 & $-0,2069$ \\
\hline 70 & $1,22^{1}$ & 0,793 & 0,794 & $-2,083$ & 0,0788 & $-0,2069$ \\
\hline 88 & $1,22^{1}$ & 0,793 & 0,794 & $-2,083$ & 0,0788 & $-0,2069$ \\
\hline 61 & $1,22^{1}$ & 0,793 & 0,794 & $-2,083$ & 0,0788 & $-0,2069$ \\
\hline 28 & $1,22^{1}$ & 0,793 & 0,794 & $-2,083$ & 0,0788 & $-0,2069$ \\
\hline 62 & $1,23^{1}$ & 0,793 & 0,794 & $-2,083$ & 0,0788 & $-0,2069$ \\
\hline 50 & $1,23^{1}$ & 0,793 & 0,794 & $-2,083$ & 0,0788 & $-0,2069$ \\
\hline 7 & $1,23^{1}$ & 0,793 & 0,794 & $-2,083$ & 0,0788 & $-0,2069$ \\
\hline 22 & $1,25^{1}$ & 0,793 & 0,794 & $-2,083$ & 0,0788 & $-0,2069$ \\
\hline 20 & $1,25^{1}$ & 0,793 & 0,794 & $-2,083$ & 0,0788 & $-0,2069$ \\
\hline 25 & $1,25^{1}$ & 0,793 & 0,794 & $-2,083$ & 0,0788 & $-0,2069$ \\
\hline 5 & $1,25^{1}$ & 0,793 & 0,794 & $-2,083$ & 0,0788 & $-0,2069$ \\
\hline 4 & $1,25^{1}$ & 0,793 & 0,794 & $-2,083$ & 0,0788 & $-0,2069$ \\
\hline 40 & $1,25^{1}$ & 0,793 & 0,794 & $-2,083$ & 0,0788 & $-0,2069$ \\
\hline 86 & $1,25^{1}$ & 0,793 & 0,794 & $-2,083$ & 0,0788 & $-0,2069$ \\
\hline 77 & $1,26^{1}$ & 0,793 & 0,794 & $-2,083$ & 0,0788 & $-0,2069$ \\
\hline 75 & $1,26^{1}$ & 0,793 & 0,794 & $-2,083$ & 0,0788 & $-0,2069$ \\
\hline 27 & $1,27^{1}$ & 0,793 & 0,794 & $-2,083$ & 0,0788 & $-0,2069$ \\
\hline 43 & $1,27^{1}$ & 0,793 & 0,794 & $-2,083$ & 0,0788 & $-0,2069$ \\
\hline 18 & $1,27^{1}$ & 0,793 & 0,794 & $-2,083$ & 0,0788 & $-0,2069$ \\
\hline 73 & $1,27^{1}$ & 0,793 & 0,794 & $-2,083$ & 0,0788 & $-0,2069$ \\
\hline 63 & $1,27^{1}$ & 0,793 & 0,794 & $-2,083$ & 0,0788 & $-0,2069$ \\
\hline 76 & $1,27^{1}$ & 0,793 & 0,794 & $-2,083$ & 0,0788 & $-0,2069$ \\
\hline 57 & $1,27^{1}$ & 0,793 & 0,794 & $-2,083$ & 0,0788 & $-0,2069$ \\
\hline 71 & $1,28^{1}$ & 0,793 & 0,794 & $-2,083$ & 0,0788 & $-0,2069$ \\
\hline 34 & $1,28^{1}$ & 0,793 & 0,794 & $-2,083$ & 0,0788 & $-0,2069$ \\
\hline 24 & $1,29^{1}$ & 0,793 & 0,794 & $-2,083$ & 0,0788 & $-0,2069$ \\
\hline 52 & $1,29^{1}$ & 0,793 & 0,794 & $-2,083$ & 0,0788 & $-0,2069$ \\
\hline 9 & $1,29^{1}$ & 0,793 & 0,794 & $-2,083$ & 0,0788 & $-0,2069$ \\
\hline 12 & $1,30^{1}$ & 0,793 & 0,794 & $-2,083$ & 0,0788 & $-0,2069$ \\
\hline 26 & $1,30^{1}$ & 0,793 & 0,794 & $-2,083$ & 0,0788 & $-0,2069$ \\
\hline 19 & $1,30^{1}$ & 0,793 & 0,794 & $-2,083$ & 0,0788 & $-0,2069$ \\
\hline 87 & $1,31^{1}$ & 0,793 & 0,794 & $-2,083$ & 0,0788 & $-0,2069$ \\
\hline 42 & $1,31^{1}$ & 0,793 & 0,794 & $-2,083$ & 0,0788 & $-0,2069$ \\
\hline 31 & $1,31^{1}$ & 0,793 & 0,794 & $-2,083$ & 0,0788 & $-0,2069$ \\
\hline 80 & $1,32^{1}$ & 0,793 & 0,794 & $-2,083$ & 0,0788 & $-0,2069$ \\
\hline 11 & $1,32^{1}$ & 0,793 & 0,794 & $-2,083$ & 0,0788 & $-0,2069$ \\
\hline 45 & $1,33^{1}$ & 0,793 & 0,794 & $-2,083$ & 0,0788 & $-0,2069$ \\
\hline 17 & $1,34^{1}$ & 0,793 & 0,794 & $-2,083$ & 0,0788 & $-0,2069$ \\
\hline
\end{tabular}


Tabela 9. Médias individuais, de grupos, médias transformadas $\left(Z_{\mathrm{i}, \mathrm{s}}\right.$ e $\left.Y_{\mathrm{i}, \mathrm{s}}\right)$ e respectivos desvios, do acamamento (AC), para a estimação das Distâncias Euclidiana e de Mahalanobis

\begin{tabular}{|c|c|c|c|c|c|c|}
\hline \multirow[b]{2}{*}{ Linhagens } & \multicolumn{2}{|c|}{ Médias } & \multicolumn{2}{|c|}{ Dist. Eucliana } & \multicolumn{2}{|c|}{ Dist. Mahalanobis } \\
\hline & Individuais & Grupos $^{(1)}$ & $Z_{i j}$ & Desvios & $Y_{i j}$ & Desvios \\
\hline 83 & $1,35^{1}$ & 0,793 & 0,794 & $-2,083$ & 0,0788 & $-0,2069$ \\
\hline 59 & $1,35^{1}$ & 0,793 & 0,794 & $-2,083$ & 0,0788 & $-0,2069$ \\
\hline 33 & $1,36^{2}$ & 0,714 & 0,000 & $-2,877$ & 0,0000 & $-0,2858$ \\
\hline 49 & $1,37^{2}$ & 0,714 & 0,000 & $-2,877$ & 0,0000 & $-0,2858$ \\
\hline 47 & $1,38^{2}$ & 0,714 & 0,000 & $-2,877$ & 0,0000 & $-0,2858$ \\
\hline 6 & $1,38^{2}$ & 0,714 & 0,000 & $-2,877$ & 0,0000 & $-0,2858$ \\
\hline 29 & $1,39^{2}$ & 0,714 & 0,000 & $-2,877$ & 0,0000 & $-0,2858$ \\
\hline 67 & $1,39^{2}$ & 0,714 & 0,000 & $-2,877$ & 0,0000 & $-0,2858$ \\
\hline 55 & $1,40^{2}$ & 0,714 & 0,000 & $-2,877$ & 0,0000 & $-0,2858$ \\
\hline 84 & $1,40^{2}$ & 0,714 & 0,000 & $-2,877$ & 0,0000 & $-0,2858$ \\
\hline 30 & $1,40^{2}$ & 0,714 & 0,000 & $-2,877$ & 0,0000 & $-0,2858$ \\
\hline 51 & $1,41^{2}$ & 0,714 & 0,000 & $-2,877$ & 0,0000 & $-0,2858$ \\
\hline 21 & $1,41^{2}$ & 0,714 & 0,000 & $-2,877$ & 0,0000 & $-0,2858$ \\
\hline 23 & $1,42^{2}$ & 0,714 & 0,000 & $-2,877$ & 0,0000 & $-0,2858$ \\
\hline 44 & $1,42^{2}$ & 0,714 & 0,000 & $-2,877$ & 0,0000 & $-0,2858$ \\
\hline 79 & $1,43^{2}$ & 0,714 & 0,000 & $-2,877$ & 0,0000 & $-0,2858$ \\
\hline 35 & $1,45^{2}$ & 0,714 & 0,000 & $-2,877$ & 0,0000 & $-0,2858$ \\
\hline 16 & $1,46^{3}$ & 0,662 & $-0,530$ & $-3,407$ & $-0,0526$ & $-0,3384$ \\
\hline 74 & $1,47^{3}$ & 0,662 & $-0,530$ & $-3,407$ & $-0,0526$ & $-0,3384$ \\
\hline 10 & $1,47^{3}$ & 0,662 & $-0,530$ & $-3,407$ & $-0,0526$ & $-0,3384$ \\
\hline 64 & $1,47^{3}$ & 0,662 & $-0,530$ & $-3,407$ & $-0,0526$ & $-0,3384$ \\
\hline 78 & $1,47^{3}$ & 0,662 & $-0,530$ & $-3,407$ & $-0,0526$ & $-0,3384$ \\
\hline 38 & $1,47^{3}$ & 0,662 & $-0,530$ & $-3,407$ & $-0,0526$ & $-0,3384$ \\
\hline 1 & $1,49^{3}$ & 0,662 & $-0,530$ & $-3,407$ & $-0,0526$ & $-0,3384$ \\
\hline 39 & $1,49^{3}$ & 0,662 & $-0,530$ & $-3,407$ & $-0,0526$ & $-0,3384$ \\
\hline 68 & $1,50^{3}$ & 0,662 & $-0,530$ & $-3,407$ & $-0,0526$ & $-0,3384$ \\
\hline 81 & $1,50^{3}$ & 0,662 & $-0,530$ & $-3,407$ & $-0,0526$ & $-0,3384$ \\
\hline 82 & $1,50^{3}$ & 0,662 & $-0,530$ & $-3,407$ & $-0,0526$ & $-0,3384$ \\
\hline 69 & $1,53^{3}$ & 0,662 & $-0,530$ & $-3,407$ & $-0,0526$ & $-0,3384$ \\
\hline 85 & $1,53^{3}$ & 0,662 & $-0,530$ & $-3,407$ & $-0,0526$ & $-0,3384$ \\
\hline 46 & $1,54^{3}$ & 0,662 & $-0,530$ & $-3,407$ & $-0,0526$ & $-0,3384$ \\
\hline 72 & $1,58^{3}$ & 0,662 & $-0,530$ & $-3,407$ & $-0,0526$ & $-0,3384$ \\
\hline 37 & $1,62^{3}$ & 0,662 & $-0,530$ & $-3,407$ & $-0,0526$ & $-0,3384$ \\
\hline 54 & $1,63^{3}$ & 0,662 & $-0,530$ & $-3,407$ & $-0,0526$ & $-0,3384$ \\
\hline 56 & $1,78^{4}$ & 0,563 & $-1,520$ & $-4,397$ & $-0,1510$ & $-0,4368$ \\
\hline 8 & $1,95^{5}$ & 0,509 & $-2,062$ & $-4,938$ & $-0,2048$ & $-0,4906$ \\
\hline 2 & $1,96^{5}$ & 0,509 & $-2,062$ & $-4,938$ & $-0,2048$ & $-0,4906$ \\
\hline 48 & $1,98^{5}$ & 0,509 & $-2,062$ & $-4,938$ & $-0,2048$ & $-0,4906$ \\
\hline 66 & $2,03^{6}$ & 0,480 & $-2,355$ & $-5,232$ & $-0,2340$ & $-0,5198$ \\
\hline 13 & $2.05^{6}$ & 0,480 & $-2,355$ & $-5,232$ & $-0,2340$ & $-0,5198$ \\
\hline 58 & $2,06^{6}$ & 0,480 & $-2,355$ & $-5,232$ & $-0,2340$ & $-0,5198$ \\
\hline 36 & $2,09^{6}$ & 0,480 & $-2,355$ & $\begin{array}{l}-5,232 \\
\end{array}$ & $-0,2340$ & $-0,5198$ \\
\hline 32 & $2,09^{6}$ & 0,480 & $-2,355$ & $-5,232$ & $-0,2340$ & $-0,5198$ \\
\hline 14 & $2,18^{6}$ & 0,480 & $-2,355$ & $-5,232$ & $-0,2340$ & $-0,5198$ \\
\hline Ide & & & & & & \\
\hline
\end{tabular}

(1): obtidas com os recíprocos $\left(1 / X_{i j}\right)$ das médias individuais. 
visto que o interesse é por plantas de menor acamamento. Os desvios desse caráter para a estimação das Distâncias Euclidiana e Generalizada de Mahalanobis são apresentados, respectivamente, na quinta e sétima colunas da Tabela 9.

$\mathrm{Na}$ Tabela 10 são apresentadas as médias da altura da planta na maturação (AM). O teste de Scott-Knott classificou as médias desse caráter em 11 grupos, cuja numeração é apresentada em sobrescrito, à direita das médias individuais. As médias estandardizadas ( $Z_{\mathrm{i}, \mathrm{s}}$, na quarta coluna), e transformadas ( $Y_{\mathrm{ij}, \mathrm{s}}$, na sexta coluna) dos grupos 6 a 11 são negativas, o que mostra que as linhagens pertencentes a esses grupos não são selecionáveis, uma vez que o interesse é por plantas de menor porte.

Os dados referentes à produção de grãos (PG) são apresentados na Tabela 11. Apesar de esse ter sido o caráter para o qual adotou-se o maior nível de significância, na aplicação do teste de Scott-Knott, formaram-se apenas oito grupos, enquanto na altura da planta na maturação, formaram-se 11. Provavelmente, isso ocorreu em razão de AM ter sido medido com maior precisão que PG, e também, por apresentar maior variabilidade (Tabela 10). Os desvios desse caráter para a estimação das Distâncias Euclidiana e de Mahalanobis são mostrados, respectivamente, na quinta e sétima colunas dessa tabela.

Observa-se na segunda coluna da Tabela 11 que a numeração dos grupos, em sobrescrito à direita das médias, está em ordem decrescente, por ter sido invertida, de modo a fazer com que, do mesmo modo que em AC e AM, quanto maior o número do grupo, piores as médias. As médias não selecionáveis de $P G$ são as pertencentes aos grupos 6,7 e 8, cujos $Z_{i j, s}$ e $Y_{i j, s}$ estão em negrito.

Na Tabela 12 são apresentadas as estimativas do parâmetro de adaptabilidade (b). Como convencionou-se 0,70 como o valor de descarte para 
Tabela 10. Médias individuais, de grupos, médias transformadas $\left(Z_{i, s}\right.$ e $\left.Y_{i, s}\right)$ e respectivos desvios, da Altura da Planta na Maturação (AM), para a estimação das Distâncias Euclidiana e de Mahalanobis

\begin{tabular}{|c|c|c|c|c|c|c|}
\hline \multirow[b]{2}{*}{ Linhagens } & \multicolumn{2}{|c|}{ Médias } & \multicolumn{2}{|c|}{ Dist. Eucliana } & \multicolumn{2}{|c|}{ Dist. Mahalanobis } \\
\hline & Individuais & Grupos $^{(1)}$ & $\mathrm{Z}_{\mathrm{ij}}$ & Desvios & $Y_{i j}$ & Desvios \\
\hline 61 & $60,1^{1}$ & 0,01623 & 2,0186 & 1,0690 & 0,00421 & 0,00223 \\
\hline 45 & $60,3^{1}$ & 0,01623 & 2,0186 & 1,0690 & 0,00421 & 0,00223 \\
\hline 25 & $63,0^{1}$ & 0,01623 & 2,0186 & 1,0690 & 0,00421 & 0,00223 \\
\hline 60 & $63,2^{1}$ & 0,01623 & 2,0186 & 1,0690 & 0,00421 & 0,00223 \\
\hline 65 & $63,8^{2}$ & 0,01526 & 1,5531 & 0,6036 & 0,00324 & 0,00126 \\
\hline 88 & $64,1^{2}$ & 0,01526 & 1,5531 & 0,6036 & 0,00324 & 0,00126 \\
\hline 62 & $65,2^{2}$ & 0,01526 & 1,5531 & 0,6036 & 0,00324 & 0,00126 \\
\hline 70 & $65,5^{2}$ & 0,01526 & 1,5531 & 0,6036 & 0,00324 & 0,00126 \\
\hline 76 & $65,7^{2}$ & 0,01526 & 1,5531 & 0,6036 & 0,00324 & 0,00126 \\
\hline 50 & $66,3^{2}$ & 0,01526 & 1,5531 & 0,6036 & 0,00324 & 0,00126 \\
\hline 41 & $66,7^{2}$ & 0,01526 & 1,5531 & 0,6036 & 0,00324 & 0,00126 \\
\hline 7 & $67,1^{2}$ & 0,01526 & 1,5531 & 0,6036 & 0,00324 & 0,00126 \\
\hline 27 & $68,2^{3}$ & 0,01417 & 1,0323 & 0,0827 & 0,00215 & 0,00017 \\
\hline 40 & $68,3^{3}$ & 0,01417 & 1,0323 & 0,0827 & 0,00215 & 0,00017 \\
\hline 51 & $68,5^{3}$ & 0,01417 & 1,0323 & 0,0827 & 0,00215 & 0,00017 \\
\hline 29 & $68,8^{3}$ & 0,01417 & 1,0323 & 0,0827 & 0,00215 & 0,00017 \\
\hline 75 & $68,9^{3}$ & 0,01417 & 1,0323 & 0,0827 & 0,00215 & 0,00017 \\
\hline 10 & $69,4^{3}$ & 0,01417 & 1,0323 & 0,0827 & 0,00215 & 0,00017 \\
\hline 47 & $69,5^{3}$ & 0,01417 & 1,0323 & 0,0827 & 0,00215 & 0,00017 \\
\hline 79 & $69,7^{3}$ & 0,01417 & 1,0323 & 0,0827 & 0,00215 & 0,00017 \\
\hline 18 & $69,9^{3}$ & 0,01417 & 1,0323 & 0,0827 & 0,00215 & 0,00017 \\
\hline 19 & $70,0^{3}$ & 0,01417 & 1,0323 & 0,0827 & 0,00215 & 0,00017 \\
\hline 63 & $70,0^{3}$ & 0,01417 & 1,0323 & 0,0827 & 0,00215 & 0,00017 \\
\hline 71 & $70,0^{3}$ & 0,01417 & 1,0323 & 0,0827 & 0,00215 & 0,00017 \\
\hline 57 & $70,3^{3}$ & 0,01417 & 1,0323 & 0,0827 & 0,00215 & 0,00017 \\
\hline 87 & $70,4^{3}$ & 0,01417 & 1,0323 & 0,0827 & 0,00215 & 0,00017 \\
\hline 78 & $70,5^{3}$ & 0,01417 & 1,0323 & 0,0827 & 0,00215 & 0,00017 \\
\hline 23 & $70,7^{3}$ & 0,01417 & 1,0323 & 0,0827 & 0,00215 & 0,00017 \\
\hline 11 & $70,7^{3}$ & 0,01417 & 1,0323 & 0,0827 & 0,00215 & 0,00017 \\
\hline 17 & $70,9^{3}$ & 0,01417 & 1,0323 & 0,0827 & 0,00215 & 0,00017 \\
\hline 81 & $71,0^{3}$ & 0,01417 & 1,0323 & 0,0827 & 0,00215 & 0,00017 \\
\hline 35 & $71,4^{3}$ & 0,01417 & 1,0323 & 0,0827 & 0,00215 & 0,00017 \\
\hline 9 & $71,6^{3}$ & 0,01417 & 1,0323 & 0,0827 & 0,00215 & 0,00017 \\
\hline 86 & $71,8^{3}$ & 0,01417 & 1,0323 & 0,0827 & 0,00215 & 0,00017 \\
\hline 3 & $72,1^{3}$ & 0,01417 & 1,0323 & 0,0827 & 0,00215 & 0,00017 \\
\hline 6 & $72,2^{3}$ & 0,01417 & 1,0323 & 0,0827 & 0,00215 & 0,00017 \\
\hline 33 & $72,3^{3}$ & 0,01417 & 1,0323 & 0,0827 & 0,00215 & 0,00017 \\
\hline 38 & $72,3^{3}$ & 0,01417 & 1,0323 & 0,0827 & 0,00215 & 0,00017 \\
\hline 73 & $72,4^{3}$ & 0,01417 & 1,0323 & 0,0827 & 0,00215 & 0,00017 \\
\hline 12 & $72,4^{3}$ & 0,01417 & 1,0323 & 0,0827 & 0,00215 & 0,00017 \\
\hline 28 & $72,8^{3}$ & 0,01417 & 1,0323 & 0,0827 & 0,00215 & 0,00017 \\
\hline 5 & $74,2^{4}$ & 0,01299 & 0,4649 & $-0,4847$ & 0,00097 & $-0,00101$ \\
\hline 53 & $74,5^{4}$ & 0,01299 & 0,4649 & $-0,4847$ & 0,00097 & $-0,00101$ \\
\hline 83 & $74,8^{4}$ & 0,01299 & 0,4649 & $-0,4847$ & 0,00097 & $-0,00101$ \\
\hline
\end{tabular}


Tabela 10. Médias individuais, de grupos, médias transformadas $\left(Z_{i, s}\right.$ e $\left.Y_{i, s}\right)$ e respectivos desvios, da Altura da Planta na Maturação (AM), para a estimação das Distâncias Euclidiana e de Mahalanobis

\begin{tabular}{|c|c|c|c|c|c|c|}
\hline \multirow[b]{2}{*}{ Linhagens } & \multicolumn{2}{|c|}{ Médias } & \multicolumn{2}{|c|}{ Dist. Eucliana } & \multicolumn{2}{|c|}{ Dist. Mahalanobis } \\
\hline & Individuais & Grupos ${ }^{(1)}$ & $Z_{i j}$ & desvios & $Y_{\mathrm{ij}}$ & desvios \\
\hline 84 & $75,0^{4}$ & 0,01299 & 0,4649 & $-0,4847$ & 0,00097 & $-0,00101$ \\
\hline 68 & $75,0^{4}$ & 0,01299 & 0,4649 & $-0,4847$ & 0,00097 & $-0,00101$ \\
\hline 77 & $75,9^{4}$ & 0,01299 & 0,4649 & $-0,4847$ & 0,00097 & $-0,00101$ \\
\hline 43 & $76,0^{4}$ & 0,01299 & 0,4649 & $-0,4847$ & 0,00097 & $-0,00101$ \\
\hline 85 & $76,8^{4}$ & 0,01299 & 0,4649 & $-0,4847$ & 0,00097 & $-0,00101$ \\
\hline 15 & $77,3^{4}$ & 0,01299 & 0,4649 & $-0,4847$ & 0,00097 & $-0,00101$ \\
\hline 52 & $77,6^{4}$ & 0,01299 & 0,4649 & $-0,4847$ & 0,00097 & $-0,00101$ \\
\hline 69 & $77,9^{4}$ & 0,01299 & 0,4649 & $-0,4847$ & 0,00097 & $-0,00101$ \\
\hline 34 & $78,5^{4}$ & 0,01299 & 0,4649 & $-0,4847$ & 0,00097 & $-0,00101$ \\
\hline 80 & $78,6^{4}$ & 0,01299 & 0,4649 & $-0,4847$ & 0,00097 & $-0,00101$ \\
\hline 42 & $78,9^{4}$ & 0,01299 & 0,4649 & $-0,4847$ & 0,00097 & $-0,00101$ \\
\hline 4 & $79,3^{4}$ & 0,01299 & 0,4649 & $-0,4847$ & 0,00097 & $-0,00101$ \\
\hline 16 & $79,4^{4}$ & 0,01299 & 0,4649 & $-0,4847$ & 0,00097 & $-0,00101$ \\
\hline 22 & $79,7^{4}$ & 0,01299 & 0,4649 & $-0,4847$ & 0,00097 & $-0,00101$ \\
\hline 26 & $80,4^{5}$ & 0,01202 & 0,0000 & $-0,9496$ & 0,00000 & $-0,00198$ \\
\hline 39 & $80,9^{5}$ & 0,01202 & 0,0000 & $-0,9496$ & 0,00000 & $-0,00198$ \\
\hline 24 & $81,2^{5}$ & 0,01202 & 0,0000 & $-0,9496$ & 0,00000 & $-0,00198$ \\
\hline 55 & $82,6^{5}$ & 0,01202 & 0,0000 & $-0,9496$ & 0,00000 & $-0,00198$ \\
\hline 59 & $83,3^{5}$ & 0,01202 & 0,0000 & $-0,9496$ & 0,00000 & $-0,00198$ \\
\hline 13 & $84,0^{5}$ & 0,01202 & 0,0000 & $-0,9496$ & 0,00000 & $-0,00198$ \\
\hline 1 & $84,2^{5}$ & 0,01202 & 0,0000 & $-0,9496$ & 0,00000 & $-0,00198$ \\
\hline 49 & $84,3^{5}$ & 0,01202 & 0,0000 & $-0,9496$ & 0,00000 & $-0,00198$ \\
\hline 72 & $84,3^{5}$ & 0,01202 & 0,0000 & $-0,9496$ & 0,00000 & $-0,00198$ \\
\hline 46 & $87,1^{5}$ & 0,01202 & 0,0000 & $-0,9496$ & 0,00000 & $-0,00198$ \\
\hline 32 & $89,2^{6}$ & 0,01117 & $-0,4079$ & $-1,3575$ & $-0,00085$ & $-0,00283$ \\
\hline 20 & $89,9^{6}$ & 0,01117 & $-0,4079$ & $-1,3575$ & $-0,00085$ & $-0,00283$ \\
\hline 48 & $93,3^{7}$ & 0,01055 & $-0,7080$ & $-1,6576$ & $-0,00148$ & $-0,00345$ \\
\hline 21 & $94,1^{7}$ & 0,01055 & $-0,7080$ & $-1,6576$ & $-0,00148$ & $-0,00345$ \\
\hline 36 & $94,2^{7}$ & 0,01055 & $-0,7080$ & $-1,6576$ & $-0,00148$ & $-0,00345$ \\
\hline 58 & $94,2^{7}$ & 0,01055 & $-0,7080$ & $-1,6576$ & $-0,00148$ & $-0,00345$ \\
\hline 56 & $94,7^{7}$ & 0,01055 & $-0,7080$ & $-1,6576$ & $-0,00148$ & $-0,00345$ \\
\hline 54 & $95,9^{7}$ & 0,01055 & $-0,7080$ & $-1,6576$ & $-0,00148$ & $-0,00345$ \\
\hline 8 & $97,6^{7}$ & 0,01055 & $-0,7080$ & $-1,6576$ & $-0,00148$ & $-0,00345$ \\
\hline 14 & $103,5^{8}$ & 0,00966 & $-1,1330$ & $-2,0825$ & $-0,00236$ & $-0,00434$ \\
\hline 2 & $105,9^{9}$ & 0,00931 & $-1,2985$ & $-2,2480$ & $-0,00271$ & $-0,00469$ \\
\hline 67 & $108,8^{9}$ & 0,00931 & $-1,2985$ & $-2,2480$ & $-0,00271$ & $-0,00469$ \\
\hline 30 & $111,2^{10}$ & 0,00894 & $-1,4775$ & $-2,4271$ & $-0,00308$ & $-0,00506$ \\
\hline 74 & $112,0^{10}$ & 0,00894 & $-1,4775$ & $-2,4271$ & $-0,00308$ & $-0,00506$ \\
\hline 66 & $112,4^{10}$ & 0,00894 & $-1,4775$ & $-2,4271$ & $-0,00308$ & $-0,00506$ \\
\hline 82 & $116,4^{11}$ & 0,00842 & $-1,7300$ & $-2,6796$ & $-0,00361$ & $-0,00558$ \\
\hline 31 & $117,7^{11}$ & 0,00842 & $-1,7300$ & $-2,6796$ & $-0,00361$ & $-0,00558$ \\
\hline 37 & $120,0^{11}$ & 0,00842 & $-1,7300$ & $-2,6796$ & $-0,00361$ & $-0,00558$ \\
\hline 64 & $120,0^{11}$ & 0,00842 & $-1,7300$ & $-2,6796$ & $-0,00361$ & $-0,00558$ \\
\hline 44 & $120,1^{11}$ & 0,00842 & $-1,7300$ & $-2,6796$ & $-0,00361$ & $-0,00558$ \\
\hline
\end{tabular}

Ideótipo:

0,9496

0,00198

(1): obtidas com os recíprocos $\left(1 / \mathrm{X}_{\mathrm{ij}}\right)$ das médias individuais 
Tabela 11. Médias individuais, de grupos, médias transformadas $\left(Z_{i j, s}\right.$ e $\left.Y_{i, j, s}\right)$ e respectivos desvios, da Produção de Grãos (PG), para a estimação das Distâncias Euclidiana e de Mahalanobis

\begin{tabular}{|c|c|c|c|c|c|c|}
\hline \multirow[b]{2}{*}{ Linhagens } & \multicolumn{2}{|c|}{ Médias } & \multicolumn{2}{|c|}{ Dist. Eucliana } & \multicolumn{2}{|c|}{ Dist. Mahalanobis } \\
\hline & Individuais & Grupos & $\mathrm{Z}_{\mathrm{ij}}$ & Desvios & $Y_{\mathrm{ij}}$ & Desvios \\
\hline 36 & $126,0^{8}$ & 154,5 & $-1,528$ & $-3,698$ & $-90,71$ & $-219,47$ \\
\hline 58 & $126,3^{8}$ & 154,5 & $-1,528$ & $-3,698$ & $-90,71$ & $-219,47$ \\
\hline 13 & $139,7^{8}$ & 154,5 & $-1,528$ & $-3,698$ & $-90,71$ & $-219,47$ \\
\hline 88 & $144,7^{8}$ & 154,5 & $-1,528$ & $-3,698$ & $-90,71$ & $-219,47$ \\
\hline 70 & $148,1^{8}$ & 154,5 & $-1,528$ & $-3,698$ & $-90,71$ & $-219,47$ \\
\hline 63 & $149,7^{8}$ & 154,5 & $-1,528$ & $-3,698$ & $-90,71$ & $-219,47$ \\
\hline 62 & $153,1^{8}$ & 154,5 & $-1,528$ & $-3,698$ & $-90,71$ & $-219,47$ \\
\hline 65 & $154,5^{8}$ & 154,5 & $-1,528$ & $-3,698$ & $-90,71$ & $-219,47$ \\
\hline 41 & $154,9^{8}$ & 154,5 & $-1,528$ & $-3,698$ & $-90,71$ & $-219,47$ \\
\hline 32 & $155,2^{8}$ & 154,5 & $-1,528$ & $-3,698$ & $-90,71$ & $-219,47$ \\
\hline 79 & $156,2^{8}$ & 154,5 & $-1,528$ & $-3,698$ & $-90,71$ & $-219,47$ \\
\hline 84 & $156,3^{8}$ & 154,5 & $-1,528$ & $-3,698$ & $-90,71$ & $-219,47$ \\
\hline 73 & $159,3^{8}$ & 154,5 & $-1,528$ & $-3,698$ & $-90,71$ & $-219,47$ \\
\hline 48 & $161,3^{8}$ & 154,5 & $-1,528$ & $-3,698$ & $-90,71$ & $-219,47$ \\
\hline 43 & $170,5^{8}$ & 154,5 & $-1,528$ & $-3,698$ & $-90,71$ & $-219,47$ \\
\hline 75 & $173,4^{8}$ & 154,5 & $-1,528$ & $-3,698$ & $-90,71$ & $-219,47$ \\
\hline 39 & $175,1^{8}$ & 154,5 & $-1,528$ & $-3,698$ & $-90,71$ & $-219,47$ \\
\hline 35 & $176,4^{8}$ & 154,5 & $-1,528$ & $-3,698$ & $-90,71$ & $-219,47$ \\
\hline 16 & $182,8^{7}$ & 197,2 & $-0,808$ & $-2,978$ & $-47,94$ & $-176,70$ \\
\hline 60 & $185,8^{7}$ & 197,2 & $-0,808$ & $-2,978$ & $-47,94$ & $-176,70$ \\
\hline 57 & $186,0^{7}$ & 197,2 & $-0,808$ & $-2,978$ & $-47,94$ & $-176,70$ \\
\hline 49 & $186,6^{7}$ & 197,2 & $-0,808$ & $-2,978$ & $-47,94$ & $-176,70$ \\
\hline 14 & $189,9^{7}$ & 197,2 & $-0,808$ & $-2,978$ & $-47,94$ & $-176,70$ \\
\hline 8 & $194,7^{7}$ & 197,2 & $-0,808$ & $-2,978$ & $-47,94$ & $-176,70$ \\
\hline 17 & $197,7^{7}$ & 197,2 & $-0,808$ & $-2,978$ & $-47,94$ & $-176,70$ \\
\hline 81 & $198,4^{7}$ & 197,2 & $-0,808$ & $-2,978$ & $-47,94$ & $-176,70$ \\
\hline 85 & $200,6^{7}$ & 197,2 & $-0,808$ & $-2,978$ & $-47,94$ & $-176,70$ \\
\hline 71 & $202,5^{7}$ & 197,2 & $-0,808$ & $-2,978$ & $-47,94$ & $-176,70$ \\
\hline 19 & $204,9^{7}$ & 197,2 & $-0,808$ & $-2,978$ & $-47,94$ & $-176,70$ \\
\hline 78 & $205,5^{7}$ & 197,2 & $-0,808$ & $-2,978$ & $-47,94$ & $-176,70$ \\
\hline 77 & $206,2^{7}$ & 197,2 & $-0,808$ & $-2,978$ & $-47,94$ & $-176,70$ \\
\hline 28 & $208,3^{7}$ & 197,2 & $-0,808$ & $-2,978$ & $-47,94$ & $-176,70$ \\
\hline 25 & $208,9^{7}$ & 197,2 & $-0,808$ & $-2,978$ & $-47,94$ & $-176,70$ \\
\hline 45 & $220,0^{6}$ & 225,4 & $-0,334$ & $-2,504$ & $-19,81$ & $-148,57$ \\
\hline 72 & $221,0^{6}$ & 225,4 & $-0,334$ & $-2,504$ & $-19,81$ & $-148,57$ \\
\hline 27 & $222,3^{6}$ & 225,4 & $-0,334$ & $-2,504$ & $-19,81$ & $-148,57$ \\
\hline 69 & $222,8^{6}$ & 225,4 & $-0,334$ & $-2,504$ & $-19,81$ & $-148,57$ \\
\hline 61 & $223,9^{6}$ & 225,4 & $-0,334$ & $-2,504$ & $-19,81$ & $-148,57$ \\
\hline 29 & $226,3^{6}$ & 225,4 & $-0,334$ & $-2,504$ & $-19,81$ & $-148,57$ \\
\hline 2 & $226,9^{6}$ & 225,4 & $-0,334$ & $-2,504$ & $-19,81$ & $-148,57$ \\
\hline 80 & $229,0^{6}$ & 225,4 & $-0,334$ & $-2,504$ & $-19,81$ & $-148,57$ \\
\hline 11 & $230,0^{6}$ & 225,4 & $-0,334$ & $-2,504$ & $-19,81$ & $-148,57$ \\
\hline 68 & $231,7^{6}$ & 225,4 & $-0,334$ & $-2,504$ & $-19,81$ & $-148,57$ \\
\hline 38 & $236,4^{5}$ & 245,2 & 0,000 & $-2,170$ & 0,00 & $-128,76$ \\
\hline
\end{tabular}


Tabela 11. Médias individuais, de grupos, médias transformadas ( $Z_{i, s}$ e $\left.Y_{i, s}\right)$ e respectivos desvios, da Produção de Grãos (PG), para a estimação das Distâncias Euclidiana e de Mahalanobis

\begin{tabular}{|c|c|c|c|c|c|c|}
\hline \multirow[b]{2}{*}{ Linhagens } & \multicolumn{2}{|c|}{ Médias } & \multicolumn{2}{|c|}{ Dist. Eucliana } & \multicolumn{2}{|c|}{ Dist. Mahalanobis } \\
\hline & Individuais & Grupos & $Z_{i j}$ & Desvios & $Y_{\mathrm{ij}}$ & Desvios \\
\hline 1 & $236,6^{5}$ & 245,2 & 0,000 & $-2,170$ & 0,00 & $-128,76$ \\
\hline 86 & $239,1^{5}$ & 245,2 & 0,000 & $-2,170$ & 0,00 & $-128,76$ \\
\hline 50 & $240,7^{5}$ & 245,2 & 0,000 & $-2,170$ & 0,00 & $-128,76$ \\
\hline 87 & $240,7^{5}$ & 245,2 & 0,000 & $-2,170$ & 0,00 & $-128,76$ \\
\hline 23 & $243,8^{5}$ & 245,2 & 0,000 & $-2,170$ & 0,00 & $-128,76$ \\
\hline 3 & $244,1^{5}$ & 245,2 & 0,000 & $-2,170$ & 0,00 & $-128,76$ \\
\hline 51 & $244,8^{5}$ & 245,2 & 0,000 & $-2,170$ & 0,00 & $-128,76$ \\
\hline 66 & $246,5^{5}$ & 245,2 & 0,000 & $-2,170$ & 0,00 & $-128,76$ \\
\hline 7 & $246,6^{5}$ & 245,2 & 0,000 & $-2,170$ & 0,00 & $-128,76$ \\
\hline 10 & $246,9^{5}$ & 245,2 & 0,000 & $-2,170$ & 0,00 & $-128,76$ \\
\hline 40 & $250,3^{5}$ & 245,2 & 0,000 & $-2,170$ & 0,00 & $-128,76$ \\
\hline 76 & $250,8^{5}$ & 245,2 & 0,000 & $-2,170$ & 0,00 & $-128,76$ \\
\hline 6 & $253,0^{5}$ & 245,2 & 0,000 & $-2,170$ & 0,00 & $-128,76$ \\
\hline 83 & $257,5^{5}$ & 245,2 & 0,000 & $-2,170$ & 0,00 & $-128,76$ \\
\hline 33 & $266,5^{4}$ & 275,7 & 0,515 & $-1,655$ & 30,56 & $-98,20$ \\
\hline 24 & $272,4^{4}$ & 275,7 & 0,515 & $-1,655$ & 30,56 & $-98,20$ \\
\hline 54 & $272,4^{4}$ & 275,7 & 0,515 & $-1,655$ & 30,56 & $-98,20$ \\
\hline 52 & $275,4^{4}$ & 275,7 & 0,515 & $-1,655$ & 30,56 & $-98,20$ \\
\hline 47 & $275,6^{4}$ & 275,7 & 0,515 & $-1,655$ & 30,56 & $-98,20$ \\
\hline 34 & $276,4^{4}$ & 275,7 & 0,515 & $-1,655$ & 30,56 & $-98,20$ \\
\hline 15 & $277,6^{4}$ & 275,7 & 0,515 & $-1,655$ & 30,56 & $-98,20$ \\
\hline 22 & $281,5^{4}$ & 275,7 & 0,515 & $-1,655$ & 30,56 & $-98,20$ \\
\hline 46 & $283,9^{4}$ & 275,7 & 0,515 & $-1,655$ & 30,56 & $-98,20$ \\
\hline 4 & $287,9^{3}$ & 305,1 & 1,010 & $-1,160$ & 59,93 & $-68,84$ \\
\hline 5 & $291,4^{3}$ & 305,1 & 1,010 & $-1,160$ & 59,93 & $-68,84$ \\
\hline 9 & $292,7^{3}$ & 305,1 & 1,010 & $-1,160$ & 59,93 & $-68,84$ \\
\hline 42 & $292,8^{3}$ & 305,1 & 1,010 & $-1,160$ & 59,93 & $-68,84$ \\
\hline 26 & $294,3^{3}$ & 305,1 & 1,010 & $-1,160$ & 59,93 & $-68,84$ \\
\hline 53 & $297,1^{3}$ & 305,1 & 1,010 & $-1,160$ & 59,93 & $-68,84$ \\
\hline 18 & $298,3^{3}$ & 305,1 & 1,010 & $-1,160$ & 59,93 & $-68,84$ \\
\hline 44 & $308,3^{3}$ & 305,1 & 1,010 & $-1,160$ & 59,93 & $-68,84$ \\
\hline 59 & $310,1^{3}$ & 305,1 & 1,010 & $-1,160$ & 59,93 & $-68,84$ \\
\hline 12 & $313,4^{3}$ & 305,1 & 1,010 & $-1,160$ & 59,93 & $-68,84$ \\
\hline 31 & $314,9^{3}$ & 305,1 & 1,010 & $-1,160$ & 59,93 & $-68,84$ \\
\hline 67 & $316,9^{3}$ & 305,1 & 1,010 & $-1,160$ & 59,93 & $-68,84$ \\
\hline 30 & $318,4^{3}$ & 305,1 & 1,010 & $-1,160$ & 59,93 & $-68,84$ \\
\hline 82 & $319,9^{3}$ & 305,1 & 1,010 & $-1,160$ & 59,93 & $-68,84$ \\
\hline 55 & $320,3^{3}$ & 305,1 & 1,010 & $-1,160$ & 59,93 & $-68,84$ \\
\hline 21 & $328,6^{2}$ & 333,6 & 1,489 & $-0,680$ & 88,39 & $-40,37$ \\
\hline 56 & $333,4^{2}$ & 333,6 & 1,489 & $-0,680$ & 88,39 & $-40,37$ \\
\hline 37 & $334,6^{2}$ & 333,6 & 1,489 & $-0,680$ & 88,39 & $-40,37$ \\
\hline 74 & $335,4^{2}$ & 333,6 & 1,489 & $-0,680$ & 88,39 & $-40,37$ \\
\hline 64 & $336,0^{2}$ & 333,6 & 1,489 & $-0,680$ & 88,39 & $-40,37$ \\
\hline 20 & $380,1^{1}$ & 380,1 & 2,274 & 0,104 & 134,95 & 6,19 \\
\hline Tde & & & & & & \\
\hline
\end{tabular}


Tabela 12. Médias individuais, transformadas $\left(Z_{\mathrm{ij}, \mathrm{s}}\right)$ e respectivos desvios, do parâmetro b (adaptabilidade), da produção de grãos, para a estimação da Distância Euclidiana

\begin{tabular}{|c|c|c|c|c|c|c|c|}
\hline Linhagens & Médias & $Z_{i j}$ & Desvios & Linhagens & Médias & $Z_{i j}$ & Desvios \\
\hline 36 & $-0,215$ & $-1,7639$ & $-2,3425$ & 86 & 1,070 & 0,7130 & 0,1345 \\
\hline 8 & $-0,179$ & $-1,6948$ & $-2,2733$ & 34 & 1,081 & 0,7344 & 0,1558 \\
\hline 6 & $-0,109$ & $-1,5608$ & $-2,1393$ & 72 & 1,102 & 0,7744 & 0,1958 \\
\hline 56 & $-0,047$ & $-1,4414$ & $-2,0199$ & 48 & 1,106 & 0,7825 & 0,2040 \\
\hline 14 & $-0,044$ & $-1,4344$ & $-2,0130$ & 29 & 1,116 & 0,8024 & 0,2239 \\
\hline 58 & 0,020 & $-1,3114$ & $-1,8900$ & 45 & 1,120 & 0,8092 & 0,2306 \\
\hline 32 & 0,085 & $-1,1860$ & $-1,7646$ & 10 & 1,144 & 0,8554 & 0,2769 \\
\hline 66 & 0,343 & $-0,6891$ & $-1,2677$ & 59 & 1,154 & 0,8761 & 0,2975 \\
\hline 33 & 0,355 & $-0,6647$ & $-1,2432$ & 44 & 1,160 & 0,8867 & 0,3082 \\
\hline 84 & 0,364 & $-0,6471$ & $-1,2257$ & 85 & 1,163 & 0,8932 & 0,3147 \\
\hline 2 & 0,375 & $-0,6267$ & $-1,2052$ & 79 & 1,166 & 0,8981 & 0,3196 \\
\hline 31 & 0,396 & $-0,5867$ & $-1,1653$ & 15 & 1,176 & 0,9179 & 0,3393 \\
\hline 54 & 0,405 & $-0,5694$ & $-1,1479$ & 63 & 1,177 & 0,9207 & 0,3422 \\
\hline 47 & 0,463 & $-0,4576$ & $-1,0362$ & 21 & 1,180 & 0,9252 & 0,3467 \\
\hline 68 & 0,492 & $-0,4002$ & $-0,9787$ & 88 & 1,201 & 0,9654 & 0,3869 \\
\hline 83 & 0,539 & $-0,3104$ & $-0,8889$ & 49 & 1,229 & 1,0204 & 0,4419 \\
\hline 13 & 0,547 & $-0,2946$ & $-0,8731$ & 65 & 1,272 & 1,1034 & 0,5248 \\
\hline 46 & 0,600 & $-0,1927$ & $-0,7713$ & 78 & 1,310 & 1,1772 & 0,5987 \\
\hline 39 & 0,610 & $-0,1729$ & $-0,7515$ & 82 & 1,320 & 1,1954 & 0,6169 \\
\hline 24 & 0,631 & $-0,1332$ & $-0,7117$ & 28 & 1,347 & 1,2468 & 0,6682 \\
\hline 23 & 0,652 & $-0,0926$ & $-0,6711$ & 61 & 1,378 & 1,3071 & 0,7285 \\
\hline 19 & 0,653 & $-0,0902$ & $-0,6687$ & 7 & 1,383 & 1,3179 & 0,7393 \\
\hline 20 & 0,654 & $-0,0885$ & $-0,6670$ & 5 & 1,396 & 1,3417 & 0,7631 \\
\hline 38 & 0,679 & $-0,0404$ & $-0,6190$ & 60 & 1,405 & 1,3592 & 0,7806 \\
\hline 18 & 0,690 & $-0,0192$ & $-0,5978$ & 80 & 1,424 & 1,3958 & 0,8173 \\
\hline 52 & 0,696 & $-0,0084$ & $-0,5869$ & 27 & 1,443 & 1,4322 & 0,8537 \\
\hline 1 & 0,697 & $-0,0059$ & $-0,5844$ & 69 & 1,466 & 1,4769 & 0,8983 \\
\hline 43 & 0,699 & $-0,0017$ & $-0,5803$ & 64 & 1,485 & 1,5131 & 0,9345 \\
\hline 12 & 0,732 & 0,0616 & $-0,5169$ & 30 & 1,540 & 1,6198 & 1,0413 \\
\hline 81 & 0,785 & 0,1646 & $-0,4139$ & 87 & 1,549 & 1,6369 & 1,0583 \\
\hline 26 & 0,790 & 0,1745 & $-0,4041$ & 4 & 1,561 & 1,6599 & 1,0813 \\
\hline 42 & 0,806 & 0,2045 & $-0,3740$ & 3 & 1,569 & 1,6758 & 1,0973 \\
\hline 25 & 0,838 & 0,2653 & $-0,3132$ & 73 & 1,615 & 1,7648 & 1,1863 \\
\hline 16 & 0,854 & 0,2975 & $-0,2810$ & 40 & 1,620 & 1,7742 & 1,1956 \\
\hline 35 & 0,869 & 0,3257 & $-0,2528$ & 75 & 1,622 & 1,7775 & 1,1989 \\
\hline 55 & 0,869 & 0,3260 & $-0,2526$ & 76 & 1,650 & 1,8319 & 1,2534 \\
\hline 62 & 0,893 & 0,3715 & $-0,2070$ & 51 & 1,704 & 1,9358 & 1,3572 \\
\hline 57 & 0,913 & 0,4106 & $-0,1679$ & 22 & 1,709 & 1,9466 & 1,3681 \\
\hline 77 & 0,923 & 0,4293 & $-0,1492$ & 67 & 1,749 & 2,0239 & 1,4453 \\
\hline 70 & 0,997 & 0,5718 & $-0,0067$ & 11 & 1,753 & 2,0303 & 1,4518 \\
\hline 71 & 1,002 & 0,5815 & 0,0029 & 37 & 1,772 & 2,0673 & 1,4887 \\
\hline 53 & 1,046 & 0,6679 & 0,0894 & 50 & 1,889 & 2,2926 & 1,7140 \\
\hline 41 & 1,046 & 0,6681 & 0,0896 & 9 & 1,912 & 2,3381 & 1,7595 \\
\hline 17 & 1,059 & 0,6919 & 0,1134 & 74 & 2,020 & 2,5465 & 1,9679 \\
\hline
\end{tabular}

Ideótipo: 0,5785 
esse parâmetro, as 28 primeiras linhagens possuem $Z_{i j, s}$ negativos (valores em negrito), indicando que pelo critério adotado, elas não são selecionáveis.

Observa-se que nove linhagens $(17,34,41,53,57,70,71,77$ e 86) apresentam estimativas de b entre 0,90 e 1,10, ou seja, muito próximas de 1,0. Esses valores indicam que essas linhagens não sofreram aumentos drásticos na média de PG nos melhores anos, nem uma diminuição muito acentuada, nos piores. Deve-se ressaltar que as estimativas de b das linhagens $70(0,997)$ e 71 $(1,002)$ são praticamente iguais a 1,0 .

Em virtude de não ter sido possível aplicar o teste de Scott-Knott ao parâmetro $b$ e ao $R^{2}$, cada linhagem tem um valor próprio de $Z_{i j}$ e, conseqüentemente, um desvio próprio. Os desvios do parâmetro b para a Distância Euclidiana são apresentados na quarta e na oitava colunas da Tabela 12.

Os dados relativos ao coeficiente de determinação $\left(R^{2}\right)$ encontram-se na Tabela 13. As 30 primeiras linhagens possuem $Z_{i j, s}$ negativos, por suas estimativas de $R^{2}$ serem menores que a da testemunha IAC Foscarin 31 $(48,9 \%)$, valor que foi fixado como $\circ \mathrm{N}_{\mathrm{j}}$ para esse parâmetro. Entre as 58 linhagens cujas estimativas são maiores que o valor de descarte, 23 possuem estimativas de $\mathrm{R}^{2}$ acima de $80 \%$, indicando que elas possuem alta estabilidade. Da mesma forma que no parâmetro de adaptabilidade (b), não foi possível aplicar o teste de Scott-Knott às estimativas de $\mathrm{R}^{2}$.

Os valores de AC mostrados nas Tabelas 14, 15 e 16 são as médias de grupos, calculadas a partir dos valores originais, e não dos valores transformados $(\sqrt{x+0,5})$, que foram empregados no cálculo dos índices. $A$ razão de se apresentarem as médias de grupos, ao invés dos valores individuais, foi que a classificação das médias transformadas era diferente da das médias originais. Sendo assim, se os valores apresentados nessas três tabelas fossem os individuais, haveria confusão quando se comparassem esses com os valores transformados, mostrados na Tabela 9 
Tabela 13. Médias individuais, transformadas $\left(Z_{\mathrm{ij}, \mathrm{s}}\right)$ e respectivos desvios, do coeficiente de determinação ( $R^{2} \%$ : estabilidade), da produção de grãos, para a estimação da Distância Euclidiana

\begin{tabular}{|c|c|c|c|c|c|c|c|}
\hline Linhagens & Médias & $Z_{i j}$ & Desvios & Linhagens & Médias & $Z_{i j}$ & Desvios \\
\hline 58 & 0,10 & $\begin{array}{l}-1,8178 \\
\end{array}$ & $-3,7139$ & 59 & 63,59 & 0,5423 & $-1,3538$ \\
\hline 56 & 0,12 & $-1,8173$ & $-3,7134$ & 5 & 63,93 & 0,5553 & $-1,3408$ \\
\hline 14 & 0,21 & $-1,8140$ & $-3,7101$ & 70 & 64,50 & 0,5765 & $-1,3196$ \\
\hline 32 & 0,89 & $-1,7887$ & $-3,6848$ & 26 & 64,78 & 0,5868 & $-1,3093$ \\
\hline 6 & 0,93 & $-1,7869$ & $-3,6830$ & 35 & 65,99 & 0,6315 & $-1,2646$ \\
\hline 8 & 4,70 & $-1,6469$ & $-3,5430$ & 65 & 66,26 & 0,6416 & $-1,2545$ \\
\hline 36 & 6,10 & $-1,5948$ & $-3,4909$ & 43 & 66,80 & 0,6618 & $-1,2343$ \\
\hline 33 & 9,58 & $-1,4655$ & $-3,3616$ & 74 & 66,90 & 0,6657 & $-1,2304$ \\
\hline 66 & 10,01 & $-1,4496$ & $-3,3457$ & 45 & 68,57 & 0,7277 & $-1,1684$ \\
\hline 2 & 17,11 & $-1,1855$ & $-3,0816$ & 67 & 68,68 & 0,7318 & $-1,1642$ \\
\hline 20 & 18,41 & $-1,1372$ & $-3,0333$ & 22 & 68,95 & 0,7419 & $-1,1542$ \\
\hline 47 & 20,80 & $-1,0483$ & $-2,9444$ & 52 & 70,04 & 0,7823 & $-1,1138$ \\
\hline 68 & 26,14 & $-0,8498$ & $-2,7459$ & 29 & 70,87 & 0,8131 & $-1,0830$ \\
\hline 54 & 26,91 & $-0,8212$ & $-2,7173$ & 88 & 71,45 & 0,8346 & $-1,0615$ \\
\hline 46 & 28,38 & $-0,7664$ & $-2,6625$ & 37 & 71,52 & 0,8374 & $-1,0587$ \\
\hline 84 & 31,49 & $-0,6508$ & $-2,5469$ & 85 & 72,75 & 0,8829 & $-1,0132$ \\
\hline 13 & 32,92 & $-0,5977$ & $-2,4938$ & 10 & 73,22 & 0,9003 & $-0,9958$ \\
\hline 31 & 36,92 & $-0,4492$ & $-2,3452$ & 75 & 74,11 & 0,9335 & $-0,9626$ \\
\hline 44 & 37,78 & $-0,4171$ & $-2,3132$ & 3 & 75,61 & 0,9892 & $-0,9069$ \\
\hline 55 & 37,86 & $-0,4141$ & $-2,3102$ & 53 & 76,04 & 1,0053 & $-0,8908$ \\
\hline 57 & 38,15 & $-0,4034$ & $-2,2995$ & 48 & 76,88 & 1,0367 & $-0,8594$ \\
\hline 19 & 38,47 & $-0,3914$ & $-2,2875$ & 60 & 80,08 & 1,1554 & $-0,7407$ \\
\hline 18 & 42,03 & $-0,2590$ & $-2,1551$ & 1 & 80,09 & 1,1560 & $-0,7401$ \\
\hline 83 & 42,56 & $-0,2395$ & $-2,1356$ & 15 & 80,91 & 1,1864 & $-0,7097$ \\
\hline 64 & 42,64 & $-0,2365$ & $-2,1326$ & 24 & 81,67 & 1,2148 & $-0,6813$ \\
\hline 21 & 44,17 & $-0,1794$ & $-2,0755$ & 11 & 82,47 & 1,2444 & $-0,6517$ \\
\hline 23 & 44,65 & $-0,1619$ & $-2,0579$ & 69 & 82,60 & 1,2493 & $-0,6468$ \\
\hline 81 & 45,02 & $-0,1478$ & $-2,0439$ & 79 & 84,47 & 1,3188 & $-0,5773$ \\
\hline 12 & 47,83 & $-0,0433$ & $-1,9394$ & 4 & 85,03 & 1,3395 & $-0,5566$ \\
\hline 34 & 48,21 & $-0,0292$ & $-1,9253$ & 28 & 85,61 & 1,3611 & $-0,5350$ \\
\hline 25 & 50,54 & 0,0575 & $-1,8386$ & 51 & 86,55 & 1,3959 & $-0,5002$ \\
\hline 78 & 51,06 & 0,0767 & $-1,8194$ & 40 & 86,75 & 1,4034 & $-0,4927$ \\
\hline 61 & 52,81 & 0,1418 & $-1,7543$ & 72 & 87,23 & 1,4212 & $-0,4749$ \\
\hline 39 & 53,30 & 0,1598 & $-1,7363$ & 7 & 87,45 & 1,4296 & $-0,4665$ \\
\hline 62 & 53,79 & 0,1781 & $-1,7180$ & 42 & 88,03 & 1,4511 & $-0,4450$ \\
\hline 71 & 55,45 & 0,2398 & $-1,6563$ & 76 & 89,55 & 1,5076 & $-0,3885$ \\
\hline 38 & 55,82 & 0,2536 & $-1,6425$ & 50 & 90,50 & 1,5431 & $-0,3530$ \\
\hline 16 & 56,26 & 0,2700 & $-1,6261$ & 63 & 90,78 & 1,5532 & $-0,3429$ \\
\hline 17 & 56,94 & 0,2952 & $-1,6009$ & 9 & 91,57 & 1,5826 & $-0,3135$ \\
\hline 30 & 57,34 & 0,3100 & $-1,5861$ & 49 & 92,70 & 1,6249 & $-0,2712$ \\
\hline 41 & 57,62 & 0,3205 & $-1,5756$ & 73 & 93,12 & 1,6402 & $-0,2559$ \\
\hline 77 & 59,14 & 0,3772 & $-1,5189$ & 27 & 93,19 & 1,6431 & $-0,2530$ \\
\hline 86 & 61,04 & 0,4476 & $-1,4485$ & 87 & 94,74 & 1,7007 & $-0,1954$ \\
\hline 82 & 63,38 & 0,5346 & $-1,3615$ & 80 & 97,27 & 1,7948 & $-0,1013$ \\
\hline
\end{tabular}

Ideótipo: 1,8961 
Tabela 14. Distância Euclidiana estimada com base nos caracteres acamamento (AC), altura da planta na maturação (AM) e produção de grãos (PG), médias desses caracteres e estimativas do parâmetro de adaptabilidade (b) e do coeficiente de determinação ( $R^{2} \%$; estabilidade)

\begin{tabular}{|c|c|c|c|c|c|c|c|}
\hline & \multirow[b]{2}{*}{ Linhagens } & \multirow[b]{2}{*}{ D.E. } & \multicolumn{5}{|c|}{ Médias dos caracteres* e grupos respectivos } \\
\hline & & & $A C^{* *}$ & AM & $P G$ & b & $\mathrm{R}^{2} \%$ \\
\hline 1 & $9^{\mathrm{CM}}$ & 1,38 & $1,16^{1}$ & $71,6^{3}$ & $292,7^{3}$ & $1,912^{2}$ & $91,57^{6}$ \\
\hline 1 & $12^{\mathrm{CM}}$ & 1,38 & $1,16^{1}$ & $72,4^{3}$ & $313,4^{3}$ & $0,732^{60}$ & $47,83^{60}$ \\
\hline 1 & $18^{\mathrm{CM}}$ & 1,38 & $1,16^{1}$ & $69,9^{3}$ & $298,3^{3}$ & $0,690^{64}$ & $42,03^{66}$ \\
\hline 2 & $4^{\mathrm{CM}}$ & 1,40 & $1,16^{1}$ & $79,3^{4}$ & $287,9^{3}$ & $1,561^{14}$ & $85,03^{16}$ \\
\hline 2 & $5^{\mathrm{CM}}$ & 1,40 & $1,16^{1}$ & $74,2^{4}$ & $291,4^{3}$ & $1,396^{22}$ & $63,93^{43}$ \\
\hline 2 & $42^{\mathrm{CM}}$ & 1,40 & $1,16^{1}$ & $78,9^{4}$ & $292,8^{3}$ & $0,806^{57}$ & $88,03^{10}$ \\
\hline 2 & $53^{\mathrm{CM}}$ & 1,40 & $1,16^{1}$ & $74,5^{4}$ & $297,1^{3}$ & $1,046^{46}$ & $76,04^{25}$ \\
\hline 3 & $20^{\mathrm{ST}}$ & 1,44 & $1,16^{1}$ & $89,9^{6}$ & $380,1^{1}$ & $\mathbf{0 , 6 5 4}$ & $18,41^{78}$ \\
\hline 4 & $26^{\mathrm{ST}}$ & 1,48 & $1,16^{1}$ & $80,4^{5}$ & $294,3^{3}$ & $0,790^{58}$ & $64,78^{41}$ \\
\hline 4 & $59^{\mathrm{CM}}$ & 1,48 & $1,16^{1}$ & $83,3^{5}$ & $310,1^{3}$ & $1,154^{37}$ & $63,59^{44}$ \\
\hline 5 & $15^{\mathrm{ST}}$ & 1,56 & $1,16^{1}$ & $77,3^{4}$ & $277,6^{4}$ & $1,176^{33}$ & $80,91^{21}$ \\
\hline 5 & $22^{\mathrm{CM}}$ & 1,56 & $1,16^{1}$ & $79,7^{4}$ & $281,5^{4}$ & $1,709^{7}$ & $68,95^{34}$ \\
\hline 5 & $34^{\mathrm{CM}}$ & 1,56 & $1,16^{1}$ & $78,5^{4}$ & $276,4^{4}$ & $1,081^{43}$ & $\mathbf{4 8 , 2 1}$ \\
\hline 5 & $52^{\mathrm{CM}}$ & 1,56 & $1,16^{1}$ & $77,6^{4}$ & $275,4^{4}$ & $0,696^{63}$ & $70,04^{33}$ \\
\hline 6 & $24^{\mathrm{CM}}$ & 1,63 & $1,16^{1}$ & $81,2^{5}$ & $272,4^{4}$ & $\mathbf{0 , 6 3 1}$ & $81,67^{20}$ \\
\hline 7 & $3^{\mathrm{CM}}$ & 1,74 & $1,16^{1}$ & $72,1^{3}$ & $244,1^{5}$ & $1,569^{13}$ & $75,61^{26}$ \\
\hline 7 & $40^{\mathrm{CM}}$ & 1,74 & $1,16^{1}$ & $68,3^{3}$ & $250,3^{5}$ & $1,620^{11}$ & $86,75^{13}$ \\
\hline 7 & $86^{\mathrm{CM}}$ & 1,74 & $1,16^{1}$ & $71,8^{3}$ & $239,1^{5}$ & $1,070^{44}$ & $61,04^{46}$ \\
\hline 7 & $87^{\mathrm{CM}}$ & 1,74 & $1,16^{1}$ & $70,4^{3}$ & $240,7^{5}$ & $1,549^{15}$ & $94,74^{2}$ \\
\hline 8 & $83^{\mathrm{CM}}$ & 1,76 & $1,16^{1}$ & $74,8^{4}$ & $257,5^{5}$ & $0,539^{73}$ & $42,56^{65}$ \\
\hline 9 & $7^{\mathrm{CM}}$ & 1,77 & $1,16^{1}$ & $67,1^{2}$ & $246,6^{5}$ & $1,383^{23}$ & $87,45^{11}$ \\
\hline 9 & $50^{\mathrm{CM}}$ & 1,77 & $1,16^{1}$ & $66,3^{2}$ & $240,7^{5}$ & $1,889^{3}$ & $90,50^{8}$ \\
\hline 9 & $76^{\mathrm{CM}}$ & 1,77 & $1,16^{1}$ & $65,7^{2}$ & $250,8^{5}$ & $1,650^{9}$ & $89,55^{9}$ \\
\hline 10 & $55^{\mathrm{CM}}$ & 1,87 & $1,54^{2}$ & $82,6^{5}$ & $320,3^{3}$ & $0,869^{53}$ & $\mathbf{3 7 , 8 6 ^ { 6 9 }}$ \\
\hline 11 & $11^{\mathrm{SP}}$ & 1,88 & $1,16^{1}$ & $70,7^{3}$ & $\mathbf{2 3 0 , 0 ^ { 6 }}$ & $1,753^{5}$ & $82,47^{19}$ \\
\hline 11 & $27^{\mathrm{CM}}$ & 1,88 & $1,16^{1}$ & $68,2^{3}$ & $222,3^{6}$ & $1,443^{19}$ & $93,19^{3}$ \\
\hline 12 & $80^{\mathrm{CM}}$ & 1,90 & $1,16^{1}$ & $78,6^{4}$ & $229,0^{6}$ & $1,424^{20}$ & $97,27^{1}$ \\
\hline 13 & $33^{\mathrm{CM}}$ & 1,92 & $1,54^{2}$ & $72,3^{3}$ & $266,5^{4}$ & $0,355^{80}$ & $9,58^{81}$ \\
\hline 13 & $47^{\mathrm{SP}}$ & 1,92 & $1,54^{2}$ & $69,5^{3}$ & $275,6^{4}$ & $\mathbf{0 , 4 6 3 ^ { 7 5 }}$ & $20,80^{77}$ \\
\hline 14 & $21^{\mathrm{CM}}$ & 1,96 & $1,54^{2}$ & $94,1^{7}$ & $328,6^{2}$ & $1,180^{31}$ & $\mathbf{4 4 , 1 7}$ \\
\hline 15 & $45^{S P}$ & 1,98 & $1,16^{1}$ & $60,3^{1}$ & $\mathbf{2 2 0 , 0 ^ { 6 }}$ & $1,120^{39}$ & $68,57^{36}$ \\
\hline 15 & $61^{\mathrm{CM}}$ & 1,98 & $1,16^{1}$ & $60,1^{1}$ & $223,9^{6}$ & $1,378^{24}$ & $52,81^{56}$ \\
\hline 16 & $31^{\mathrm{CM}}$ & 2,07 & $1,16^{1}$ & $117,7^{11}$ & $314,9^{3}$ & $0,396^{77}$ & $36,92^{71}$ \\
\hline 17 & $6^{\mathrm{CM}}$ & 2,08 & $1,54^{2}$ & $72,2^{3}$ & $253,0^{5}$ & $-0,109^{86}$ & $0,93^{84}$ \\
\hline 17 & $23^{\mathrm{CM}}$ & 2,08 & $1,54^{2}$ & $70,7^{3}$ & $243,8^{5}$ & $\mathbf{0 , 6 5 2} 2^{68}$ & $44,65^{62}$ \\
\hline 17 & $51^{\mathrm{CM}}$ & 2,08 & $1,54^{2}$ & $68,5^{3}$ & $244,8^{5}$ & $1,704^{8}$ & $86,55^{14}$ \\
\hline 18 & $17^{\mathrm{SP}}$ & 2,10 & $1,16^{1}$ & $70,9^{3}$ & $197,7^{7}$ & $1,059^{45}$ & $56,94^{50}$ \\
\hline 18 & $19^{\mathrm{CM}}$ & 2,10 & $1,16^{1}$ & $70,0^{3}$ & $204,9^{7}$ & $\mathbf{0 , 6 5 3}{ }^{67}$ & $\mathbf{3 8 , 4 7}{ }^{67}$ \\
\hline 18 & $28^{\mathrm{CM}}$ & 2,10 & $1,16^{1}$ & $72,8^{3}$ & $208,3^{7}$ & $1,347^{25}$ & $85,61^{15}$ \\
\hline 18 & $57^{\mathrm{CM}}$ & 2,10 & $1,16^{1}$ & $70,3^{3}$ & $186,0^{7}$ & $0,913^{51}$ & $\mathbf{3 8 , 1 5}{ }^{68}$ \\
\hline 18 & $71^{\mathrm{CM}}$ & 2,10 & $1,16^{1}$ & $70,0^{3}$ & $202,5^{7}$ & $1,002^{48}$ & $55,45^{53}$ \\
\hline 19 & $77^{\mathrm{CM}}$ & 2,12 & $1,16^{1}$ & $75,9^{4}$ & $206,2^{7}$ & $0,923^{50}$ & $59,14^{47}$ \\
\hline 20 & $25^{\mathrm{CM}}$ & 2,19 & $1,16^{1}$ & $63,0^{1}$ & $208,9^{7}$ & $0,838^{56}$ & $50,54^{58}$ \\
\hline 20 & $60^{\mathrm{SP}}$ & 2,19 & $1,16^{1}$ & $63,2^{1}$ & $185,8^{7}$ & $1,405^{21}$ & $80,08^{23}$ \\
\hline
\end{tabular}


Tabela 14. Distância Euclidiana estimada com base nos caracteres acamamento (AC), altura da planta na maturação (AM) e produção de grãos (PG), médias desses caracteres e estimativas do parâmetro de adaptabilidade (b) e do coeficiente de determinação ( $R^{2} \%$; estabilidade)

\begin{tabular}{|c|c|c|c|c|c|c|c|}
\hline & \multirow[b]{2}{*}{ Linhagens } & \multirow[b]{2}{*}{ D.E. } & \multicolumn{5}{|c|}{ Médias dos caracteres* e grupos respectivos } \\
\hline & & & $A C^{* *}$ & AM & $P G$ & $b$ & $\mathrm{R}^{2} \%$ \\
\hline 21 & $29^{\text {SP }}$ & 2,20 & $1,54^{2}$ & $68,8^{3}$ & $226,3^{6}$ & $1,116^{40}$ & $70,87^{32}$ \\
\hline 22 & $67^{\mathrm{CM}}$ & 2,21 & $1,54^{2}$ & $108,8^{9}$ & $316,9^{3}$ & $1,749^{6}$ & $68,68^{35}$ \\
\hline 23 & $46^{\mathrm{CM}}$ & 2,25 & $1,90^{3}$ & $87,1^{5}$ & $283,9^{4}$ & $0,600^{71}$ & $28,38^{74}$ \\
\hline 24 & $30^{\mathrm{CM}}$ & 2,27 & $1,54^{2}$ & $111,2^{10}$ & $318,4^{3}$ & $1,540^{16}$ & $57,34^{49}$ \\
\hline 25 & $10^{\mathrm{CM}}$ & 2,33 & $1,90^{3}$ & $69,4^{3}$ & $246,9^{5}$ & $1,144^{38}$ & $73,22^{28}$ \\
\hline 25 & $38^{\mathrm{CM}}$ & 2,33 & $1,90^{3}$ & $72,3^{3}$ & $236,4^{5}$ & $\mathbf{0 , 6 7 9} 9^{65}$ & $55,82^{52}$ \\
\hline 26 & $44^{\mathrm{CM}}$ & 2,37 & $1,54^{2}$ & $120,1^{11}$ & $308,3^{3}$ & $1,160^{36}$ & $37,78^{70}$ \\
\hline 27 & $54^{\mathrm{CM}}$ & 2,39 & $1,90^{3}$ & $95,9^{7}$ & $272,4^{4}$ & $\mathbf{0 , 4 0 5 ^ { 7 6 }}$ & $\mathbf{2 6 , 9 1}{ }^{75}$ \\
\hline 28 & $1^{\mathrm{CM}}$ & 2,40 & $1,90^{3}$ & $84,2^{5}$ & $236,6^{5}$ & $0,697^{62}$ & $80,09^{22}$ \\
\hline 29 & $74^{\mathrm{CM}}$ & 2,45 & $1,90^{3}$ & $112,0^{10}$ & $335,4^{2}$ & $2,020^{1}$ & $66,90^{37}$ \\
\hline 30 & $63^{\mathrm{CM}}$ & 2,45 & $1,16^{1}$ & $70,0^{3}$ & $149,7^{8}$ & $1,177^{32}$ & $90,78^{7}$ \\
\hline 30 & $73^{S P}$ & 2,45 & $1,16^{1}$ & $72,4^{3}$ & $159,3^{8}$ & $1,615^{12}$ & $93,12^{4}$ \\
\hline 30 & $75^{\mathrm{CM}}$ & 2,45 & $1,16^{1}$ & $68,9^{3}$ & $173,4^{8}$ & $1,622^{10}$ & $74,11^{27}$ \\
\hline 31 & $49^{\mathrm{CM}}$ & 2,45 & $1,54^{2}$ & $84,3^{5}$ & $186,6^{7}$ & $1,229^{29}$ & $92,70^{5}$ \\
\hline 32 & $68^{\mathrm{CM}}$ & 2,46 & $1,90^{3}$ & $75,0^{4}$ & $231,7^{6}$ & $0,492^{74}$ & $\mathbf{2 6 , 1 4}{ }^{76}$ \\
\hline 32 & $69^{\mathrm{CM}}$ & 2,46 & $1,90^{3}$ & $77,9^{4}$ & $222,8^{6}$ & $1,466^{18}$ & $82,60^{18}$ \\
\hline 33 & $43^{\mathrm{CM}}$ & 2,47 & $1,16^{1}$ & $76,0^{4}$ & $170,5^{8}$ & $0,699^{61}$ & $66,80^{38}$ \\
\hline 34 & $41^{\mathrm{SP}}$ & 2,48 & $1,16^{1}$ & $66,7^{2}$ & $154,9^{8}$ & $1,046^{47}$ & $57,62^{48}$ \\
\hline 34 & $62^{S P}$ & 2,48 & $1,16^{1}$ & $65,2^{2}$ & $153,1^{8}$ & $0,893^{52}$ & $53,79^{54}$ \\
\hline 34 & $65^{\mathrm{SP}}$ & 2,48 & $1,16^{1}$ & $63,8^{2}$ & $154,5^{8}$ & $1,272^{28}$ & $66,26^{39}$ \\
\hline 34 & $70^{S P}$ & 2,48 & $1,16^{1}$ & $65,5^{2}$ & $148,1^{8}$ & $0,997^{49}$ & $64,50^{42}$ \\
\hline 34 & $88^{\mathrm{SP}}$ & 2,48 & $1,16^{1}$ & $64,1^{2}$ & $144,7^{8}$ & $1,201^{30}$ & $71,45^{31}$ \\
\hline 35 & $72^{\mathrm{CM}}$ & 2,50 & $1,90^{3}$ & $84,3^{5}$ & $\mathbf{2 2 1 , 0 ^ { 6 }}$ & $1,102^{42}$ & $87,23^{12}$ \\
\hline 36 & $37^{\mathrm{CM}}$ & 2,53 & $1,90^{3}$ & $120,0^{11}$ & $334,6^{2}$ & $1,772^{4}$ & $71,52^{30}$ \\
\hline 36 & $64^{\mathrm{CM}}$ & 2,53 & $1,90^{3}$ & $120,0^{11}$ & $336,0^{2}$ & $1,485^{17}$ & $42,64^{64}$ \\
\hline 37 & $82^{\mathrm{CM}}$ & 2,59 & $1,90^{3}$ & $116,4^{11}$ & $319,9^{3}$ & $1,320^{26}$ & $63,38^{45}$ \\
\hline 38 & $78^{\mathrm{CM}}$ & 2,61 & $1,90^{3}$ & $70,5^{3}$ & $205,5^{7}$ & $1,310^{27}$ & $51,06^{57}$ \\
\hline 38 & $81^{\mathrm{SP}}$ & 2,61 & $1,90^{3}$ & $71,0^{3}$ & $198,4^{7}$ & $0,785^{59}$ & $45,02^{61}$ \\
\hline 39 & $16^{\mathrm{CM}}$ & 2,63 & $1,90^{3}$ & $79,4^{4}$ & $182,8^{7}$ & $0,854^{55}$ & $56,26^{51}$ \\
\hline 39 & $85^{\mathrm{SP}}$ & 2,63 & $1,90^{3}$ & $76,8^{4}$ & $200,6^{7}$ & $1,163^{35}$ & $72,75^{29}$ \\
\hline 40 & $35^{\mathrm{CM}}$ & 2,71 & $1,54^{2}$ & $71,4^{3}$ & $176,4^{8}$ & $0,869^{54}$ & $65,99^{40}$ \\
\hline 40 & $79^{S P}$ & 2,71 & $1,54^{2}$ & $69,7^{3}$ & $156,2^{8}$ & $1,166^{34}$ & $84,47^{17}$ \\
\hline 41 & $84^{\mathrm{SP}}$ & 2,72 & $1,54^{2}$ & $75,0^{4}$ & $156,3^{8}$ & $\mathbf{0 , 3 6 4 ^ { 7 9 }}$ & $31,49^{73}$ \\
\hline 42 & $56^{\mathrm{ST}}$ & 2,74 & $2,85^{4}$ & $94,7^{7}$ & $333,4^{2}$ & $-0,047^{85}$ & $0,12^{87}$ \\
\hline 43 & $39^{S P}$ & 2,95 & $1,90^{3}$ & $80,9^{5}$ & $175,1^{8}$ & $\mathbf{0 , 6 1 0}{ }^{70}$ & $53,30^{55}$ \\
\hline 44 & $2^{\mathrm{CM}}$ & 3,45 & $3,46^{5}$ & $105,9^{9}$ & $226,9^{6}$ & $0,375^{78}$ & $17,11^{79}$ \\
\hline 45 & $8^{\mathrm{cM}}$ & 3,46 & $3,46^{5}$ & $97,6^{7}$ & $194,7^{7}$ & $-0,179^{87}$ & $4,70^{83}$ \\
\hline 46 & $66^{\mathrm{CM}}$ & 3,56 & $3,46^{6}$ & $112,4^{10}$ & $246,5^{5}$ & $0,343^{81}$ & $10,01^{80}$ \\
\hline 47 & $14^{\mathrm{CM}}$ & 3,68 & $3,46^{6}$ & $103,5^{8}$ & $189,9^{7}$ & $-0,044^{84}$ & $\mathbf{0 , 2 1}{ }^{86}$ \\
\hline 48 & $48^{\mathrm{CM}}$ & 3,69 & $3,46^{5}$ & $93,3^{7}$ & $161,3^{8}$ & $1,106^{41}$ & $76,88^{24}$ \\
\hline 49 & $13^{\mathrm{CM}}$ & 3,74 & $3,46^{6}$ & $84,0^{5}$ & $139,7^{8}$ & $0,547^{72}$ & $32,92^{72}$ \\
\hline 50 & $32^{\mathrm{CM}}$ & 3,78 & $3,46^{6}$ & $89,2^{6}$ & $155,2^{8}$ & $0,085^{82}$ & $\mathbf{0 , 8 9}{ }^{85}$ \\
\hline 51 & $36^{\mathrm{CM}}$ & 3,82 & $3,46^{6}$ & $94,2^{7}$ & $126,0^{8}$ & $-0,215^{88}$ & $\mathbf{6 , 1 0} 82$ \\
\hline 51 & $58^{\mathrm{CM}}$ & 3,82 & $3,46^{6}$ & $94,2^{7}$ & $126,3^{8}$ & $0,020^{83}$ & $0,10^{88}$ \\
\hline
\end{tabular}

*: médias em negrito estão abaixo (PG) ou acima ( $A C$ e $A M)$ do valor de descarte estabelecido;

**: os valores individuais (em unidades originais) foram substituídos pela média da classe correspondente. 
Tabela 15. Distância Euclidiana estimada com base nos caracteres acamamento (AC), altura da planta na maturação (AM), produção de grãos (PG), no parâmetro de adaptabilidade (b) e no coeficiente de determinação ( $R^{2} \%$; estabilidade), médias desses caracteres e estimativas de b e $\mathrm{R}^{2}$

\begin{tabular}{|c|c|c|c|c|c|c|c|}
\hline & \multirow[b]{2}{*}{ Linhagens } & \multirow[b]{2}{*}{ D.E. } & \multicolumn{5}{|c|}{ Médias dos caracteres* e grupos respectivos } \\
\hline & & & $A C^{* *}$ & AM & PG & $b$ & $\mathrm{R}^{2} \%$ \\
\hline 1 & $42^{\mathrm{CM}}$ & 1,12 & $1,16^{1}$ & $78,9^{4}$ & $292,8^{3}$ & $0,806^{57}$ & $88,03^{10}$ \\
\hline 2 & $53 \mathrm{~cm}$ & 1,16 & $1,16^{1}$ & $74,5^{4}$ & $297,1^{3}$ & $1,046^{47}$ & $76,04^{25}$ \\
\hline 3 & $4^{\mathrm{CM}}$ & 1,22 & $1,16^{1}$ & $79,3^{4}$ & $287,9^{3}$ & $1,561^{14}$ & $85,03^{16}$ \\
\hline 4 & $15^{\mathrm{ST}}$ & 1,26 & $1,16^{1}$ & $77,3^{4}$ & $277,6^{4}$ & $1,176^{33}$ & $80,91^{21}$ \\
\hline 5 & $5^{\mathrm{CM}}$ & 1,29 & $1,16^{1}$ & $74,2^{4}$ & $291,4^{3}$ & $1,396^{22}$ & $63,93^{43}$ \\
\hline 6 & $26^{\mathrm{ST}}$ & 1,30 & $1,16^{1}$ & $80,4^{5}$ & $294,3^{3}$ & $0,790^{58}$ & $64,78^{41}$ \\
\hline 7 & $59^{\mathrm{CM}}$ & 1,30 & $1,16^{1}$ & $83,3^{5}$ & $310,1^{3}$ & $1,154^{37}$ & $63,59^{44}$ \\
\hline 8 & $9^{\mathrm{CM}}$ & 1,33 & $1,16^{1}$ & $71,6^{3}$ & $292,7^{3}$ & $1,912^{2}$ & $91,57^{6}$ \\
\hline 9 & $52^{\mathrm{CM}}$ & 1,33 & $1,16^{1}$ & $77,6^{4}$ & $275,4^{4}$ & $0,696^{63}$ & $70,04^{33}$ \\
\hline 10 & $24 \mathrm{CM}$ & 1,34 & $1,16^{1}$ & $81,2^{5}$ & $272,4^{4}$ & $\mathbf{0 , 6 3 1}$ & $81,67^{20}$ \\
\hline 11 & $12^{\mathrm{CM}}$ & 1,39 & $1,16^{1}$ & $72,4^{3}$ & $313,4^{3}$ & $0,732^{60}$ & $\mathbf{4 7 , 8 3 ^ { 6 0 }}$ \\
\hline 12 & $7^{\mathrm{CM}}$ & 1,43 & $1,16^{1}$ & $67,1^{2}$ & $246,6^{5}$ & $1,383^{23}$ & $87,45^{11}$ \\
\hline 13 & $87^{\mathrm{CM}}$ & 1,43 & $1,16^{1}$ & $70,4^{3}$ & $240,7^{5}$ & $1,549^{15}$ & $94,74^{2}$ \\
\hline 14 & $22^{\mathrm{CM}}$ & 1,45 & $1,16^{1}$ & $79,7^{4}$ & $281,5^{4}$ & $1,709^{7}$ & $68,95^{34}$ \\
\hline 15 & $18^{\mathrm{cM}}$ & 1,46 & $1,16^{1}$ & $69,9^{3}$ & $298,3^{3}$ & $\mathbf{0 , 6 9 0}$ & $42,03^{66}$ \\
\hline 16 & $40^{\mathrm{CM}}$ & 1,46 & $1,16^{1}$ & $68,3^{3}$ & $250,3^{5}$ & $1,620^{11}$ & $86,75^{13}$ \\
\hline 17 & $34^{\mathrm{CM}}$ & 1,49 & $1,16^{1}$ & $78,5^{4}$ & $276,4^{4}$ & $1,081^{43}$ & $\mathbf{4 8 , 2 1}$ \\
\hline 18 & $3^{\mathrm{CM}}$ & 1,49 & $1,16^{1}$ & $72,1^{3}$ & $244,1^{5}$ & $1,569^{13}$ & $75,61^{26}$ \\
\hline 19 & $76^{\mathrm{CM}}$ & 1,49 & $1,16^{1}$ & $65,7^{2}$ & $250,8^{5}$ & $1,650^{9}$ & $89,55^{9}$ \\
\hline 20 & $86^{\mathrm{CM}}$ & 1,49 & $1,16^{1}$ & $71,8^{3}$ & $239,1^{5}$ & $1,070^{44}$ & $61,04^{46}$ \\
\hline 21 & $27^{\mathrm{CM}}$ & 1,51 & $1,16^{1}$ & $68,2^{3}$ & $222,3^{6}$ & $1,443^{19}$ & $93,19^{3}$ \\
\hline 22 & $80^{\mathrm{CM}}$ & 1,52 & $1,16^{1}$ & $78,6^{4}$ & $\mathbf{2 2 9 , 0} 0^{6}$ & $1,424^{20}$ & $97,27^{1}$ \\
\hline 23 & $50^{\mathrm{CM}}$ & 1,58 & $1,16^{1}$ & $66,3^{2}$ & $240,7^{5}$ & $1,889^{3}$ & $90,50^{8}$ \\
\hline 24 & $11^{\mathrm{SP}}$ & 1,62 & $1,16^{1}$ & $70,7^{3}$ & $230,0^{6}$ & $1,753^{5}$ & $82,47^{19}$ \\
\hline 25 & $45^{S P}$ & 1,62 & $1,16^{1}$ & $60,3^{1}$ & $\mathbf{2 2 0 , 0 ^ { 6 }}$ & $1,120^{39}$ & $68,57^{36}$ \\
\hline 26 & $28^{\mathrm{CM}}$ & 1,67 & $1,16^{1}$ & $72,8^{3}$ & $208,3^{7}$ & $1,347^{25}$ & $85,61^{15}$ \\
\hline 27 & $83^{\mathrm{CM}}$ & 1,71 & $1,16^{1}$ & $74,8^{4}$ & $257,5^{5}$ & $0,539^{73}$ & $42,56^{65}$ \\
\hline 28 & $51^{\mathrm{CM}}$ & 1,74 & $1,54^{2}$ & $68,5^{3}$ & $244,8^{5}$ & $1,704^{8}$ & $86,55^{14}$ \\
\hline 29 & $61^{\mathrm{CM}}$ & 1,75 & $1,16^{1}$ & $60,1^{1}$ & $223,9^{6}$ & $1,378^{24}$ & $52,81^{56}$ \\
\hline 30 & $60^{S P}$ & 1,76 & $1,16^{1}$ & $63,2^{1}$ & $185,8^{7}$ & $1,405^{21}$ & $80,08^{23}$ \\
\hline 31 & $77^{\mathrm{CM}}$ & 1,78 & $1,16^{1}$ & $75,9^{4}$ & $206,2^{7}$ & $0,923^{50}$ & $59,14^{47}$ \\
\hline 32 & $29^{S P}$ & 1,78 & $1,54^{2}$ & $68,8^{3}$ & $226,3^{6}$ & $1,116^{40}$ & $70,87^{32}$ \\
\hline 33 & $17^{\mathrm{SP}}$ & 1,78 & $1,16^{1}$ & $70,9^{3}$ & $197,7^{7}$ & $1,059^{45}$ & $56,94^{50}$ \\
\hline 34 & $20^{\mathrm{ST}}$ & 1,78 & $1,16^{1}$ & $89,9^{6}$ & $380,1^{1}$ & $\mathbf{0 , 6 5 4}$ & $18,41^{78}$ \\
\hline 35 & $21^{\mathrm{CM}}$ & 1,78 & $1,54^{2}$ & $94,1^{7}$ & $328,6^{2}$ & $1,180^{31}$ & 44,17 \\
\hline 36 & $55^{\mathrm{CM}}$ & 1,78 & $1,54^{2}$ & $82,6^{5}$ & $320,3^{3}$ & $0,869^{53}$ & $\mathbf{3 7 , 8 6}{ }^{69}$ \\
\hline 37 & $71^{\mathrm{CM}}$ & 1,79 & $1,16^{1}$ & $70,0^{3}$ & $202,5^{7}$ & $1,002^{48}$ & $55,45^{53}$ \\
\hline 38 & $10^{\mathrm{CM}}$ & 1,86 & $1,90^{3}$ & $69,4^{3}$ & $246,9^{5}$ & $1,144^{38}$ & $73,22^{28}$ \\
\hline 39 & $23^{\mathrm{CM}}$ & 1,88 & $1,54^{2}$ & $70,7^{3}$ & $243,8^{5}$ & $0,652^{68}$ & $44,65^{62}$ \\
\hline 40 & $25^{\mathrm{CM}}$ & 1,89 & $1,16^{1}$ & $63,0^{1}$ & $208,9^{7}$ & $0,838^{56}$ & $50,54^{58}$ \\
\hline 41 & $1^{\mathrm{CM}}$ & 1,90 & $1,90^{3}$ & $84,2^{5}$ & $236,6^{5}$ & $\mathbf{0 , 6 9 7 ^ { 6 2 }}$ & $80,09^{22}$ \\
\hline 42 & $67^{\mathrm{CM}}$ & 1,90 & $1,54^{2}$ & $108,8^{9}$ & $316,9^{3}$ & $1,749^{6}$ & $68,68^{35}$ \\
\hline 43 & $63^{\mathrm{CM}}$ & 1,91 & $1,16^{1}$ & $70,0^{3}$ & $149,7^{8}$ & $1,177^{32}$ & $90,78^{7}$ \\
\hline 44 & $49^{\mathrm{CM}}$ & 1,91 & $1,54^{2}$ & $84,3^{5}$ & $186,6^{7}$ & $1,229^{29}$ & $92,70^{5}$ \\
\hline
\end{tabular}


Tabela 15. Distância Euclidiana estimada com base nos caracteres acamamento (AC), altura da planta na maturação (AM), produção de grãos (PG), no parâmetro de adaptabilidade (b) e no coeficiente de determinação ( $R^{2} \%$; estabilidade), médias desses caracteres e estimativas de b e $\mathrm{R}^{2}$

\begin{tabular}{|c|c|c|c|c|c|c|c|}
\hline & \multirow[b]{2}{*}{ Linhagens } & \multirow[b]{2}{*}{ D.E. } & \multicolumn{5}{|c|}{ Médias dos caracteres* e grupos respectivos } \\
\hline & & & $A C^{* *}$ & AM & $P G$ & $b$ & $\mathrm{R}^{2} \%$ \\
\hline 45 & $57^{\mathrm{CM}}$ & 1,92 & $1,16^{1}$ & $70,3^{3}$ & $186,0^{7}$ & $0,913^{51}$ & $38,15^{68}$ \\
\hline 46 & $19^{\mathrm{CM}}$ & 1,94 & $1,16^{1}$ & $70,0^{3}$ & $204,9^{7}$ & $\mathbf{0 , 6 5 3} 3^{67}$ & $\mathbf{3 8 , 4 7} \mathbf{7}^{67}$ \\
\hline 47 & $72^{\mathrm{CM}}$ & 1,95 & $1,90^{3}$ & $84,3^{5}$ & $221,0^{6}$ & $1,102^{42}$ & $87,23^{12}$ \\
\hline 48 & $30^{\mathrm{CM}}$ & 1,96 & $1,54^{2}$ & $\mathbf{1 1 1 , 2 ^ { 1 0 }}$ & $318,4^{3}$ & $1,540^{16}$ & 57,3449 \\
\hline 49 & $69^{\mathrm{CM}}$ & 1,97 & $1,90^{3}$ & $77,9^{4}$ & $222,8^{6}$ & $1,466^{18}$ & $82,60^{18}$ \\
\hline 50 & $38^{\mathrm{CM}}$ & 1,97 & $1,90^{3}$ & $72,3^{3}$ & $236,4^{5}$ & $\mathbf{0 , 6 7 9}{ }^{65}$ & $55,82^{52}$ \\
\hline 51 & $73^{S P}$ & 1,97 & $1,16^{1}$ & $72,4^{3}$ & $159,3^{8}$ & $1,615^{12}$ & $93,12^{4}$ \\
\hline 52 & $88^{S P}$ & 1,98 & $1,16^{1}$ & $64,1^{2}$ & $144,7^{8}$ & $1,201^{30}$ & $71,45^{31}$ \\
\hline 53 & $31^{\mathrm{CM}}$ & 1,99 & $1,16^{1}$ & $117, \mathbf{7}^{11}$ & $314,9^{3}$ & $0,396^{77}$ & $36,92^{71}$ \\
\hline 54 & $43^{\mathrm{CM}}$ & 2,01 & $1,16^{1}$ & $76,0^{4}$ & $170,5^{8}$ & $\mathbf{0 , 6 9 9} 61$ & $66,80^{38}$ \\
\hline 55 & $70^{\mathrm{SP}}$ & 2,01 & $1,16^{1}$ & $65,5^{2}$ & $148,1^{8}$ & $0,997^{49}$ & $64,50^{42}$ \\
\hline 56 & $65^{S P}$ & 2,01 & $1,16^{1}$ & $63,8^{2}$ & $154,5^{8}$ & $1,272^{28}$ & $66,26^{39}$ \\
\hline 57 & $75^{\mathrm{CM}}$ & 2,02 & $1,16^{1}$ & $68,9^{3}$ & $173,4^{8}$ & $1,622^{10}$ & $74,11^{27}$ \\
\hline 58 & $47^{\mathrm{SP}}$ & 2,04 & $1,54^{2}$ & $69,5^{3}$ & $275,6^{4}$ & $\mathbf{0 , 4 6 3} 3^{75}$ & $20,80^{77}$ \\
\hline 59 & $41^{\mathrm{SP}}$ & 2,04 & $1,16^{1}$ & $66,7^{2}$ & $154,9^{8}$ & $1,046^{46}$ & $57,62^{48}$ \\
\hline 60 & $62^{S P}$ & 2,07 & $1,16^{1}$ & $65,2^{2}$ & $153,1^{8}$ & $0,893^{52}$ & $53,79^{54}$ \\
\hline 61 & $85^{\mathrm{SP}}$ & 2,09 & $1,90^{3}$ & $76,8^{4}$ & $200,6^{7}$ & $1,163^{35}$ & $72.75^{29}$ \\
\hline 62 & $44^{\mathrm{CM}}$ & 2,11 & $1,54^{2}$ & $120,1^{11}$ & $308,3^{3}$ & $1,160^{36}$ & $37,78^{70}$ \\
\hline 63 & $82^{\mathrm{CM}}$ & 2,11 & $1,90^{3}$ & $\mathbf{1 1 6 , 4}$ & $319,9^{3}$ & $1,320^{26}$ & $63,38^{45}$ \\
\hline 64 & $79^{S P}$ & 2,12 & $1,54^{2}$ & $69,7^{3}$ & $156,2^{8}$ & $1,166^{34}$ & $84,47^{17}$ \\
\hline 65 & $37^{\mathrm{CM}}$ & 2,13 & $1,90^{3}$ & $120,0^{11}$ & $334,6^{2}$ & $1,772^{4}$ & $71,52^{30}$ \\
\hline 66 & $46^{\mathrm{CM}}$ & 2,14 & $1,90^{3}$ & $87,1^{5}$ & $283,9^{4}$ & $0,600^{71}$ & $\mathbf{2 8 , 3 8 ^ { 7 4 }}$ \\
\hline 67 & $74^{\mathrm{CM}}$ & 2,16 & $1,90^{3}$ & $112,0^{10}$ & $335,4^{2}$ & $2,020^{1}$ & $66,90^{37}$ \\
\hline 68 & $16^{\mathrm{CM}}$ & 2,16 & $1,90^{3}$ & $79,4^{4}$ & $182,8^{7}$ & $0,854^{55}$ & $56,26^{51}$ \\
\hline 69 & $35^{\mathrm{CM}}$ & 2,17 & $1,54^{2}$ & $71,4^{3}$ & $176,4^{8}$ & $0,869^{54}$ & $65,99^{40}$ \\
\hline 70 & $33^{\mathrm{CM}}$ & 2,18 & $1,54^{2}$ & $72,3^{3}$ & $266,5^{4}$ & $0,355^{80}$ & $\mathbf{9 , 5 8}$ \\
\hline 71 & $78^{\mathrm{CM}}$ & 2,20 & $1,90^{3}$ & $70,5^{3}$ & $205,5^{7}$ & $1,310^{27}$ & $51,06^{57}$ \\
\hline 72 & $64^{\mathrm{CM}}$ & 2,22 & $1,90^{3}$ & $120,0^{11}$ & $336,0^{2}$ & $1,485^{17}$ & $\mathbf{4 2 , 6 4 ^ { 6 4 }}$ \\
\hline 73 & $81^{\mathrm{SP}}$ & 2,23 & $1,90^{3}$ & $71,0^{3}$ & $198,4^{7}$ & $0,785^{59}$ & $45,02^{61}$ \\
\hline 74 & $54^{\mathrm{CM}}$ & 2,27 & $1,90^{3}$ & $95,9^{7}$ & $272,4^{4}$ & $0,405^{76}$ & $\mathbf{2 6 , 9 1}$ \\
\hline 75 & $68^{\mathrm{CM}}$ & 2,31 & $1,90^{3}$ & $75,0^{4}$ & $231,7^{6}$ & $0,492^{74}$ & $26,14^{76}$ \\
\hline 76 & $39^{S P}$ & 2,44 & $1,90^{3}$ & $80,9^{5}$ & $175,1^{8}$ & $\mathbf{0 , 6 1 0} \mathbf{7 0}^{70}$ & $53,30^{55}$ \\
\hline 77 & $84^{S P}$ & 2,46 & $1,54^{2}$ & $75,0^{4}$ & $156,3^{8}$ & $\mathbf{0 , 3 6 4 ^ { 7 9 }}$ & $31,49^{73}$ \\
\hline 78 & $6^{\mathrm{CM}}$ & 2,50 & $1,54^{2}$ & $72,2^{3}$ & $253,0^{5}$ & $-0,109^{86}$ & $\mathbf{0 , 9 3}$ \\
\hline 79 & $56^{\mathrm{ST}}$ & 2,84 & $2,85^{4}$ & $94,7^{7}$ & $333,4^{2}$ & $-0,047^{85}$ & $0,12^{87}$ \\
\hline 80 & $48^{\mathrm{CM}}$ & 2,88 & $3,46^{5}$ & $93,3^{7}$ & $161,3^{8}$ & $1,106^{41}$ & $76,88^{24}$ \\
\hline 81 & $2^{\mathrm{CM}}$ & 3,05 & $3,46^{5}$ & $105,9^{9}$ & $226,9^{6}$ & $0,375^{78}$ & $17,11^{79}$ \\
\hline 82 & $13^{\mathrm{CM}}$ & 3,13 & $3,46^{6}$ & $84,0^{5}$ & $139,7^{8}$ & $0,547^{72}$ & 32,92 \\
\hline 83 & $66^{\mathrm{CM}}$ & 3,19 & $3,46^{6}$ & $\mathbf{1 1 2 , 4 ^ { 1 0 }}$ & $246,5^{5}$ & $0,343^{81}$ & $10,01^{80}$ \\
\hline 84 & $8^{\mathrm{CM}}$ & 3,28 & $3,46^{5}$ & $97,6^{7}$ & $194,7^{7}$ & $-0,179^{87}$ & $\mathbf{4 , 7 0}$ \\
\hline 85 & $14^{\mathrm{CM}}$ & 3,42 & $3,46^{6}$ & $103,5^{8}$ & $189,9^{7}$ & $-0,044^{84}$ & $\mathbf{0 , 2 1}{ }^{86}$ \\
\hline 86 & $32^{\mathrm{CM}}$ & 3,45 & $3,46^{6}$ & $89,2^{6}$ & $155,2^{8}$ & $\mathbf{0 , 0 8 5 ^ { 8 2 }}$ & $\mathbf{0 , 8 9} 85$ \\
\hline 87 & $58^{\mathrm{CM}}$ & 3,50 & $3,46^{6}$ & $94,2^{7}$ & $126,3^{8}$ & $\mathbf{0 , 0 2 0} 83$ & $\mathbf{0 , 1 0 ^ { 8 8 }}$ \\
\hline 88 & $36^{\mathrm{CM}}$ & 3,51 & $3,46^{6}$ & $94,2^{7}$ & $126,0^{8}$ & $-0,215^{88}$ & $\mathbf{6}, 10^{82}$ \\
\hline
\end{tabular}

*: médias em negrito estão abaixo (PG) ou acima ( $A C$ e $A M)$ do valor de descarte estabelecido;

**: os valores individuais (em unidades originais) foram substituídos pela média da classe correspondente. 
Tabela 16. Distância de Mahalanobis estimada com base nos caracteres acamamento (AC), altura da planta na maturação (AM) e produção de grãos (PG), médias desses caracteres e estimativas do parâmetro de adaptabilidade (b) e do coeficiente de determinação ( $\mathrm{R}^{2} \%$; estabilidade)

\begin{tabular}{|c|c|c|c|c|c|c|c|}
\hline & \multirow[b]{2}{*}{ Linhagens } & \multirow[b]{2}{*}{ D.M. } & \multicolumn{5}{|c|}{ Médias dos caracteres* e grupos respectivos } \\
\hline & & & $A C^{* *}$ & AM & PG & $b$ & $\mathrm{R}^{2} \%$ \\
\hline 1 & $20^{\text {ST }}$ & 1,44 & $1,16^{1}$ & $89,9^{6}$ & $380,1^{1}$ & $0,654^{66}$ & $18,41^{78}$ \\
\hline 2 & $31^{\mathrm{CM}}$ & 2,99 & $1,16^{1}$ & $117,7^{11}$ & $314,9^{3}$ & $0,396^{77}$ & $36,92^{71}$ \\
\hline 3 & $26^{\mathrm{ST}}$ & 2,99 & $1,16^{1}$ & $80,4^{5}$ & $294,3^{3}$ & $0,790^{58}$ & $64,78^{41}$ \\
\hline 3 & $59^{\mathrm{CM}}$ & 2,99 & $1,16^{1}$ & $83,3^{5}$ & $310,1^{3}$ & $1,154^{37}$ & $63,59^{44}$ \\
\hline 4 & $4^{\mathrm{CM}}$ & 2,99 & $1,16^{1}$ & $79,3^{4}$ & $287,9^{3}$ & $1,561^{14}$ & $85,03^{16}$ \\
\hline 4 & $5^{\mathrm{CM}}$ & 2,99 & $1,16^{1}$ & $74,2^{4}$ & $291,5^{3}$ & $1,396^{22}$ & $63,93^{43}$ \\
\hline 4 & $42^{\mathrm{CM}}$ & 2,99 & $1,16^{1}$ & $78,9^{4}$ & $292,8^{3}$ & $0,806^{57}$ & $88,03^{10}$ \\
\hline 4 & $53^{\mathrm{CM}}$ & 2,99 & $1,16^{1}$ & $74,5^{4}$ & $297,2^{3}$ & $1,046^{46}$ & $76,04^{25}$ \\
\hline 5 & $9^{\mathrm{CM}}$ & 2,99 & $1,16^{1}$ & $71,6^{3}$ & $292,7^{3}$ & $1,912^{2}$ & $91,57^{6}$ \\
\hline 5 & $12^{\mathrm{CM}}$ & 2,99 & $1,16^{1}$ & $72,4^{3}$ & $313,4^{3}$ & $0,732^{60}$ & $\mathbf{4 7 , 8 3 ^ { 6 0 }}$ \\
\hline 5 & $18^{\mathrm{CM}}$ & 2,99 & $1,16^{1}$ & $69,9^{3}$ & $298,3^{3}$ & $\mathbf{0 , 6 9 0}{ }^{64}$ & $\mathbf{4 2 , 0 3}{ }^{66}$ \\
\hline 6 & $21^{\mathrm{CM}}$ & 3,46 & $1,54^{2}$ & $94,1^{7}$ & $328,6^{2}$ & $1,180^{31}$ & $\mathbf{4 4 , 1 7 ^ { 6 3 }}$ \\
\hline 7 & $24^{\mathrm{CM}}$ & 4,39 & $1,16^{1}$ & $81,3^{5}$ & $272,4^{4}$ & $\mathbf{0 , 6 3 1} 69$ & $81,67^{20}$ \\
\hline 8 & $15^{\mathrm{ST}}$ & 4,39 & $1,16^{1}$ & $77,3^{4}$ & $277,6^{4}$ & $1,176^{33}$ & $80,91^{21}$ \\
\hline 8 & $22^{\mathrm{CM}}$ & 4,39 & $1,16^{1}$ & $79,7^{4}$ & $281,5^{4}$ & $1,709^{7}$ & $68,95^{34}$ \\
\hline 8 & $34 \mathrm{CM}$ & 4,39 & $1,16^{1}$ & $78,5^{4}$ & $276,4^{4}$ & $1,081^{43}$ & $\mathbf{4 8 , 2 1}$ \\
\hline 8 & $52^{\mathrm{CM}}$ & 4,39 & $1,16^{1}$ & $77,6^{4}$ & $275,4^{4}$ & $0,696^{63}$ & $70,04^{33}$ \\
\hline 9 & $44^{\mathrm{CM}}$ & 4,43 & $1,54^{2}$ & $\mathbf{1 2 0 , \mathbf { 1 } ^ { 1 1 }}$ & $308,3^{3}$ & $1,160^{36}$ & $37,78^{70}$ \\
\hline 10 & $30^{\mathrm{CM}}$ & 4,43 & $1,54^{2}$ & $111,2^{10}$ & $318,4^{3}$ & $1,540^{16}$ & $57,34^{49}$ \\
\hline 10 & $67^{\mathrm{CM}}$ & 4,43 & $1,54^{2}$ & $108,8^{9}$ & $316,9^{3}$ & $1,749^{6}$ & $68,68^{35}$ \\
\hline 11 & $55^{\mathrm{CM}}$ & 4,43 & $1,54^{2}$ & $82,6^{5}$ & $320,3^{3}$ & $0,869^{53}$ & $\mathbf{3 7 , 8 6}{ }^{69}$ \\
\hline 12 & $37^{\mathrm{CM}}$ & 4,62 & $1,90^{3}$ & $\mathbf{1 2 0}, \mathbf{0}^{11}$ & $334,6^{2}$ & $1,772^{4}$ & $71,52^{30}$ \\
\hline 12 & $64^{\mathrm{CM}}$ & 4,62 & $1,90^{3}$ & $120,0^{11}$ & $336,0^{2}$ & $1,485^{17}$ & $\mathbf{4 2 , 6 4}$ \\
\hline 12 & $74^{\mathrm{CM}}$ & 4,62 & $1,90^{3}$ & $112,0^{10}$ & $335,4^{2}$ & $2,020^{1}$ & $66,90^{37}$ \\
\hline 13 & $82^{\mathrm{CM}}$ & 5,63 & $1,90^{3}$ & $116,4^{11}$ & $319,9^{3}$ & $1,320^{26}$ & $63,38^{45}$ \\
\hline 14 & $33^{\mathrm{CM}}$ & 5,88 & $1,54^{2}$ & $72,3^{3}$ & $266,5^{4}$ & $0,355^{80}$ & $9,58^{81}$ \\
\hline 14 & $47^{\mathrm{SP}}$ & 5,88 & $1,54^{2}$ & $69,5^{3}$ & $275,6^{4}$ & $0,463^{75}$ & $20,80^{77}$ \\
\hline 15 & $83^{\mathrm{CM}}$ & 6,31 & $1,16^{1}$ & $74,8^{4}$ & $257,5^{5}$ & $0,539^{73}$ & $42,56^{65}$ \\
\hline 16 & $3^{\mathrm{CM}}$ & 6,31 & $1,16^{1}$ & $72,1^{3}$ & $244,1^{5}$ & $1,569^{13}$ & $75,61^{26}$ \\
\hline 16 & $40^{\mathrm{CM}}$ & 6,31 & $1,16^{1}$ & $68,4^{3}$ & $250,3^{5}$ & $1,620^{11}$ & $86,75^{13}$ \\
\hline 16 & $86^{\mathrm{CM}}$ & 6,31 & $1,16^{1}$ & $71,8^{3}$ & $239,1^{5}$ & $1,070^{44}$ & $61,04^{46}$ \\
\hline 16 & $87^{\mathrm{CM}}$ & 6,31 & $1,16^{1}$ & $70,4^{3}$ & $240,7^{5}$ & $1,549^{15}$ & $94,74^{2}$ \\
\hline 17 & $7^{\mathrm{CM}}$ & 6,31 & $1,16^{1}$ & $67,1^{2}$ & $246,6^{5}$ & $1,383^{23}$ & $87,45^{11}$ \\
\hline 17 & $50^{\mathrm{CM}}$ & 6,31 & $1,16^{1}$ & $66,3^{2}$ & $240,7^{5}$ & $1,889^{3}$ & $90,50^{8}$ \\
\hline 17 & $76^{\mathrm{CM}}$ & 6,31 & $1,16^{1}$ & $65,7^{2}$ & $250,9^{5}$ & $1,650^{9}$ & $89,55^{9}$ \\
\hline 18 & $54^{\mathrm{CM}}$ & 7,11 & $1,90^{3}$ & $95,9^{7}$ & $272,4^{4}$ & $0,405^{76}$ & $\mathbf{2 6 , 9 1}{ }^{75}$ \\
\hline 19 & $46^{\mathrm{CM}}$ & 7,11 & $1,90^{3}$ & $87,1^{5}$ & $283,9^{4}$ & $\mathbf{0 , 6 0 0}{ }^{71}$ & $\mathbf{2 8 , 3 8}$ \\
\hline 20 & $56^{\mathrm{ST}}$ & 7,31 & $2,85^{4}$ & $94,7^{7}$ & $333,4^{2}$ & $-0,047^{85}$ & $\mathbf{0 , 1 2}{ }^{87}$ \\
\hline 21 & $80^{\mathrm{CM}}$ & 7,81 & $1,16^{1}$ & $78,6^{4}$ & $229,0^{6}$ & $1,424^{20}$ & $97,27^{1}$ \\
\hline 22 & $11^{\mathrm{SP}}$ & 7,81 & $1,16^{1}$ & $70,7^{3}$ & $230,0^{6}$ & $1,753^{5}$ & $82,47^{19}$ \\
\hline 22 & $27^{\mathrm{CM}}$ & 7,81 & $1,16^{1}$ & $68,2^{3}$ & $222,3^{6}$ & $1,443^{19}$ & $93,19^{3}$ \\
\hline 23 & $45^{\mathrm{SP}}$ & 7,81 & $1,16^{1}$ & $60,3^{1}$ & $220,0^{6}$ & $1,120^{39}$ & $68,57^{36}$ \\
\hline 23 & $61^{\mathrm{CM}}$ & 7,81 & $1,16^{1}$ & $60,1^{1}$ & $223,9^{6}$ & $1,378^{24}$ & $52,81^{56}$ \\
\hline 24 & $6^{\mathrm{CM}}$ & 7,85 & $1,54^{2}$ & $72,2^{3}$ & $253,0^{5}$ & $-0,109^{86}$ & $0,93^{84}$ \\
\hline
\end{tabular}


Tabela 16. Distância de Mahalanobis estimada com base nos caracteres acamamento (AC), altura da planta na maturação (AM) e produção de grãos (PG), médias desses caracteres e estimativas do parâmetro de adaptabilidade (b) e do coeficiente de determinação ( $R^{2} \%$; estabilidade)

\begin{tabular}{|c|c|c|c|c|c|c|c|}
\hline & \multirow[b]{2}{*}{ Linhagens } & \multirow[b]{2}{*}{ D.M. } & \multicolumn{5}{|c|}{ Médias dos caracteres* e grupos respectivos } \\
\hline & & & $A C^{* *}$ & AM & PG & b & $\mathrm{R}^{2} \%$ \\
\hline 25 & $23^{\mathrm{CM}}$ & 7,85 & $1,54^{2}$ & $70,7^{3}$ & $243,8^{5}$ & $0,652^{68}$ & $44,65^{62}$ \\
\hline 25 & $51^{\mathrm{CM}}$ & 7,85 & $1,54^{2}$ & $68,5^{3}$ & $244,8^{5}$ & $1,704^{8}$ & $86,55^{14}$ \\
\hline 26 & $1^{\mathrm{CM}}$ & 9,12 & $1,90^{3}$ & $84,2^{5}$ & $236,6^{5}$ & $0,697^{62}$ & $80,09^{22}$ \\
\hline 27 & $10^{\mathrm{CM}}$ & 9,12 & $1,90^{3}$ & $69,4^{3}$ & $246,9^{5}$ & $1,144^{38}$ & $73,22^{28}$ \\
\hline 27 & $38^{\mathrm{CM}}$ & 9,12 & $1,90^{3}$ & $72,3^{3}$ & $236,4^{5}$ & $0,679^{65}$ & $55,82^{52}$ \\
\hline 28 & $29^{S P}$ & 9,39 & $1,54^{2}$ & $68,8^{3}$ & $226,3^{6}$ & $1,116^{40}$ & $70,87^{32}$ \\
\hline 29 & $77^{\mathrm{CM}}$ & 10,30 & $1,16^{1}$ & $75,9^{4}$ & $206,2^{7}$ & $0,923^{50}$ & $59,14^{47}$ \\
\hline 30 & $17^{\mathrm{SP}}$ & 10,30 & $1,16^{1}$ & $70,9^{3}$ & $197,7^{7}$ & $1,059^{45}$ & $56,94^{50}$ \\
\hline 30 & $19^{\mathrm{CM}}$ & 10,30 & $1,16^{1}$ & $70,0^{3}$ & $204,9^{7}$ & $\mathbf{0 , 6 5 3}{ }^{67}$ & $\mathbf{3 8 , 4 7}{ }^{67}$ \\
\hline 30 & $28^{\mathrm{CM}}$ & 10,30 & $1,16^{1}$ & $72,8^{3}$ & $208,3^{7}$ & $1,347^{25}$ & $85,61^{15}$ \\
\hline 30 & $57^{\mathrm{CM}}$ & 10,30 & $1,16^{1}$ & $70,3^{3}$ & $186,0^{7}$ & $0,913^{51}$ & $38,15^{68}$ \\
\hline 30 & $71^{\mathrm{CM}}$ & 10,30 & $1,16^{1}$ & $70,0^{3}$ & $202,5^{7}$ & $1,002^{48}$ & $55,45^{53}$ \\
\hline 31 & $25^{\mathrm{CM}}$ & 10,30 & $1,16^{1}$ & $63,0^{1}$ & $208,9^{7}$ & $0,838^{56}$ & $50,54^{58}$ \\
\hline 31 & $60^{\mathrm{SP}}$ & 10,30 & $1,16^{1}$ & $63,2^{1}$ & $185,8^{7}$ & $1,405^{21}$ & $80,08^{23}$ \\
\hline 32 & $72^{\mathrm{CM}}$ & 10,68 & $1,90^{3}$ & $84,3^{5}$ & $221,0^{6}$ & $1,102^{42}$ & $87,23^{12}$ \\
\hline 33 & $68^{\mathrm{CM}}$ & 10,68 & $1,90^{3}$ & $75,0^{4}$ & $231,7^{6}$ & $0,492^{74}$ & $26,14^{76}$ \\
\hline 33 & $69^{\mathrm{CM}}$ & 10,68 & $1,90^{3}$ & $77,9^{4}$ & $222,8^{6}$ & $1,466^{18}$ & $82,60^{18}$ \\
\hline 34 & $49^{\mathrm{CM}}$ & 11,92 & $1,54^{2}$ & $84,3^{5}$ & $186,6^{7}$ & $1,229^{29}$ & $92,70^{5}$ \\
\hline 35 & $16^{\mathrm{CM}}$ & 13,24 & $1,90^{3}$ & $79,4^{4}$ & $182,8^{7}$ & $0,854^{55}$ & $56,26^{51}$ \\
\hline 35 & $85^{S P}$ & 13,24 & $1,90^{3}$ & $76,8^{4}$ & $200,6^{7}$ & $1,163^{35}$ & $72,75^{29}$ \\
\hline 36 & $78^{\mathrm{CM}}$ & 13,24 & $1,90^{3}$ & $70,5^{3}$ & $205,5^{7}$ & $1,310^{27}$ & $51,06^{57}$ \\
\hline 36 & $81^{\mathrm{SP}}$ & 13,24 & $1,90^{3}$ & $71,0^{3}$ & $198,4^{7}$ & $0,785^{59}$ & $45,02^{61}$ \\
\hline 37 & $43^{\mathrm{CM}}$ & 14,85 & $1,16^{1}$ & $76,0^{4}$ & $170,5^{8}$ & $0,699^{61}$ & $66,80^{38}$ \\
\hline 38 & $63^{\mathrm{cM}}$ & 14,85 & $1,16^{1}$ & $70,0^{3}$ & $149,7^{8}$ & $1,177^{32}$ & $90,78^{7}$ \\
\hline 38 & $73^{S P}$ & 14,85 & $1,16^{1}$ & $72,4^{3}$ & $159,3^{8}$ & $1,615^{12}$ & $93,12^{4}$ \\
\hline 38 & $75^{\mathrm{CM}}$ & 14,85 & $1,16^{1}$ & $68,9^{3}$ & $173,4^{8}$ & $1,622^{10}$ & $74,11^{27}$ \\
\hline 39 & $41^{\mathrm{SP}}$ & 14,85 & $1,16^{1}$ & $66,7^{2}$ & $154,9^{8}$ & $1,046^{47}$ & $57,62^{48}$ \\
\hline 39 & $62^{S P}$ & 14,85 & $1,16^{1}$ & $65,2^{2}$ & $153,1^{8}$ & $0,893^{52}$ & $53,79^{54}$ \\
\hline 39 & $65^{\mathrm{SP}}$ & 14,85 & $1,16^{1}$ & $63,8^{2}$ & $154,5^{8}$ & $1,272^{28}$ & $66,26^{39}$ \\
\hline 39 & $70^{S P}$ & 14,85 & $1,16^{1}$ & $65,5^{2}$ & $148,1^{8}$ & $0,997^{49}$ & $64,50^{42}$ \\
\hline 39 & $88^{S P}$ & 14,85 & $1,16^{1}$ & $64,1^{2}$ & $144,7^{8}$ & $1,201^{30}$ & $71,45^{31}$ \\
\hline 40 & $66^{\mathrm{CM}}$ & 14,94 & $3,46^{6}$ & $112,4^{10}$ & $246,5^{5}$ & $0,343^{81}$ & $10,01^{80}$ \\
\hline 41 & $2^{\mathrm{CM}}$ & 15,48 & $3,46^{5}$ & $105,9^{9}$ & $226,9^{6}$ & $0,375^{78}$ & $17,11^{79}$ \\
\hline 42 & $84^{\mathrm{SP}}$ & 16,55 & $1,54^{2}$ & $75,0^{4}$ & $156,3^{8}$ & $\mathbf{0 , 3 6 4 ^ { 7 9 }}$ & $31,49^{73}$ \\
\hline 43 & $35^{\mathrm{CM}}$ & 16,55 & $1,54^{2}$ & $71,4^{3}$ & $176,4^{8}$ & $0,869^{54}$ & $65,99^{40}$ \\
\hline 43 & $79^{S P}$ & 16,55 & $1,54^{2}$ & $69,7^{3}$ & $156,2^{8}$ & $1,166^{34}$ & $84,47^{17}$ \\
\hline 44 & $39^{S P}$ & 17,92 & $1,90^{3}$ & $80,9^{5}$ & $175,1^{8}$ & $\mathbf{0 , 6 1 0}{ }^{70}$ & $53,30^{55}$ \\
\hline 45 & $8^{\mathrm{CM}}$ & 18,13 & $3,46^{5}$ & $97,6^{7}$ & $194,7^{7}$ & $-0,179^{87}$ & $\mathbf{4 , 7 0} 83$ \\
\hline 46 & $14^{\mathrm{CM}}$ & 19,25 & $3,46^{6}$ & $103,5^{8}$ & $189,9^{7}$ & $-0,044^{84}$ & $\mathbf{0 , 2 1}{ }^{86}$ \\
\hline 47 & $48^{\mathrm{CM}}$ & 22,95 & $3,46^{5}$ & $93,3^{7}$ & $161,3^{8}$ & $1,106^{41}$ & $76,88^{24}$ \\
\hline 48 & $36^{\mathrm{CM}}$ & 24,09 & $3,46^{6}$ & $94,2^{7}$ & $126,0^{8}$ & $-0,215^{88}$ & $\mathbf{6 , 1 0}$ \\
\hline 48 & $58^{\mathrm{CM}}$ & 24,09 & $3,46^{6}$ & $94,2^{7}$ & $126,3^{8}$ & $\mathbf{0 , 0 2 0} 83$ & $0,10^{88}$ \\
\hline 49 & $32^{\mathrm{CM}}$ & 24,09 & $3,46^{6}$ & $89,2^{6}$ & $155,2^{8}$ & $0,085^{82}$ & $0,89^{85}$ \\
\hline 50 & $13^{\mathrm{CM}}$ & 24,09 & $3,46^{6}$ & $84,0^{5}$ & $139,7^{8}$ & $0,547^{72}$ & $32,92^{72}$ \\
\hline
\end{tabular}

*: médias em negrito estão abaixo (PG) ou acima (AC e AM) do valor de descarte estabelecido;

**: os valores individuais (em unidades originais) foram substituídos pela média da classe correspondente. 


\subsection{Avaliação dos índices de seleção}

$\mathrm{Na}$ Tabela 14 são apresentados os valores da Distância Euclidiana Média, calculada com base nos caracteres AC, AM e PG. As estimativas do parâmetro de adaptabilidade (b) e do coeficiente de determinação $\left(R^{2}\right)$ também são apresentadas, apesar de não terem sido empregadas no cálculo da distância. Deve-se ressaltar que na prática, para estimar distâncias, normalmente são empregados mais caracteres do que se empregou nesse trabalho.

Pode-se observar que algumas linhagens, como as linhagens 9, 12 e 18 apresentam os mesmos valores de distâncias, tendo sido classificadas em $1^{\text {o }}$ lugar. Isso ocorre porque, como pode-se ver pelos números em sobrescrito ao lado das médias, essas três linhagens pertencem ao mesmo grupo, nos três caracteres. Como as médias individuais pertencentes a um mesmo grupo foram substituídas pela média do grupo, essas três linhagens passaram a ter a mesma média, e conseqüentemente, o mesmo desvio, em cada um dos três caracteres (Tabelas 9, 10 e 11), do que resulta o mesmo valor da Distância Euclidiana. Em virtude disso, os números que referem-se à classificação das linhagens com base no seu valor de distância ao ideótipo, mostrados à esquerda dos números das linhagens, somam apenas 51 , e não 88 , como seria se cada linhagem tivesse um valor de distância diferente.

Observa-se (Tabela 14), que entre as 24 linhagens com os menores valores de distâncias (classificadas de 1 a 10), com exceção da linhagem 20 (3ํㅡㄴ lugar), cuja média de AM é maior que o valor de descarte, todas as demais são selecionáveis, por AC, AM e PG, que foram os caracteres incluídos no cálculo da Distância Euclidiana, demonstrando uma correspondência muito boa entre os valores de distâncias (ou os valores do índice) e o desempenho das linhagens nos caracteres individualmente. Além dessas 23 linhagens, somente mais cinco são selecionáveis pelos três caracteres: linhagens 33, 47, 6, 23 e 51, 
classificadas, respectivamente, em $13^{\circ}, 13^{\circ}, 17^{\circ}, 17^{\circ}$ e $17^{\circ}$ lugares. Essas 28 linhagens selecionáveis podem ser identificadas por não terem nenhuma média dos três caracteres em negrito. Quando se consideram, além desses três caracteres, os valores de $b$ e $\mathrm{R}^{2}$, o número de linhagens selecionáveis passa a ser 17.

É importante salientar que, embora, obviamente, o valor do índice seja levado em conta na seleção, não é somente ele que define se o genótipo é ou não selecionável, mas os $Z_{\mathrm{i}, \mathrm{s}}$ (para a Distância Euclidiana) ou $\mathrm{Y}_{\mathrm{i}, \mathrm{s}}$ (para a Distância Generalizada de Mahalanobis), de forma que, uma vez obtidos esses valores para todos os caracteres que farão parte do índice, já se pode saber quais genótipos são selecionáveis pelos critérios estabelecidos, antes de calcular o índice. Entretanto, quando têm-se muitos caracteres, pode ocorrer que um genótipo de desempenho geral muito bom tenha uma média indesejável em apenas um caráter, sendo por isso considerado como descartável, se forem levadas em consideração apenas as suas médias estandardizadas. Ao se adotar uma medida de distância, esse genótipo poderá mostrar a sua superioridade, e assim, tendo as informações de cada um dos caracteres que compõem o índice, além do próprio valor do índice, o pesquisador pode optar por selecioná-lo, mesmo porque, como se trata de uma pré-cultivar, para ser recomendada aos agricultores, ele ainda terá que ser avaliado em ensaios regionais e/ou nacionais, isto é, será ainda submetido a novas avaliações.

Inversamente, como já foi discutido, ao se calcular uma medida de distância, não é raro genótipos de desempenhos não tão bons apresentarem menores valores de distâncias que outros que são melhores. Da mesma forma que na situação anterior, além do índice, têm-se informações adicionais (os $Z_{i j}, S$ e $Y_{i j}, s$ ), por meio das quais o pesquisador pode decidir por selecionar ou não um dado genótipo, com mais segurança do que faria se fosse com base em apenas um critério. 
Ainda na Tabela 14, e considerando o caráter AC, observa-se, entre os menores valores de distâncias, uma predominância das linhagens do grupo 1 , de média 1,16, o que é desejável, uma vez que nesse caráter, assim como em AM, o objetivo da seleção é diminuir a média. Entretanto, as médias de AM e $P G$ dessas linhagens pertencem predominantemente aos grupos 3 , 4 e 5 , e assim, embora elas sejam selecionáveis pelos critérios estabelecidos para esses dois caracteres, seu desempenho neles é apenas intermediário. Isso se dá em virtude de a correlação genética entre AM e PG ser positiva $(0,38$, nesse trabalho) e, portanto, indesejável, tendo em vista que em AM, tem-se interesse nas menores médias, enquanto em PG buscam-se as médias maiores. Devido a essa correlação, há uma tendência de os valores selecionáveis de PG, ou seja, os maiores valores, estarem associados aos maiores de AM; por isso, essa tendência de as linhagens selecionáveis quanto a AM (mais baixas) e a PG (mais produtivas) terem maiores valores de distâncias.

Para visualizar melhor a associação existente entre AM e PG, e a má classificação de alguns genótipos, em conseqüência dela, pode-se observar que as cinco linhagens pertencentes ao grupo 2, isto é, de altas médias de PG (linhagens 21, 74, 37, 64 e 56) possuem médias de AM maiores que o valor de descarte, tendo sido classificadas, respectivamente, em $14^{\circ}, 29^{\circ}, 36^{\circ}, 36^{\circ}$ e $42^{\circ}$ lugares, quanto à Distância Euclidiana. Dessas, apenas a linhagem 21 possui média selecionável de AC. Tomando agora o caráter AM como referencial, verifica-se que com exceção das linhagens 7, 50 e 76, classificadas em 9응 lugar, todas as nove demais linhagens pertencentes aos grupos 1 e 2 têm médias de PG abaixo do valor de descarte (linhagens 45, 61, 25, 60, 41, 62, 65 , 70 e 88 , classificadas, respectivamente, em $15^{\circ}, 15^{\circ}, 20^{\circ}, 20^{\circ}, 34^{\circ}, 34^{\circ}, 34^{\circ}, 34^{\circ}$ e $34^{\circ}$ lugares, quanto ao índice).

O problema de a planta ser muito alta é que isso a predispõe ao acamamento, embora essa não seja uma associação absoluta, como pode-se constatar no caso da linhagem 20 (3ํlugar), que, apesar de ter média de AM acima do valor de descarte, tem nota baixa de $A C(1,16)$, de modo que, numa 
situação prática, com certeza ela seria selecionada, por ter a maior média de PG. Entretanto, quando se consideram a adaptabilidade e a estabilidade, observa-se que essa é uma linhagem pouco responsiva $(b=0,65)$ e de estabilidade muito baixa $\left(R^{2}=18,4 \%\right)$. Outro aspecto que precisa ser considerado, com relação a essa linhagem, é que ela é semi-tardia, o que pode não ser uma boa característica para o agricultor interessado em plantar soja em sistema de rotação de culturas, situação em que são requeridas cultivares de ciclo menor. Entretanto, nesse trabalho, não há nenhuma linhagem precoce, e entre as semi-precoces, a 47, classificada em 13ํํㄱ lugar quanto à Distância Euclidiana (Tabela 14), é a única que possui média selecionável de PG.

$\mathrm{Na}$ Tabela 15 são apresentados os valores da Distância Euclidiana Média, em cujo cálculo, além dos caracteres $A C, A M$ e PG, foram incluídos o parâmetro b e o coeficiente de determinação $\left(R^{2}\right)$. Observa-se na primeira coluna dessa tabela, que a numeração relativa à classificação das linhagens pelo valor da Distância Euclidiana vai de 1 a 88, indicando que cada linhagem possui um valor de distância diferente dos valores das demais. Isso ocorreu pelo fato de o $\mathrm{b}$ e o $\mathrm{R}^{2}$ terem sido empregados no cálculo da distância. Como não foi possível aplicar o teste de Scott-Knott às estimativas de $b$ e de $R^{2}$, cada linhagem possui um desvio próprio, e conseqüentemente, um valor próprio de Distância Euclidiana.

As 20 primeiras linhagens (classificadas de 1 a 20 pelo índice) possuem médias selecionáveis de AC, AM e PG. Dessas, entretanto, cinco apresentaram problemas quanto à adaptabilidade e/ou estabilidade: as linhagens 52 (9ㅇ) e 24 $\left(10^{\circ}\right)$ não são selecionáveis pelo $b$, as linhagens $12\left(11^{\circ}\right)$ e $34\left(17^{\circ}\right)$, pelo $R^{2}$, e a linhagem $18\left(15^{\circ}\right)$, por ambos. As duas linhagens que faltam para completar as 17 que são selecionáveis pelos três caracteres e pelo b e o $R^{2}$ são a 50 (23ํ) e $51\left(28^{\circ}\right)$.

Se por um lado, as 20 linhagens de menores valores de distâncias são selecionáveis pelos três caracteres, por outro observa-se que as médias de AM e PG dessas linhagens pertencem predominantemente aos grupos 3, 4 e 5, 
uma vez que, como já foi visto, as linhagens dos grupos 1 e 2 de PG tendem a ter médias não selecionáveis de $A M$, e vice-versa. Assim, as linhagens 20 (grupo 1 quanto à PG) e 21, 37, 74, 64 e 56, pertencentes ao grupo 2, foram classificadas, respectivamente, em $34^{\circ}, 35^{\circ}, 65^{\circ}, 67^{\circ}$ e $79^{\circ}$ lugares. Considerando agora, o caráter AM, as linhagens 45, 61, 60 e 25, pertencentes ao grupo 1, e as linhagens 7, 76, 50, 88, 70, 65, 41 e 62 (grupo 2), foram classificadas em $25^{\circ}, 29^{\circ}, 30^{\circ}, 40^{\circ}, 12^{\circ}, 19^{\circ}, 23^{\circ}, 52^{\circ}, 55^{\circ}, 56^{\circ}, 59^{\circ}$ e $60^{\circ}$ lugares, respectivamente. A linhagem 47, única do grupo das semi-precoces que possui média selecionável de $P G$, foi classificada em $58^{\circ}$ lugar.

Os valores da Distância Generalizada de Mahalanobis são apresentados na Tabela 16. As estimativas de b e $R^{2}$ são mostradas nessa tabela apenas para orientar a seleção, não tendo sido empregadas no cálculo dessa distância, por motivos já discutidos. As 38 primeiras linhagens (38 primeiros valores de distâncias) são todas selecionáveis, pelo caráter PG, o que é positivo, uma vez que esse é o caráter de maior importância. Entre essas, a linhagem 20, classificada no grupo 1, pela PG, e as linhagens $21,37,64,74$ e 56 , pertencentes ao grupo 2 , foram classificadas em $1^{\circ}, 6^{\circ}, 12^{\circ}, 12^{\circ}, 12^{\circ}$ e $20^{\circ}$ lugares, respectivamente, pela Distância de Mahalanobis. Além da linhagem 20 (grupo 1), e de quatro das cinco linhagens que formam o grupo 2, nota-se que até a 14ํㅡㄹ colocação (27 primeiras linhagens), 15 pertencem ao grupo 3 , e sete ao grupo 4. Do grupo 5, a linhagem melhor classificada é a 83 (15ํํ), e do grupo 6 é a $54\left(18^{\circ}\right)$, o que demonstra que a Distância Generalizada de Mahalanobis classificou bem as linhagens de maiores médias de PG.

Se por um lado, a Distância Generalizada de Mahalanobis classificou melhor as linhagens de maior média de PG, por outro, em razão da correlação genética positiva observada entre AM e PG (0,38), observa-se que nas primeiras posições da Tabela 16, o número de linhagens não selecionáveis, pelo caráter AM é maior, em comparação com as Tabelas 14 e 15 (Distâncias Euclidianas). Assim, as linhagens 20 (1ํำ, $31\left(2^{\circ}\right), 21\left(6^{\circ}\right), 44\left(9^{\circ}\right), 30\left(10^{\circ}\right), 67$ $\left(10^{\circ}\right), 37\left(12^{\circ}\right), 64\left(12^{\circ}\right), 74\left(12^{\circ}\right), 82\left(13^{\circ}\right), 54\left(18^{\circ}\right)$ e $56\left(20^{\circ}\right)$ são selecionáveis 
por PG, mas não o são por AM. Dessas, entretanto, as linhagens 20 (grupo 1, quanto à PG), 21 (grupo 2), 30, 31, 44 e 67 (grupo 3), em virtude de terem notas baixas de $A C$, e de suas elevadas médias de PG, muito provavelmente seriam selecionadas, na prática, tendo em vista que, apesar de terem médias de AM acima do máximo estabelecido, elas têm níveis aceitáveis de acamamento.

As linhagens $20\left(1^{\circ}\right)$ e $31\left(2^{\circ}\right)$, além de possuírem médias de AM acima do valor de descarte, têm estimativas de $b$ e $\mathrm{R}^{2}$ abaixo desses valores. As estimativas de $b$ menores que 1 , especialmente a da linhagem $31(b=0,396)$ indicam que as médias de PG dessas linhagens sofreram alterações positivas, porém pequenas, nos melhores anos, enquanto os baixos valores de $\mathrm{R}^{2}$ (18,41\% e $36,92 \%$, respectivamente) mostram que o seu comportamento nesse caráter foi pouco previsível, de um ano para outro.

As ótimas classificações dessas duas linhagens, apesar de suas debilidades em AM, mostram claramente o que já havia sido comentado anteriormente, de que, seja qual for a medida de distância empregada, o valor da distância não deve ser entendido como algo absoluto, por se tratar de um único valor, por meio do qual se procura resumir a distância de cada genótipo a um ideótipo, com base em observações de vários caracteres (três, nesse caso), e como já foi discutido, dois genótipos que apresentem os mesmos desvios (em sentido absoluto) ao ideótipo, em todos os caracteres, terão o mesmo valor de distância, mesmo que um deles não seja selecionável por nenhum dos caracteres.

Nesse ponto, percebe-se a vantagem do índice de seleção. Além dos valores de distâncias, o sinal das médias transformadas $\left(Y_{i j, s}\right)$, ou estandardizadas $\left(Z_{\mathrm{i}, \mathrm{s}}\right)$ auxilia na tarefa de verificar se o genótipo pode ou não ser selecionado. Esses valores de $Z_{\mathrm{i} j, \mathrm{~s}}$ e $\mathrm{Y}_{\mathrm{i}, \mathrm{s}}$ não são mostrados nas Tabelas 14, 15 e 16, onde as médias em negrito correspondem a $Z_{i, s}$ e $Y_{i j, s}$ negativos, que indicam que o genótipo não é selecionável, por aquele caráter. Garcia 
(1998) comparou o seu índice com o multiplicativo, o índice de distância a um ideótipo, e o índice de soma de postos, obtendo correlações de $-0,81$, (correlação negativa devido a questões de escala, segundo o autor), 0,93 e 0,70 , respectivamente. Estas inesperadas correlações altas, observa o autor, provavelmente deveram-se ao fato de os genótipos por ele avaliados já serem altamente selecionados, o que não permitiu ao índice para a seleção de cultivares proposto por ele mostrar a sua superioridade, em relação aos outros três índices não lineares. Conforme já mencionado, o índice de Garcia (1998) possui a vantagem de permitir a fixação de valores de descarte e a adoção de um teste de médias, que permite ao melhorista fazer a seleção com maior rigor estatístico.

Voltando ao b e ao $\mathrm{R}^{2}$, entre as 38 primeiras linhagens, além das linhagens 20 e 31, já comentadas, as linhagens $24\left(7^{\circ}\right)$ e 52 ( $\left.8^{\circ}\right)$ têm médias não selecionáveis de b, as linhagens $12\left(5^{\circ}\right), 21\left(6^{\circ}\right), 34\left(8^{\circ}\right), 44\left(9^{\circ}\right), 55\left(11^{\circ}\right)$ e $64\left(12^{\circ}\right)$ não são selecionáveis pelo $R^{2}$, e as linhagens $18\left(5^{\circ}\right), 33\left(14^{\circ}\right), 47$ $\left(14^{\circ}\right), 83\left(15^{\circ}\right), 54\left(18^{\circ}\right), 46\left(19^{\circ}\right)$ e $56\left(20^{\circ}\right)$ têm estimativas abaixo dos valores de descarte fixados para ambos. Dessas, as linhagens $33\left(b=0,35\right.$ e $R^{2}=$ 9,58\%), $47\left(b=0,463\right.$ e $\left.R^{2}=20,80 \%\right), 54\left(b=0,405\right.$ e $\left.R^{2}=26,91 \%\right), 46\left(R^{2}=\right.$ $28,38 \%)$ e $56\left(b=-0,047\right.$ e $\left.R^{2}=0,12\right)$ possuem valores muito baixos de $b$ e/ou $\mathrm{R}^{2}$. Os valores de b das linhagens $56\left(20^{\circ}\right), 6\left(24^{\circ}\right), 8\left(45^{\circ}\right), 14\left(46^{\circ}\right)$ e $36\left(48^{\circ}\right)$ são negativos, indicando que seu desempenho foi melhor nos piores anos.

\subsection{Comparações entre os índices}

A correlação de postos, ou correlação de Spearman entre a Distância Euclidiana Média com (Tabela 15), e sem (Tabela 14) a inclusão do b e do $R^{2}$, foi de 0,90 , mostrando que a sua inclusão não resultou em grandes mudanças nas classificações das linhagens. Apesar dessa correlação alta, observa-se, 
nas primeiras posições, que a classificação, considerando conjuntamente as médias dos três caracteres e as estimativas de $b$ e $\mathrm{R}^{2}$, foi ligeiramente melhor na Tabela 15 que na Tabela 14. Por exemplo, na Tabela 14, entre as primeiras 44 linhagens, 16 não são selecionáveis por $b$ e/ou $R^{2}$ (as estimativas não selecionáveis estão assinaladas em negrito), enquanto na Tabela 15, somente 10 linhagens não são selecionáveis. A linhagem 20, de maior média de PG, que

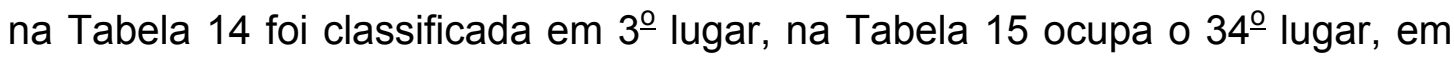
razão de suas baixas estimativas de b $(0,654)$ e, principalmente, de $\mathrm{R}^{2}$ $(18,41 \%)$. Essa classificação ligeiramente melhor das linhagens com valores selecionáveis de b e $\mathrm{R}^{2}$ observada na Tabela 15 , deve-se ao fato de que eles foram incluídos no cálculo da distância mostrada nessa tabela, enquanto a Distância Euclidiana apresentada na Tabela 14 foi estimada com base em AC, AM e PG, apenas.

Por outro lado, em comparação com a Distância Euclidiana estimada com base em AC, AM, PG, b e $\mathrm{R}^{2}$ (Tabela 15), a Distância Euclidiana estimada a partir de AC, AM e PG (Tabela 14) tendeu a classificar melhor as linhagens de maiores médias de PG. Isso pode ser visto na Tabela 17 , na qual são apresentadas as médias de PG das 11 (12,5\%) e 22 (25,0\%) linhagens de menores (superiores) e de maiores (inferiores) valores de distâncias. Observase nessa tabela, que a média de $P G$ das linhagens que têm os 11 menores valores da Distância Euclidiana estimada com base em AC, AM e PG (DE-1), foi de 303,2 g/parcela, enquanto a média de PG quando a Distância Euclidiana foi estimada a partir de AC, AM, PG, b e $R^{2}$ (DE-2) foi de 291,4 g/parcela. A mesma tendência é constatada quando observam-se as médias das 22 linhagens de menores distâncias (280,0 e 272,0 g/parcela, respectivamente).

Considerando agora, os maiores valores de distâncias (linhagens inferiores), observa-se que quando a Distância Euclidiana foi estimada a partir de $A C, A M$ e PG (DE-1), a média de PG foi menor que quando essa distância foi estimada com a inclusão do b e do $\mathrm{R}^{2}$ (DE-2), tanto na intensidade de $12,5 \%$ (188,6 g/parcela contra 195,7 g/parcela, respectivamente), quanto na 
intensidade de 25,0\% (207,4 g/parcela contra 213,1 g/parcela, respectivamente), indicando, novamente, que a Distância Euclidiana estimada com base em AC, AM e PG apenas (Tabela 14) resultou numa classificação melhor das linhagens mais produtivas.

Tabela 17. Médias da produção de grãos (g/parcela) das linhagens superiores e inferiores quanto aos índices, supondo duas intensidades de seleção $(12,5 \%$ e $25,0 \%)$ para as três medidas de distâncias: Distância Euclidiana 1 (DE-1), Distância Euclidiana 2 (DE-2) e Distância de Mahalanobis (DM)

\begin{tabular}{cccc}
\hline Critério & DE-1* & DE-2** & DM $^{* * *}$ \\
\hline 11 superiores $(12,5 \%)$ & 303,2 & 291,4 & 306,6 \\
22 superiores $(25,0 \%)$ & 280,0 & 272,0 & 303,8 \\
11 inferiores $(12,5 \%)$ & 188,6 & 195,7 & 159,7 \\
22 inferiores $(25,0 \%)$ & 207,4 & 213,1 & 165,4 \\
\hline
\end{tabular}

*: Distância Euclidiana, estimada com base em AC, AM e PG (Tabela 14);

**: Distância Euclidiana, estimada com base em AC, AM, PG, b e R² (Tabela 15);

***: Distância de Mahalanobis, estimada com base em AC, AM e PG (Tabela 16)

A correlação de Spearman entre a Distância de Mahalanobis (Tabela 16) e a Distância Euclidiana estimada com base nos caracteres AC, AM e PG (Tabela 14) foi de 0,83, e entre a Distância de Mahalanobis e a Distância Euclidiana estimada a partir de AC, AM, PG, b e $R^{2}$ (Tabela 15), de 0,69. Observa-se que ambos os valores são menores que o da correlação entre as Distâncias Euclidianas com e sem b e $R^{2}(0,90)$, o que era de se esperar, pelo fato de a Distância Euclidiana pressupor independência entre os caracteres, enquanto a Distância Generalizada de Mahalanobis leva em conta as correlações que porventura existam. E, quanto à correlação entre a Distância de Mahalanobis e a Distância Euclidiana em que incluíram-se o b e o $R^{2}$, é 
coerente que essa tenha o menor valor $(0,69)$, uma vez que, além do aspecto, já comentado, das correlações, essas duas distâncias diferem no número de variáveis envolvidas no cálculo.

A classificação das linhagens pela Distância Generalizada de Mahalanobis (Tabela 16) foi a mais distinta, pelo fato de essa distância ter classificado melhor as linhagens de maiores médias de PG. Assim, observa-se na Tabela 17, que nas duas intensidades (12,5\% e 25,0\%), as linhagens que apresentaram os menores valores de distâncias (superiores) pela Distância de Mahalanobis (DM), são as de maiores médias de PG, em comparação com as outras distâncias. Entre as 11 menores distâncias (12,5\%), a média de PG foi de 306,6 g/parcela pela DM, contra 303,2 g/parcela pela DE-1, e 291,4 g/parcela pela DE-2. Considerando os 22 menores valores de distâncias, a vantagem da Distância Generalizada de Mahalanobis foi ainda maior: a média de PG foi 303,8 g/parcela, contra 280,0 g/parcela na DE-1, e 272,0 g/parcela na DE-2.

A superioridade da Distância Generalizada de Mahalanobis em relação às Distâncias Euclidianas é observada também quando se consideram os $11 \mathrm{e}$ 22 maiores valores de distâncias, que referem-se às piores linhagens. $\mathrm{Na}$ intensidade de 25\% (22 maiores valores), a média de PG das linhagens classificadas pela DM foi de 165,4 g/parcela, enquanto na DE-1 foi de 207,4 g/parcela, e na DE-2, foi de 213,1 g/parcela. Entre os 11 maiores valores de distâncias (12,5\%), como era de se esperar, as médias de PG foram ainda menores que na intensidade de $25,0 \%$, e também nesse caso, a DM foi a que classificou as linhagens de menor média para PG (159,7 g/parcela), em relação a DE-1 (188,6 g/parcela) e DE-2 (195,7 g/parcela).

A melhor classificação das linhagens de maiores médias de $P G$ por parte da Distância de Mahalanobis pode ser melhor observada examinando-se os grupos aos quais pertencem essas linhagens. Considerando o caráter PG, observa-se na Tabela 14 (DE-1), que entre os 22 menores valores de distâncias (25\%), a linhagem 20 é a única dos grupos 1 e 2 que aparece entre esse 
valores; na Tabela 15 (DE-2), nenhuma linhagem desses dois grupos aparece entre os 22 menores valores de distâncias, e na Tabela 16 (DM), além da linhagem 20 (grupo 1), aparecem as linhagens 21 e 37, do grupo 2. Em seguida à linhagem 37, aparecem as linhagens 64 e 74, também do grupo 2, que inclusive, apresentaram o mesmo valor de distância que a linhagem 37, sendo portanto, também classificadas em $12^{\circ}$ lugar.

Essa tendência de a Distância de Mahalanobis classificar melhor as linhagens quanto à $P G$ pode ser observada também entre os maiores valores de distâncias (linhagens inferiores). Assim, na Tabela 14, entre os 22 maiores valores de distâncias (25\%), aparecem três linhagens do grupo 2: 37, 64 e 56, e a linhagem 82, do grupo 3, isto é, linhagens de alta produção. Na Tabela 15, aparecem as linhagens 74, 64 e 56, do grupo 2, novamente linhagens de alta produção. Finalmente, na Tabela 16, verifica-se que no grupo das $25 \%$ piores quanto aos índices, aparecem somente linhagens dos grupos 5, 6, 7 e 8 quanto à $P G$, isto é, linhagens de baixa produção.

Diante do que foi exposto, pode-se afirmar que o índice para a seleção de cultivares, proposto por Garcia (1998), e testado nesse trabalho mostrou-se útil para essa finalidade, tendo ainda a vantagem de ser de compreensão relativamente fácil. Sua aplicação, entretanto, é trabalhosa, dificuldade que seria eliminada com o desenvolvimento de um programa computacional, o que provavelmente o tornaria mais utilizado pelos melhoristas de plantas.

Comparando as medidas de distâncias, a Distância Generalizada de Mahalanobis mostrou-se superior às Distâncias Euclidianas, por ter classificado melhor as linhagens superiores. Estes resultados de certa forma eram esperados, visto que a Distância Generalizada de Mahalanobis foi proposta justamente para corrigir uma das deficiências da Distância Euclidiana, que não considerava a existência de correlações entre caracteres. Sendo assim, a não ser que não exista correlação alguma, a Distância Euclidiana irá favorecer alguns caracteres em detrimento de outros, devido às correlações. A Distância 
de Mahalanobis, por outro lado, através da ponderação pela matriz de variâncias e covariâncias, elimina este problema.

Portanto, com base nos resultados deste trabalho, sugere-se, quando possível, que seja utilizada a Distância Generalizada de Mahalanobis. Embora o b o $\mathrm{R}^{2}$ não possam ser incluídos nas medidas das distâncias, eles podem ser estimados e avaliados juntamente com os índices, de modo a possibilitar a seleção de genótipos com características agronômicas e econômicas superiores e mais estáveis e responsivos. 


\section{CONCLUSÕES}

Os resultados obtidos neste trabalho permitem as seguintes conclusões:

1. O índice de seleção proposto por Garcia (1998) permitiu classificar com segurança as linhagens de soja quanto às suas performances;

2. A Distância Generalizada de Mahalanobis mostrou-se mais apropriada que a Distância Euclidiana para o cálculo das distâncias entre os genótipos e o ideótipo; sendo assim, recomenda-se o uso daquela sempre que possível. 


\section{REFERÊNCIAS BIBLIOGRÁFICAS}

ARUNACHALAM, V. Genetic distance in plant breeding. Indian Journal of Genetics and Plant Breeding, v. 41, n. 2, p. 226-236, 1981.

BAKER, R.J. Selection indices in plant breeding. Boca Raton: CRC Press, 1986. $218 p$.

BARBOSA, M.H.P.; PINTO, C.A.B.P. Eficiência de índices de seleção na identificação de clones superiores de batata. Pesquisa Agropecuária Brasileira, v. 33, n. 2, p. 149-156, 1998.

BORÉM, A.; ALMEIDA, L.A.; KIIHL, R.A.S. Hibridação em soja. In: BORÉM, A. (Ed.). Hibridação artificial de plantas. Viçosa: Editora UFV, 1999, p. 443462.

BUENO FILHO, J.S.S.; VENCOVSKY, R. Efficiency of combined selection over sequential selection in forest tree progeny trials. Silvae Genetica, v. 49, n. 4-5, p. 169-173, 2000. 
BUSSAB, W.O.; MIAZAKI, E.S.; ANDRADE, D.F. Introdução à análise de agrupamentos. In: SIMPÓSIO NACIONAL DE PROBABILIDADE E ESTATíSTICA, 9., São Paulo, 1990. Anais. São Paulo: Associação Brasileira de Estatística, 1990. 105p.

CHATFIELD, C.; COLLINS, A.J. Introduction to multivariate analysis. 4. ed. London: Chapman and Hall, 1980, 246p.

COMPTON, W.A.; LONNQUIST, J.H. A multiplicative selection index applied to four cycles of full-sib recurrent selection in maize. Crop Science, v.22, n. 5, p. 981-983, 1982.

COTERILL, P.P. On index selection: II. Simple indices which require no genetic parameters or special expertise to construct. Silvae Genetica, v. 34, n. 2-3, p. 64-69, 1985.

CRUZ, C.D. Programa GENES - versão windows - aplicativo computacional em genética e estatística. Viçosa: UFV, 2001. 648p.

CRUZ, C.D.; REGAZZI, A.J. Modelos biométricos aplicados ao melhoramento genético. 2. ed. Viçosa: UFV, 2001. 390p.

EAGLES, H.A.; FREY, K.J. Expected and actual gains in economic value of oat lines from five selection methods. Crop Science, v. 14, n. 6, p. 861-864, 1974.

EBERHART, S.A.; RUSSELL, W.A. Stability parameters for comparing varieties. Crop Science, v. 6, n. 1, p. 36-40, 1966. 
ELSTON, R.C. A weight-free index for the purpose of ranking or selection with respect to several traits at a time. Biometrics, v. 19, n. 1, p. 85-97, 1963.

EMPRESA BRASILEIRA DE PESQUISA AGROPECUÁRIA. Tecnologias de produção de soja - região central do Brasil 2003. Londrina, 2002. 199 p. (Sistemas de Produção, 1).

FALCONER, D.S.; MACKAY, T.F.C. Introduction to quantitative genetics. England: Longman Group, 1996. 464p.

FERREIRA, D.F. Análises estatísticas por meio do Sisvar para Windows versão 4.0. In: REUNIÃO ANUAL DA REGIÃO BRASILEIRA DA SOCIEDADE INTERNACIONAL DE BIOMETRIA, 45., São Carlos, 2000. Resumos. São Carlos: UFSCar, 2000. p.255-258.

FERREIRA, D. F.; RIBEIRO, F. E.; RAMALHO, M. A. P. Uso de índice de seleção no melhoramento do feijoeiro. Ciência e Prática, v. 19, n. 1, p. 4347, 1995.

GARCIA, A. A. F. Índice para a seleção de cultivares. Piracicaba, 1998. 112 p. Tese (Doutorado)- Escola Superior de Agricultura "Luiz de Queiroz", Universidade de São Paulo.

GERALDI, I.O. Indice de selección en programas de mejoramiento poblacional. In: GUIMARÃES, E.P. (Ed.). Mejoramiento poblacional, una alternativa para explorar los recursos genéticos del arroz en América Latina. Cali: CIAT, 2003. cap. 3, p. 37-52. 
GODSHALK, E.B.; TIMOTHY, D.H.; BURNS, J.C. Effectiveness of index selection for switchgrass forage yield and quality. Crop Science, v. 28, n. 5, p. 825-830, 1988.

HAZEL, L. N. The genetic basis for constructing selection indexes. Genetics, v. 28, p. 476-490, 1943.

HAZEL, L.N.; LUSH, J.L. The eficiency of three methods of selection. The Journal of Heredity, v. 33, n. 11, p. 393-399, 1942.

HOLBROOK, C.C.; BURTON, J.W.; Jr, T.E.C. Evaluation of recurrent restricted index selection for increasing yield while holding seed protein constant in soybean. Crop Science, v. 29, n. 2, p. 324-329, 1989.

HUMPHREYS, M.O. Multitrait response to selection in Lolium perenne L. (perennial ryegrass) populations. Heredity, v. 74, n. 5, p. 510-517, 1995.

JACQUARD, A. The genetic structure of populations. Trad. de $B$. CHARLESWORTH e D. CHARLESWORTH. New York: Springer-Verlag, 1974. 369p.

JOHNSON, R. A.; WICHERN, D. W. Applied multivariate statistical analysis. New Jersey: Prentice-Hall, 1998, 816 p.

KEMPTHORNE, O. An introduction to genetic statistics. New York: John Wiley, 1957. 545p.

KEMPTHORNE, O.; NORDSKOG, A. W. Restricted selection indices. Biometrics, v. 15, p. 10-19, 1959. 
LIN, C. Y. Index selection for genetic improvement of quantitative characters.

Theoretical and Applied Genetics, v. 52, n. 2, p. 49-56, 1978.

MAHALANOBIS, P.C. On the generalized distance in statistics. Proceedings of the National Institute of Sciences of Índia, v. 2, n. 1, 1936.

MATZINGER, D.F.; WERNSMAN, E.A.; WEEKS, W.W. Restricted index selection for total alkaloids and yield in tobacco. Crop Science, v. 29, n. 1, p. 74-77, 1989.

MULAMBA, N.N.; MOCK, J.J. Improvement of yield potential of the eto blanco maize (Zea Mays L.) population by breeding for plant traits. Egyptian Journal of Genetics and Cytology, v. 7, n. 1, p. 40-51, 1978.

PESEK, J.; BAKER, R. J. Desired improvement in relation to selection indices. Canadian Journal of Plant Sciences, v. 49, p. 803-804, 1969.

RAMALHO, M.A.P.; FERREIRA, D.F.; OLIVEIRA, A.C. Experimentação em genética e melhoramento de plantas. Lavras: UFLA, 2000. 303p.

ROSSMANN, H. Estimativas de parâmetros genéticos e fenotípicos de uma população de soja avaliada em quatro anos. Piracicaba, 2001. 80p. Dissertação (M.S.) - Escola Superior de Agricultura "Luiz de Queiroz", Universidade de São Paulo.

ROSIELLE, A.A.; FREY, K.J. Application of restricted selection indices for grain yield improvement in oats. Crop Science, v. 15, n. 4, p. 544-547, 1975.

SAS INSTITUTE, INC. Statistical Analysis System. Release 6.08, (software). Cary, 1992. 
SCOTT, A. J.; KNOTT, M. A cluster analysis method for grouping means in the analysis of variance. Biometrics, v. 30, n. 3, p. 507-512, 1974.

SILVA, L. A.; PINTO, C. A. B. P.; LAMBERT, E. S. Seleção simultânea para vários caracteres: utilização do índice de Mulamba e Mock associado ao teste de Scott- Knott. In: SIMPÓSIO DE ESTATíSTICA APLICADA À EXPERIMENTAÇÃO AGRONÔMICA, 10.; REUNIÃO ANUAL DA REGIÃO BRASILEIRA DA SOCIEDADE INTERNACIONAL DE BIOMETRIA, 48., Lavras, 2003. Anais. Lavras: UFLA, 2003. p.85-86.

SMITH, H. F. A discriminant function for plant selection. Annals of Eugenics, v. 7, p. 240-250, 1936.

SMITH, O. S.; HALLAUER, A. R.; RUSSELL, W.A. Use of index selection in recurrent selection programs in maize. Euphytica, v. 30, n. 3, p. 611-618, 1981.

SUBANDI; COMPTON, W.A.; EMPIG, L. T. Comparison of the efficiencies of selection indices for three traits in two variety crosses of corn. Crop Science, v. 13, n. 2, p. 184-186, 1973.

VENCOVSKY, R.; BARRIGA, P. Genética biométrica no fitomelhoramento. Ribeirão Preto: Sociedade Brasileira de Genética, 1992. 486p.

WHITEMAN, P.H.; DEAN, C.A.; DORAN, J.C.; CAMERON, J.N. Genetic parameters and selection strategies for Eucalyptus nitens (Dean and Maiden) in Victoria. Silvae Genetica, v. 41, n. 2, p. 77-81, 1992.

WILLIAMS, J. S. The evaluation of a selection index. Biometrics, v. 18, n. 3, p. 375-393, 1962. 
WRICKE, G.; WEBER, W.E. Quantitative genetics and selection in plant breeding. New York: Walter de Gruyter, 1986. 406p. 
APÊNDICES 
APÊNDICE 1. Ilustração das etapas de obtenção do índice para a seleção de cultivares

A seguir, será exemplificado o processo de obtenção dos desvios para a estimação das Distâncias Euclidiana e de Mahalanobis. Para isso, será tomado como exemplo o caráter $A C$, entretanto, serão apresentadas também as informações necessárias à obtenção dos desvios para $A C, A M, P G, b$ e $R^{2}$. Os valores (relativos ao caráter AC) de cada etapa a ser mostrada a seguir encontram-se na Tabela 9.

a) Distância euclidiana

O primeiro passo foi submeter as médias de quadrados mínimos provenientes da análise conjunta de variância ao teste de Scott-Knott, o que foi feito empregando-se o programa SISVAR (Ferreira, 2000). Ao nível de significância de 0,01, o referido teste classificou as médias desse caráter em seis grupos. As médias e os números de grupos correspondentes são mostrados em sobrescrito, na segunda coluna.

Depois do agrupamento, calculou-se a média de cada grupo, e em seguida, substituíram-se os valores individuais pela média do grupo correspondente. Em AC, assim como em AM, em virtude de as médias de interesse serem as menores, houve necessidade de obtenção dos recíprocos $\left(1 / X_{i j}\right)$, de modo a fazer com que as linhagens cujas médias são maiores que o valor de descarte $\left(N_{j}\right)$ passassem a ter médias estandardizadas $\left(Z_{i j}\right.$ para a Distância Euclidiana), e transformadas ( $Y_{i j}$ para a Distância Generalizada de Mahalanobis) negativas, indicando que essas médias não são selecionáveis. 
Desse modo, calcularam-se os recíprocos das médias das linhagens, obtendo-se em seguida, as médias de grupos, pelas quais os recíprocos das médias das linhagens foram substituídos. Essas médias de grupos (valores recíprocos) são mostradas na terceira coluna da Tabela 9.

Os valores definidos como $\mathrm{N}_{\mathrm{j}, \mathrm{s}}$ para $\mathrm{AC}$, $\mathrm{AM}$ e $\mathrm{PG}$, foram as médias gerais desses caracteres, ou mais precisamente, as médias dos grupos aos quais elas pertenciam. Ao calcular-se a média geral de $A C(1,42)$, verificou-se que ela pertencia ao grupo 2 , de forma que o recíproco da média desse grupo $(0,714221)$ é que foi efetivamente empregado como $N_{j}$ de AC. As médias gerais de AM e PG situaram-se entre dois grupos. Para definir em qual grupo enquadrá-las, essas médias, juntamente com as médias das 88 linhagens foram submetidas ao teste de Scott-Knott, que classificou a média de AM $(80,1$ $\mathrm{cm} /$ planta) no grupo 5 , de modo que o recíproco da média desse grupo $(0,012021)$ foi empregado como o $N_{j}$ para $A M$. Em PG, como não foi necessária a obtenção de recíprocos, adotou-se como $N_{j}$ a média do grupo 5 $(245,1858)$, no qual o teste de Scott-Knott classificou a média geral desse caráter. (236,1 g/parcela). Para o b e o $R^{2}$, definiram-se como $\mathrm{N}_{\mathrm{j}, \mathrm{s}}$ os valores 0,70 e 48,9\%, respectivamente.

Em seguida, calculou-se o desvio-padrão $\left(\sigma_{j}=0,099334085\right)$, com base nos recíprocos das valores individuais (médias das linhagens), para permitir a estandardização das médias de grupos. A média do grupo 1, por exemplo, foi estandardizada dessa maneira:

$Z_{\mathrm{ij}}=(0,793069-0,714221) / 0,099334085=0,793770$,

como pode-se observar na quarta coluna. Assim, com os desvios-padrão de AM (0,00208408), PG $(59,344721913)$, b $(0,518545001)$ e $R^{2}(26,898143002)$, e os valores de $N_{j, s}$ de 0,012021 cm, 245,1858 g/parcela, 0,70 e 48,9\%, 
respectivamente, estimaram-se os $Z_{i, s}$ desses caracteres, que são mostrados nas Tabelas 10,11, 12 e 13 .

Os valores atribuídos ao ideótipo também foram estandardizados. Como em AC definiu-se o valor 1,0 para o ideótipo, a estandardização desse valor foi feita da seguinte maneira:

$$
Z_{\mathrm{lj}}=(1,0-0,714221) / 0,099334085=2,876948,
$$

e, finalmente, obteve-se o desvio do grupo 1 ao ideótipo (quinta coluna):

$\mathrm{d}=\mathrm{Z}_{\mathrm{ij}}-\mathrm{Z}_{\mathrm{lj}}=0,793770-2,876948=-2,083178$,

sendo os desvios dos demais grupos obtidos da mesma maneira.

Atribuindo os valores de $71,4 \mathrm{~cm}$ ao ideótipo para $\mathrm{AM}, 373,9 \mathrm{~g} /$ parcela para $P G, 1,0$ para b, e $100 \%$ para $R^{2}$, e procedendo dessa maneira, obtiveramse os desvios dos outros dois caracteres, do parâmetro b, e do coeficente de determinação $\left(R^{2}\right)$, mostrados, respectivamente, nas Tabelas 10, 11, 12 e 13.

Obtidos os desvios, pôde-se estimar a Distância Euclidiana para cada uma das linhagens. Tomando como exemplo, a linhagem 11, cuja média de AC pertence ao grupo 1, a Distância Euclidiana Média, estimada com base nos desvios de AC (Tabela 9), AM (Tabela 10), PG (Tabela 11), b (Tabela 12) e $\mathrm{R}^{2}$ (Tabela 13) é a seguinte:

$$
\begin{aligned}
\mathrm{dm}_{11} & =\sqrt{\frac{1}{5}\left[(-2,083178)^{2}+(0,082707)^{2}+(-2,503581)^{2}+(1,451776)^{2}+(-0,651733)^{2}\right]} \\
& =1,62,
\end{aligned}
$$


e dessa maneira, estimaram-se as Distâncias Euclidianas das demais linhagens, mostradas na Tabela 15. Na Tabela 14 estão as Distâncias Euclidianas estimadas com base nos caracteres AC, AM e PG, apenas.

b) Distância Generalizada de Mahalanobis

Até a obtenção das médias de grupos e substituição dos valores individuais por essas médias, os processos de obtenção dos desvios para as Distâncias Euclidiana e de Mahalanobis são iguais. A diferença começa na transformação das médias de grupos. Como ao aplicar-se a Distância de Mahalanobis, as observações (nesse caso, os desvios de cada genótipo ao ideótipo) são divididos pelo desvio-padrão do resíduo correspondente, não se fez a estandardização, isto é, a divisão do termo $X_{i j}-N_{j}$ pelo desvio-padrão fenotípico, como na Distância Euclidiana.

Desse modo, a transformação das médias de grupos consistiu apenas na subtração do valor de descarte $\left(N_{j}\right)$ de cada média de grupo, isto é, $\mathrm{Y}_{\mathrm{ij}}=\mathrm{X}_{\mathrm{ij}}-\mathrm{N}_{\mathrm{ij}}$. Assim, a média transformada do grupo 1 é

$Y_{\mathrm{ij}}=0,793069-0,714221=0,078848$,

e desse modo, obtiveram-se as médias transformadas dos demais grupos para AC (sexta coluna da Tabela 9), para AM $\left(N_{j}=0,012021\right)$ e PG $\left(N_{j}=245,1858\right)$, mostrados na sexta coluna das Tabelas 10 e 11, respectivamente.

Para colocar o valor atribuído ao ideótipo na mesma escala que as médias de grupos, esse também foi transformado, por meio da seguinte 
expressão: $Y_{\mathrm{lj}}=\mathrm{X}_{\mathrm{lj}}-\mathrm{N}_{\mathrm{j}}$. Como atribuiu-se o valor 1,0 ao ideótipo para $A C$ (Tabela 1),

$$
\mathrm{Y}_{\mathrm{lj}}=1,0-0,714221=0,285779 \text {, }
$$

e assim, o desvio do grupo 1 desse caráter (sétima coluna da Tabela 9) é $d=Y_{i j}-Y_{\mathrm{lj}}=0,078848-0,285779=-0,206931$,

sendo os desvios dos demais grupos obtidos da mesma forma.

Adotando esse mesmo procedimento, os valores atribuídos ao ideótipo para AM (71,4 cm) e PG (373,9 g/parcela) foram transformados, empregandose para isso, os valores de $\mathrm{N}_{\mathrm{j}, \mathrm{s}}$ já apresentados, possibilitando assim, a obtenção dos desvios para a estimação da Distância Generalizada de Mahalanobis. Esses desvios são mostrados na sétima coluna das Tabelas 9 (AC), 10 (AM) e 11 (PG).

Assim, por exemplo, a Distância de Mahalanobis da linhagem 11 é a seguinte:

$$
\begin{aligned}
& D_{11}^{2}=\left[\begin{array}{ll}
-0,206931 & 0,000172-148,574337
\end{array}\right]\left[\begin{array}{ccc}
0,029975 & 0,131305 & -1,033205 \\
0,131305 & 61,348179 & 99,422950 \\
-1,033205 & 99,422950 & 4095,053055
\end{array}\right]^{-1}\left[\begin{array}{c}
-0,206931 \\
0,000172 \\
-148,574337
\end{array}\right] \\
& D_{11}^{2}=\left[\begin{array}{lll}
-0,206931 & 0,000172-148,574337
\end{array}\right]\left[\begin{array}{ccc}
34,130491 & -0,09057 & 0,0108102 \\
-0,09057 & 0,0172084 & -0,000441 \\
0,0108102 & -0,000441 & 0,0002576
\end{array}\right]\left[\begin{array}{c}
-0,206931 \\
0,000172 \\
-148,574337
\end{array}\right] \\
& D_{11}^{2}=7,81
\end{aligned}
$$

Procedendo dessa maneira, estimaram-se as Distâncias Generalizadas de Mahalanobis das demais linhagens. Essas distâncias são mostradas na Tabela 16. 
APÊNDICE 2. Programa empregado para a estimação da Distância Generalizada de Mahalanobis, no programa SAS

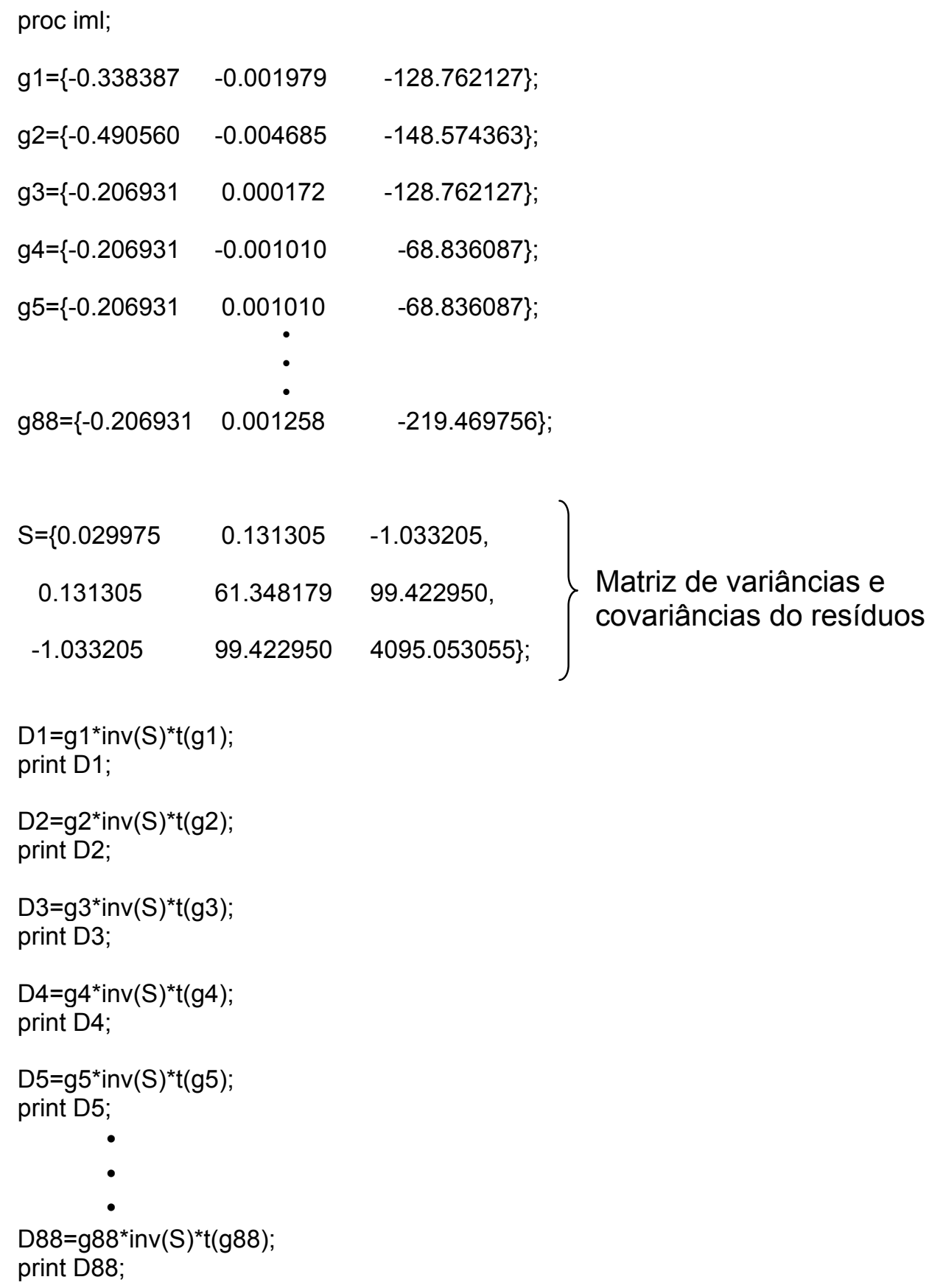


APÊNDICE 3. Correspondência entre a numeração das linhagens adotada nesse trabalho e a empregada pelo Setor de Plantas Autógamas do Departamento de Genética

\begin{tabular}{|c|c|c|c|}
\hline \multicolumn{4}{|c|}{ Numeração adotada } \\
\hline Nesse trabalho & pelo Setor & Nesse trabalho & pelo Setor \\
\hline 1 & 1 & 45 & 51 \\
\hline 2 & 2 & 46 & 52 \\
\hline 3 & 3 & 47 & 53 \\
\hline 4 & 4 & 48 & 54 \\
\hline 5 & 5 & 49 & 55 \\
\hline 6 & 6 & 50 & 57 \\
\hline 7 & 8 & 51 & 58 \\
\hline 8 & 9 & 52 & 59 \\
\hline 9 & 10 & 53 & 60 \\
\hline 10 & 11 & 54 & 61 \\
\hline 11 & 12 & 55 & 62 \\
\hline 12 & 13 & 56 & 63 \\
\hline 13 & 14 & 57 & 64 \\
\hline 14 & 15 & 58 & 66 \\
\hline 15 & 16 & 59 & 67 \\
\hline 16 & 17 & 60 & 68 \\
\hline 17 & 18 & 61 & 69 \\
\hline 18 & 19 & 62 & 70 \\
\hline 19 & 21 & 63 & 71 \\
\hline 20 & 23 & 64 & 72 \\
\hline 21 & 24 & 65 & 73 \\
\hline 22 & 25 & 66 & 74 \\
\hline 23 & 26 & 67 & 76 \\
\hline 24 & 27 & 68 & 77 \\
\hline 25 & 28 & 69 & 78 \\
\hline 26 & 29 & 70 & 80 \\
\hline 27 & 30 & 71 & 81 \\
\hline 28 & 31 & 72 & 82 \\
\hline 29 & 32 & 73 & 83 \\
\hline 30 & 33 & 74 & 84 \\
\hline 31 & 34 & 75 & 85 \\
\hline 32 & 36 & 76 & 86 \\
\hline 33 & 37 & 77 & 87 \\
\hline 34 & 38 & 78 & 89 \\
\hline 35 & 39 & 79 & 90 \\
\hline 36 & 40 & 80 & 91 \\
\hline 37 & 41 & 81 & 92 \\
\hline 38 & 42 & 82 & 93 \\
\hline 39 & 43 & 83 & 94 \\
\hline 40 & 46 & 84 & 95 \\
\hline 41 & 47 & 85 & 96 \\
\hline 42 & 48 & 86 & 97 \\
\hline 43 & 49 & 87 & 98 \\
\hline 44 & 50 & 88 & 99 \\
\hline
\end{tabular}

